DESIGN OF A MEDIUM RANGE TACTICAL

UAV AND IMPROVEMENT OF ITS PERFORMANCE BY

USING WINGLETS

A THESIS SUBMITTED TO

THE GRADUATE SCHOOL OF NATURAL AND APPLIED SCIENCES

$\mathrm{OF}$

MIDDLE EAST TECHNICAL UNIVERSITY

BY

EREN TURANOĞUZ

IN PARTIAL FULFILLMENT OF THE REQUIREMENTS

FOR

THE DEGREE OF MASTER OF SCIENCE

IN

AEROSPACE ENGINEERING

SEPTEMBER 2014 

Approval of the thesis:

\section{DESIGN OF A MEDIUM RANGE \\ TACTICAL UAV AND IMPROVEMENT \\ OF ITS PERFORMANCE BY USING \\ WINGLETS}

submitted by EREN TURANOĞUZ in partial fulfillment of the requirements for the degree of Master of Science in Aerospace Engineering Department, Middle East Technical University by,

Prof. Dr.Canan Özgen

Dean, Graduate School of Natural and Applied Sciences

Prof. Dr.Ozan Tekinalp

Head of Department, Aerospace Engineering

Prof. Dr.Nafız Alemdaroğlu

Supervisor, Aerospace Engineering Dept., METU

\section{Examining Committee Members:}

Prof. Dr.Serkan Özgen

Aerospace Engineering Dept., METU

Prof. Dr.Nafız Alemdaroğlu

Aerospace Engineering Dept., METU

Prof. Dr.Kahraman Albayrak

Mechanical Engineering Dept., METU

Assoc.Prof.Dr. Dilek Funda Kurtuluş

Aerospace Engineering Dept., METU

Assoc.Prof. Dr. Sinan Eyi

Aerospace Engineering Dept., METU

Date: 
I here declare that all information in this document has been obtained and presented accordance with academic rules and ethical conduct. I also declare that, as required by these rules and conduct, I have fully cited and referenced all material and results that are not original to this work.

Name, Last name: $\quad$ Eren TURANOĞUZ

Signature : 


\title{
ABSTRACT \\ DESIGN OF A MEDIUM RANGE \\ TACTICAL UAV AND IMPROVEMENT \\ OF ITS PERFORMANCE BY USING \\ WINGLETS
}

\author{
TURANOĞUZ, Eren \\ M.S., Department of Aerospace Engineering \\ Supervisor : Prof. Dr. Nafız ALEMDAROĞLU
}

September 2014, 92 pages

The study encompasses the design, performance analysis and aerodynamic improvement of the designed medium range tactical unmanned aerial vehicle. Main requirements are set as following; cruising altitute above $3500 \mathrm{~m}$, endurance of approximately 10-12 hours, range of $150 \mathrm{~km}$ and payload of $60 \mathrm{~kg}$. The conventional design phase is based on the employment of historical equations and experiences.

Nowadays, employement of well known equations and experiences during the desing process are not enough to reveal a competitive design. A new design must encompass a wide scope improvement processes in various aspects in order to compete in today's UAV market. The focal point of the thesis is not only to desing a conventional UAV based on well known mathematical equations and experiences, but also improve it aerodynamically by using numerical tools. A typical aerodynamic optimization process includes relationship between various parameters, notwithstanding, the improvement study performed in the thesis is based on increasing the span efficiency. For the depicted aim, a multidisciplinary comparison of various wingtip geometries have been performed.

In conclusion, the study offers a cost effective aerodynamic improvement process by reducing engineering time and complicated algorithms for an UAV.

Keywords : UAV, Conceptual Design, Aerodynamic Improvement. 


\title{
ÖZ
}

\section{TAKTIK BİR İNSANSIZ HAVA ARACININ TASARIMI VE KANAT UCU GEOMETRILERI KULLANILARAK PERFORMANSININ IYYILEŞTİIILMESI}

\author{
TURANOĞUZ, Eren \\ Yüksek Lisans, Havac1lık ve Uzay Mühendisliği Bölümü \\ Tez Yöneticisi : Prof. Dr. Nafız ALEMDAROĞLU
}

Eylül 2014, 92 sayfa

$\mathrm{Bu}$ çalışma, bir orta menzilli taktik İHA'nın tasarımı, performans analizi ve aerodinamik olarak iyileştirilmesini içermektedir. Uçak için belirlenen temel gereksinimler şunlardır: $3500 \mathrm{~m}$ üzerinde seyir edebilme, 10-12 saat dayanım süresi, $150 \mathrm{~km}$ menzil ve $60 \mathrm{~kg}$ faydalı yük taşıma kapasitesi. Konvansiyonel tasarım süreci tarihsel denklemler ve deneyimlere dayanmaktadır.

Günümüzde tasarım süresince bilinen denklem ve deneyimlerin kullanılması rekabetçi bir tasarım ortaya çıkarmak için yeterli değildir. Yeni bir tasarımın günümüz İHA pazarında rekabet edebilmesi için çok disiplinli bir iyileştirme işlemi içermelidir. Tezin odak noktası sadece bilinen matematiksel denklemler ve deneyimlere dayanarak konvansiyonel bir İHA tasarlamanın yanısıra elde edilen tasarımın nümerik araçlar kullanımı sayesinde aerodinamik olarak iyileştirilmesidir. Tipik bir aerodinamik optimizasyon işlemi birçok parametre arasındaki ilişkiyi içermektedir, ancak bu çalışmada gerçekleştirilen aerodinamik iyileştirme işlemi kanat açıklığı veriminin artırılması üzerine yoğunlaşılmıştır. Belirtilen amaç için farklı kanatçık geometrilerileri birçok disiplin bazında karşılaştırılmışıır.

Sonuç olarak, iyileştirme sürecinin ortaya koyduğu sonuçlara göre yapılan çalışma gerekli mühendislik zamanını azalttığı ve komplike algoritma gerekliliğini kaldırmak suretiyle başarılı bir fiyat performans ilişkisi ortaya çıkardığı gözlemlenmiştir.

Anahtar Kelimeler: İnsansız Hava Aracı, Kavramsal tasarım, Aerodinamik Iyileştirme. 
Dedicated to my family... 


\section{ACKNOWLEDGMENTS}

I would like to express my utmost gratitude to my supervisor Prof.Dr. Nafiz Alemdaroğlu for his guidance and encouragement during the study. I have been fortunate to have an advisor who broadens my mind and gives the freedom space to research on my own. I owe debt to him.

I would like to express my sincere appreciation to my very close friend Engin Cem Şengezer, to my friend Muharrem Özgün and to my cousin Assoc.Prof.Dr.Selim Aksoy for their encouragement, support and advices during the study.

Lastly, I would like to express my deepest gratitude to my family for their support and continious encouragement in the whole stages of the study. The study would not have been completed successfully without their support and understanding. 


\section{TABLE OF CONTENTS}

ABSTRACT

\section{CHAPTERS}

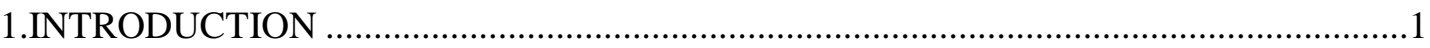

1.Introduction to Aircraft Design .............................................................................

2. Unmanned Aerial Vehicle and their Classification..................................................

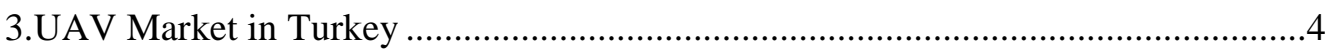

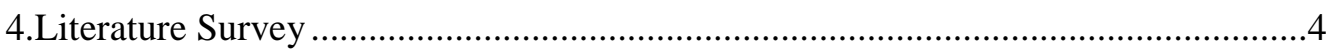

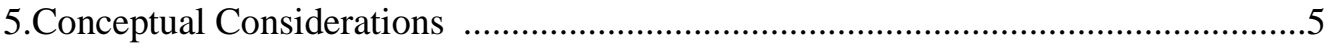

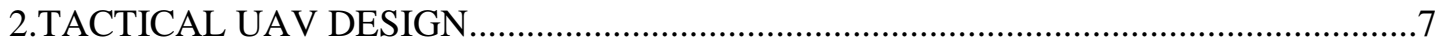

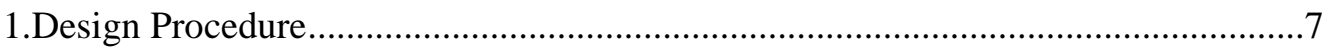

2. Specifying the Inputs: Design Parameters ……...................................................

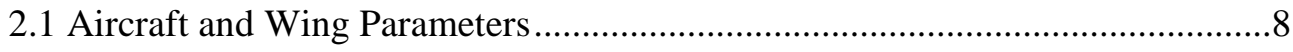

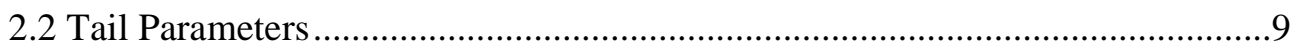

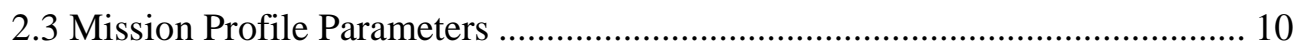

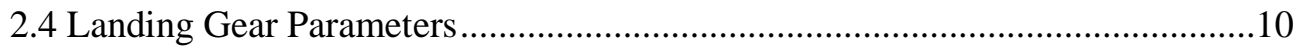




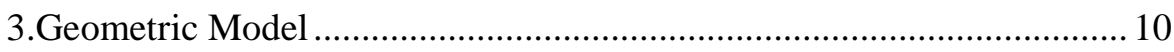

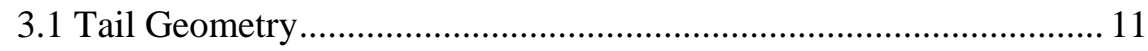

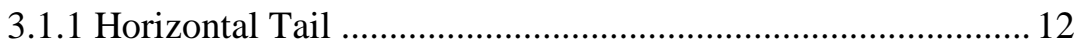

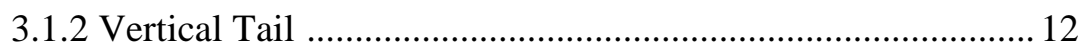

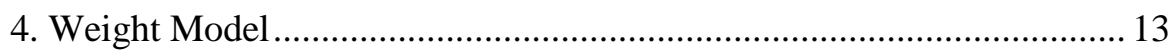

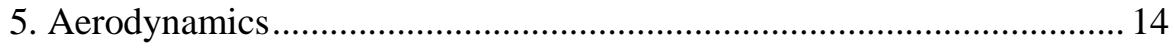

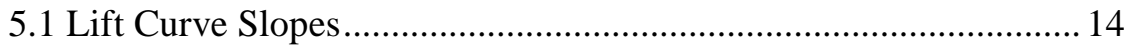

5.2 Maximum Lift Coefficient ....................................................... 15

5.3 Parasitic Drag Coefficient Estimation ............................................... 15

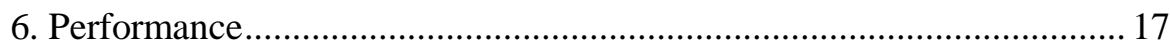

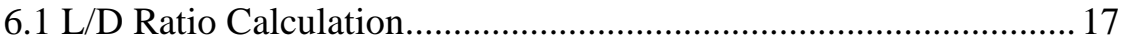

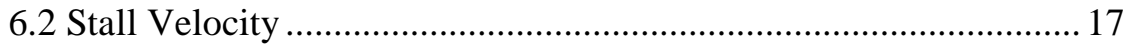

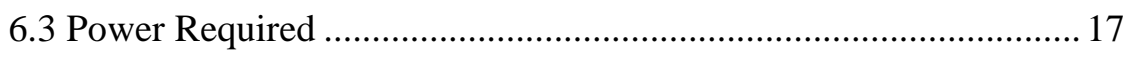

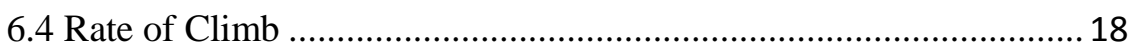

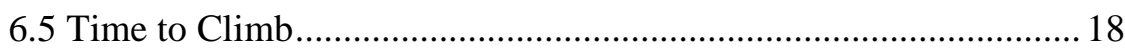

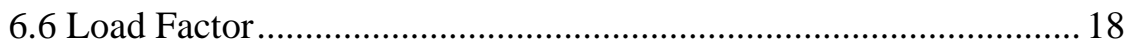

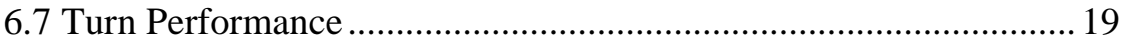

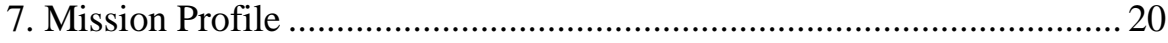

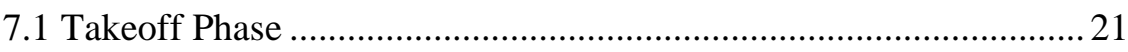

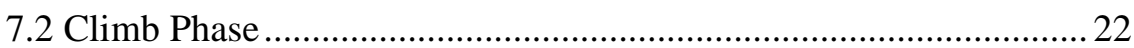

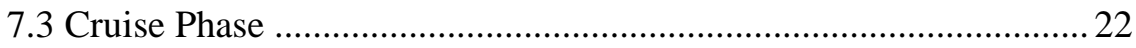

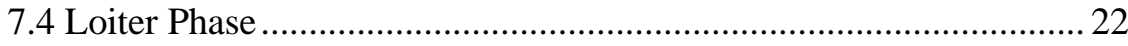

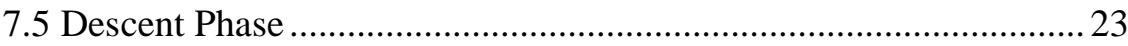

7.6 Landing Phase 


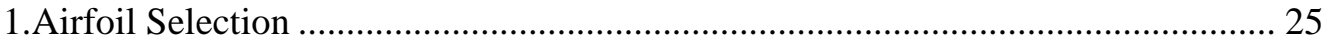

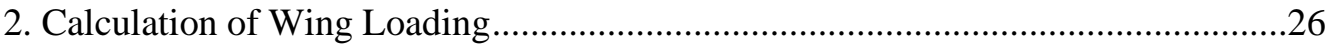

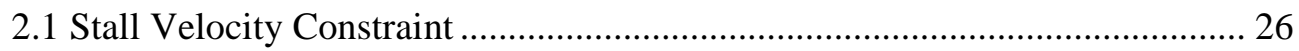

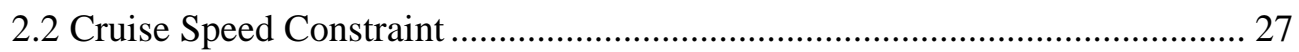

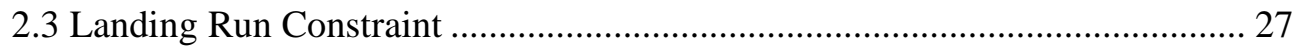

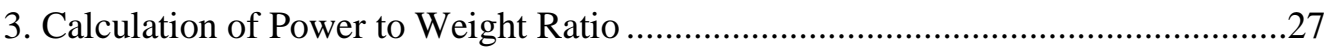

3.1 Takeoff Distance Constraint........................................................................ 27

3.2 Cruise Speed Constraint …………………….............................................. 27

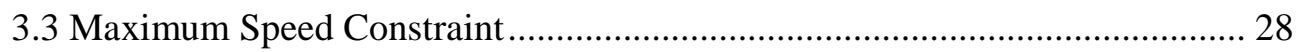

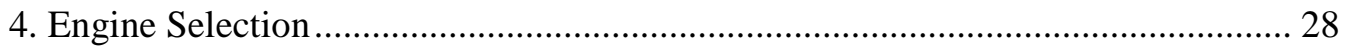

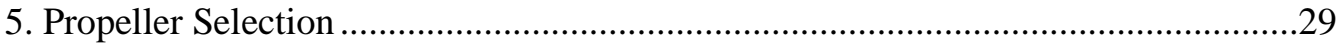

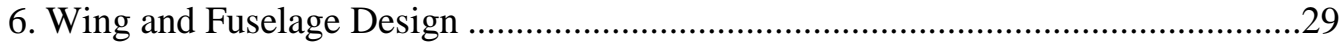

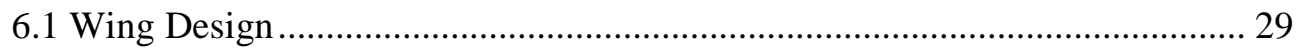

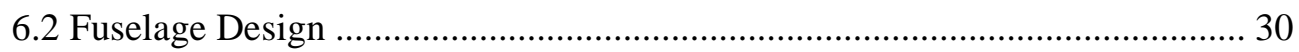

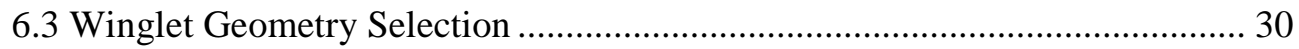

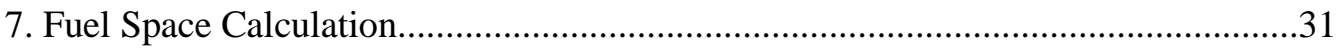

8. Landing Gear Locating and Sizing ...................................................................

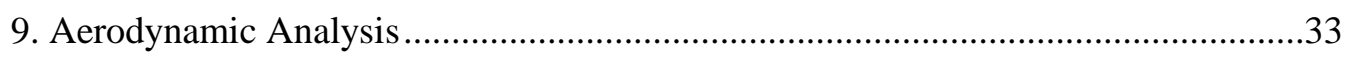

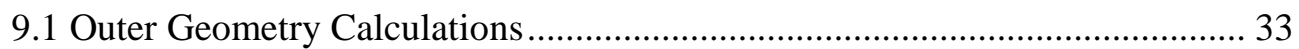

9.2 Lift Curve Slope Values and Aerodynamic Parameters \&Coefficients .......... 34

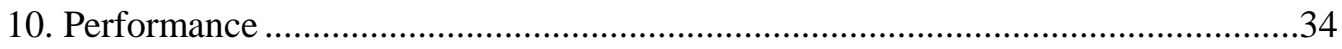

10.1 Power Available vs Power Required, Climb Rate and Climbing Time......... 34

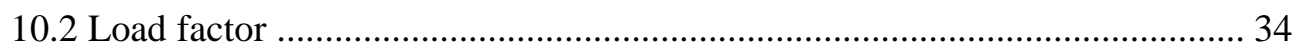

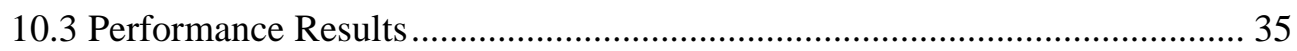

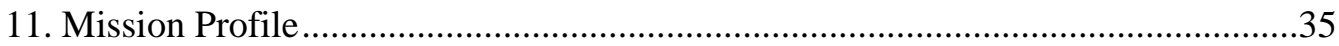




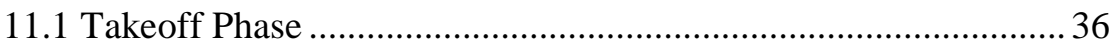

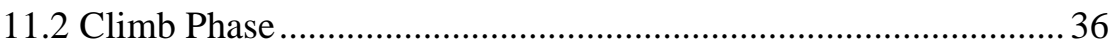

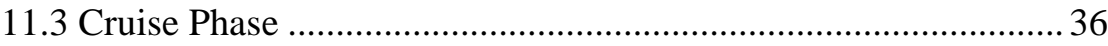

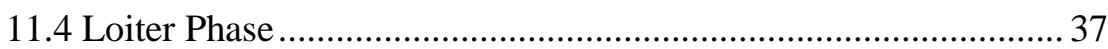

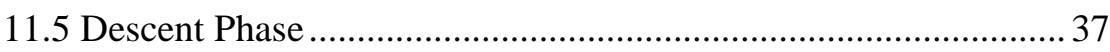

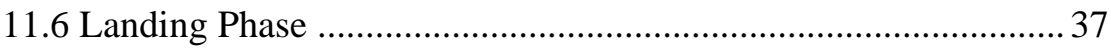

4.COMPUTATIONAL APPROACH, RESULTS AND IMPROVEMENT ...........................39

1. Computational Techniques Using CAD and CFD Analysis .................39

2. Numerical Methods for External Aerodynamic Analysis of the Aircraft 41

3. Mesh Independency Test and Boundary Conditions ........................... 43

4. Aerodynamic Design and Improvement............................................ 46

4.1 Forces for Different Wintip Geometries ......................................... 48

4.2 Moments for Different Wingtip Geometries .................................. 49

5. Selection of the Optimum Wingtip Geometry ....................................... 50

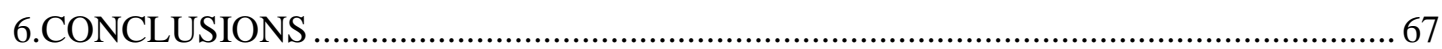

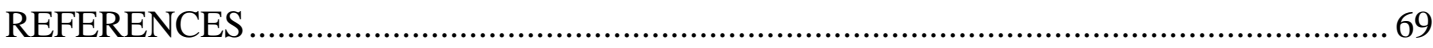

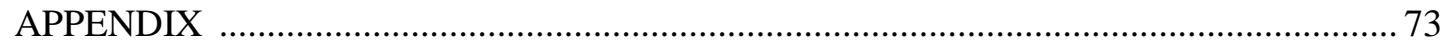

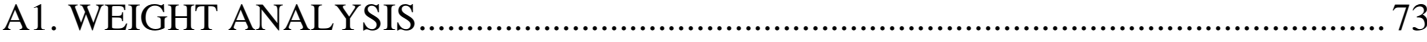

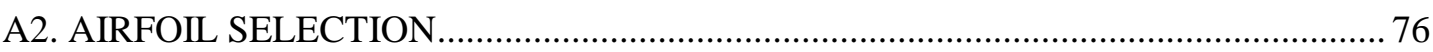

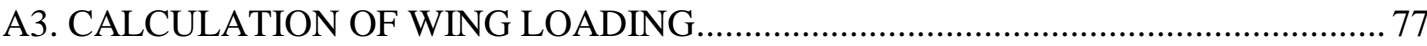

A4. CALCULATION OF POWER TO WEIGHT RATIO ……….................................... 78

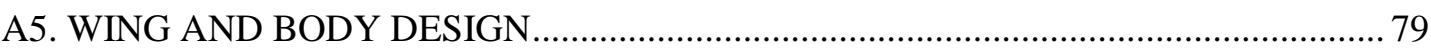

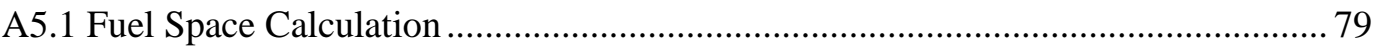

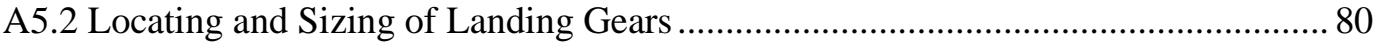


A6. AERODYNAMIC ANALYSIS .82

A6.1.Outer Geometry Dimensions. .82

A6.2 Lift Curve Slope and Aerodynamic Coefficients \& Parameters .83

A7. MANEUVRABILITY AND LOAD FACTOR PARAMETERS .87

A8. CENTER OF GRAVITY AND STATIC MARGIN CALCULATIONS .88

A9. TECHNICAL DRAWINGS. 90 


\section{LIST OF TABLES}

\section{TABLES}

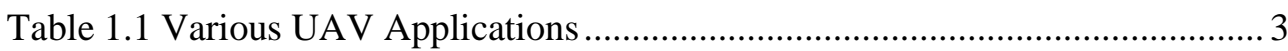

Table 1.2 Desired main specifications of the UAV ............................................ 5

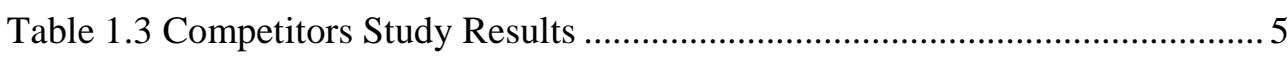

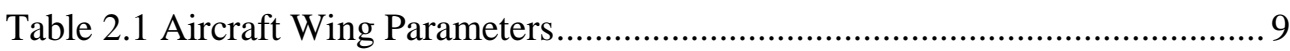

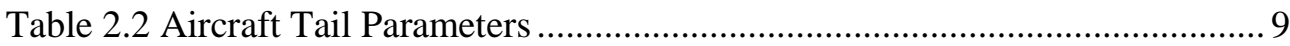

Table 2.3 Aircraft Mission Profile Parameters...................................................... 10

Table 2.4 Aircraft Landing Gear Parameters ...................................................... 10

Table 3.1 Various Airfoils Comparison Table ……................................................... 26

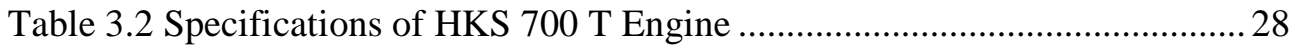

Table 3.3 Aircraft Geometrical Specifications …………........................................ 33

Table 3.4 Aircraft Aerodynamic Specification Values ........................................... 34

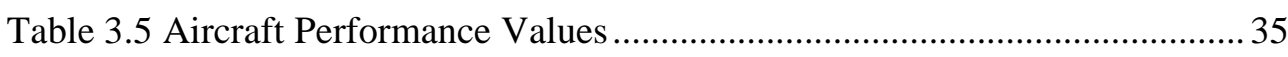

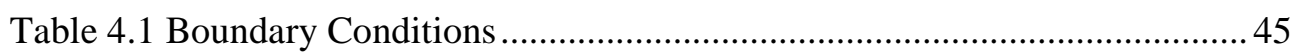

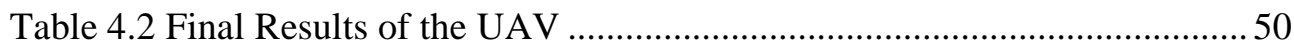

Table A5.1 Lift Specifications of Selected Tires ………………….................... 82

Table A6.1 Parameters Related with Aerodynamic Performance........................... 83

Table A6.2 Wetted and Reference Areas for Different Surfaces .......................... 87

Table A6.3 Resulting Friction Coefficients for Different Surfaces ...................... 87

Table A7.1 Different Parameters for Minimum Turning Radius Condition ..........87

Table A7.2 Different Parameters for Maximum Turn Rate Condition ................... 88 
Table A8.1 $x_{c g}$ Location for Different Components of the Aircraft .................................. 88

Table A8.2 $y_{c g}$ Location for Different Components of the Aircraft .................................. 89 


\section{LIST OF FIGURES}

\section{FIGURES}

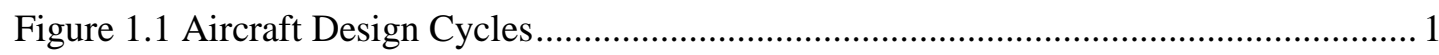

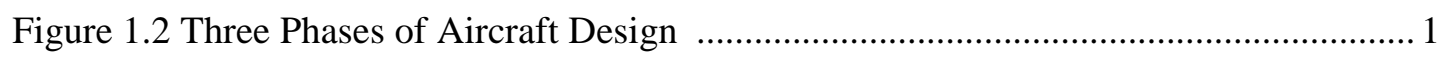

Figure 1.3 Classification of Military Purpose UAV's .......................................................... 2

Figure 1.4 Annual Rise in US UAV Market (Taken from Ref.[62]) ..................................... 3

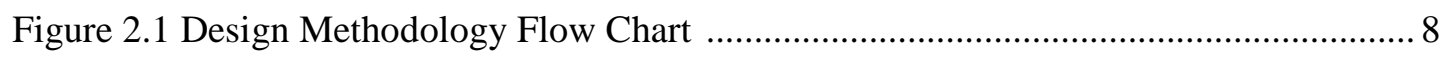

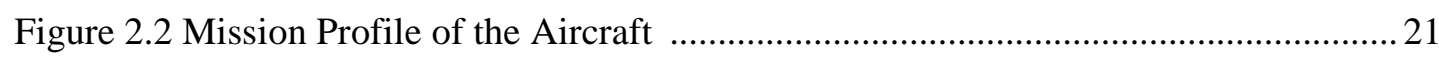

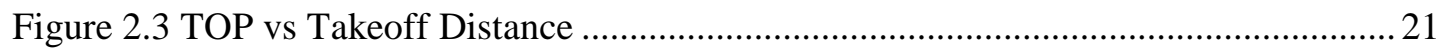

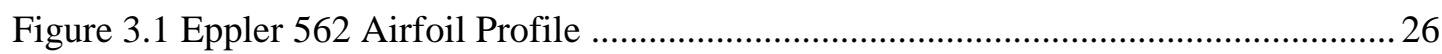

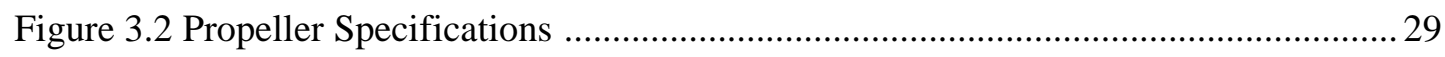

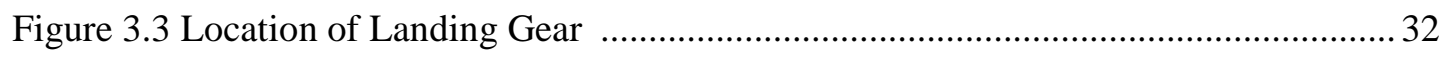

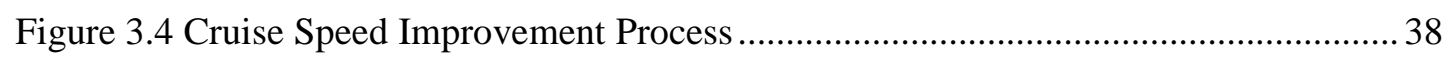

Figure 4.1 Control Volume Size With Respect to Aircraft Dimensions ...............................40

Figure 4.2 Aircraft Surfaces Afterwards Meshing .............................................................. 41

Figure 4.3 Aircraft Wing Afterwards Meshing and Detail View of Inflation Layers .......... 41

Figure 4.4 Relationship Between CPU Time and Accuracy.............................................. 42

Figure 4.5 Mesh Independence Study Results................................................................... 43

Figure 4.6 Residuals versus Number of Iterations ............................................................. 45

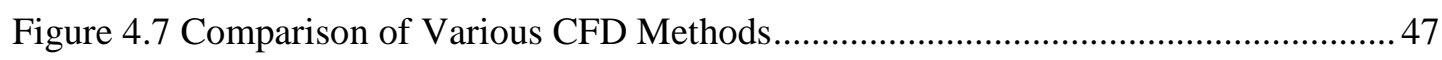

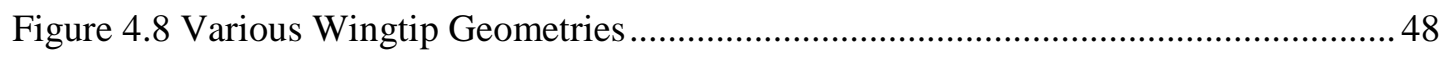

Figure 4.9 Lift Coefficient Versus Angle of Attack ......................................................... 48 
Figure 4.10 Drag Coefficient Versus Angle of Attack

Figure 4.11 Lift to Drag Ratios Versus Angle of Attack ..................................................... 49

Figure 4.12 Pitching Moment Comparison for Different Wingtip Geometries ..................... 50

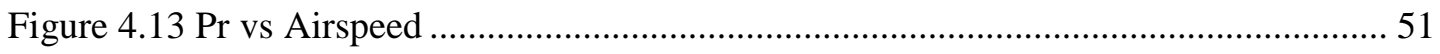

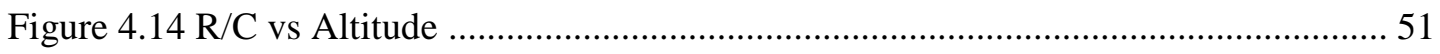

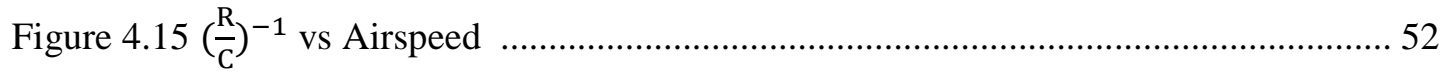

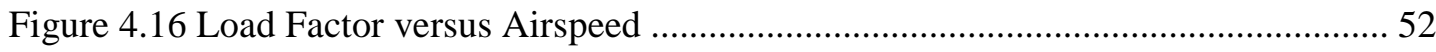

Figure 4.17 Comparison of Wing Pressure Contours for Different Wingtip Geometries at -

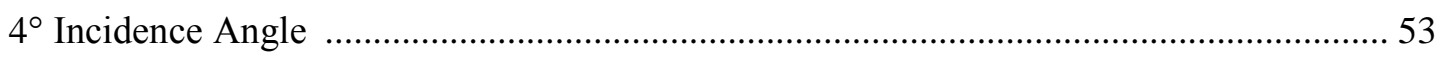

Figure 4.18 Comparison of Wing Pressure Contours for Different Wingtip Geometries at $0^{\circ}$ Incidence Angle

Figure 4.19 Comparison of Wing Pressure Contours for Different Wingtip Geometries at $2^{\circ}$ Incidence Angle

Figure 4.20 Comparison of Wing Pressure Contours for Different Wingtip Geometries at $4^{\circ}$ Incidence Angle

Figure 4.21 Comparison of Wing Pressure Contours for Different Wingtip Geometries at $6^{\circ}$ Incidence Angle 57

Figure 4.22 Comparison of Wing Pressure Contours for Different Wingtip Geometries at $8^{\circ}$ Incidence Angle 58

Figure 4.23 Comparison of Wing Pressure Contours for Different Wingtip Geometries at $10^{\circ}$ Incidence Angle

Figure 4.24 Comparison of Wing Pressure Contours for Different Wingtip Geometries at $12^{\circ}$ Incidence Angle

Figure 4.25 Comparison of Wing Pressure Contours for Different Wingtip Geometries at $14^{\circ}$ Incidence Angle 61

Figure 4.26 Wingtip Geometry Effect to Pressure Distribution at $0^{\circ}$ Incidence Angle ...... 62

Figure 4.27 Wingtip Geometry Effect to Pressure Distribution at $2^{\circ}$ Incidence Angle ...... 62

Figure 4.28 Wingtip Geometry Effect to Pressure Distribution at $4^{\circ}$ Incidence Angle ...... 63 xvii 
Figure 4.29 Wingtip Geometry Effect to Pressure Distribution at $6^{\circ}$ Incidence Angle ....... 63

Figure 4.30 Wingtip Geometry Effect to Pressure Distribution at $8^{\circ}$ Incidence Angle ........64

Figure 4.31 Wingtip Geometry Effect to Pressure Distribution at $10^{\circ}$ Incidence Angle ..... 64

Figure 4.32 Wingtip Geometry Effect to Pressure Distribution at $12^{\circ}$ Incidence Angle ..... 65

Figure 4.33 Wingtip Geometry Effect to Pressure Distribution at $14^{\circ}$ Incidence Angle ..... 65

Figure A.1 Wing Lift and Drag Coefficients for Fully Extended Flaps Case........................ 85

Figure A.2 Technical Drawing of the Aircraft Engine ......................................................90

Figure A.3 Aircraft Baseline Geometry Technical Drawing ................................................91

Figure A.4 Aircraft Final Geometry Technical Drawing ..................................................92 


\section{LIST OF SYMBOLS}

\begin{tabular}{|c|c|c|}
\hline Symbol & Description & Unit \\
\hline$a$ & Speed of sound & $\mathrm{m} / \mathrm{s}$ \\
\hline$A R_{\text {wing }}$ & Wing aspect ratio & - \\
\hline$A R_{H T}$ & Horiontal tail aspect ratio & - \\
\hline$A R_{V T}$ & Vertical tail aspect ratio & - \\
\hline$b$ & Wing span & $\mathrm{m}$ \\
\hline$c_{\text {cruise }}$ & Cruise specific fuel consumption & $1 / \mathrm{s}$ \\
\hline$c_{\text {loiter }}$ & Cruise specific fuel consumption & $1 / \mathrm{s}$ \\
\hline $\mathrm{c}_{\mathrm{r}}$ & Root chord of the wing & $\mathrm{m}$ \\
\hline$C_{r H T}$ & Horizontal tail root chord & $\mathrm{m}$ \\
\hline$C_{r V T}$ & Vertical tail root chord & $\mathrm{m}$ \\
\hline $\mathrm{c}_{\mathrm{t}}$ & Tip chord of the wing & $\mathrm{m}$ \\
\hline$C_{t H T}$ & Horizontal tail tip chord & $\mathrm{m}$ \\
\hline$C_{t V T}$ & Vertical tail tip chord & $\mathrm{m}$ \\
\hline$C_{l 0}$ & Airfoil lift coefficient at zero angle of attack & - \\
\hline$C_{l \text { design }}$ & Design lift coefficient & - \\
\hline$C_{L_{\alpha}}$ & Lift curve slope & $\operatorname{deg}^{-1}$ \\
\hline$C_{L_{\alpha \text { wing }}}$ & Lift curve slope of the wing & $\operatorname{deg}^{-1}$ \\
\hline$C_{L_{\alpha H . T}}$ & Lift curve slope of the horizontal tail & $\operatorname{deg}^{-1}$ \\
\hline$C_{L \max }$ & Maximum lift coefficient of the wing & - \\
\hline$C_{m 0}$ & Airfoil moment coefficient at zero angle of attack & - \\
\hline$\overline{C_{H T}}$ & Mean aerodynamic chord of the horizontal tail & $\mathrm{m}$ \\
\hline$\overline{C_{V T}}$ & Mean aerodynamic chord of the vertical tail & $\mathrm{m}$ \\
\hline$C_{D 0}$ & Parasitic drag coefficient & - \\
\hline$C_{D 0 \mathrm{misc}}$ & Miscellaneous parasitic drag coefficient & - \\
\hline$C_{D 0 \text { flap }}$ & Flap parasitic drag coefficient & - \\
\hline
\end{tabular}




\begin{tabular}{|c|c|c|}
\hline$C_{D 0 L G}$ & Landing gear parasitic drag coefficient & - \\
\hline$C_{f}$ & Friction coefficient & - \\
\hline $\mathrm{D}$ & Drag force & $\mathrm{N}$ \\
\hline$D_{H}$ & Hydraulic diameter & $\mathrm{m}$ \\
\hline$E$ & Endurance & $\sec$ \\
\hline$f_{v 1}$ & Viscous damping function & - \\
\hline$F$ & Shape factor & - \\
\hline$F F$ & Component form factor & - \\
\hline$F_{m}$ & Force subjected to main landing gears & $\mathrm{N}$ \\
\hline$F_{n}$ & Force subjected to front landing gear & $\mathrm{N}$ \\
\hline$L_{\mathrm{HT}}$ & Horizontal tail moment arm & $\mathrm{m}$ \\
\hline$L_{H T}$ & Horizontal tail length & $\mathrm{m}$ \\
\hline$L_{\mathrm{VT}}$ & Vertical tail moment arm & $\mathrm{m}$ \\
\hline$M$ & Mach number & - \\
\hline$n$ & Load factor & - \\
\hline$n_{R_{\min }}$ & Load factor during minimum turning radius & - \\
\hline$n_{\omega \max }$ & Load factor during maximum turning rate & - \\
\hline$L_{V T}$ & Vertical tail lenght & $\mathrm{m}$ \\
\hline$R$ & Turn radius & $\mathrm{ft}$ \\
\hline$R_{\min }$ & Minimum turn radius & $\mathrm{ft}$ \\
\hline $\operatorname{Re}$ & Reynolds number & - \\
\hline$S_{\text {wing }}$ & Wing surface area & $\mathrm{m}^{2}$ \\
\hline$S_{H T}$ & Surface area of the horizontal tail & $\mathrm{m}^{2}$ \\
\hline$S_{V T}$ & Surface area of the vertical tail & $\mathrm{m}^{2}$ \\
\hline$S_{\text {exposed }}$ & Exposed area & $\mathrm{m}^{2}$ \\
\hline $\mathrm{S}_{\mathrm{ref}}$ & Reference area & $\mathrm{m}^{2}$ \\
\hline $\mathrm{S}_{\text {wet }}$ & Wetted surface area & $\mathrm{m}^{2}$ \\
\hline$S_{\text {landing }}$ & Landing distance & $\mathrm{m}$ \\
\hline$S_{a}$ & Obstacle clearance distance & $\mathrm{m}$ \\
\hline$t_{\text {cruise }}$ & Cruising time & $\sec$ \\
\hline$t_{\text {loiter }}$ & Loitering time & $\mathrm{sec}$ \\
\hline$T$ & Air temperature & $\mathrm{K}$ \\
\hline $\mathrm{T}$ & Thrust force & $\mathrm{N}$ \\
\hline$T_{A \max }$ & Maximum available thrust & $\mathrm{N}$ \\
\hline
\end{tabular}




$u^{\prime}$
$\mathrm{v}$
$v$
$V_{\text {cruise }}$
$V_{f}$
$W_{\text {fuel burned }}$
$V_{\text {loiter }}$
$V_{\text {max }}$
$V_{R_{\text {min }}}$
$V_{\text {stall }}$
$V_{\omega \text { max }}$
$V^{*}$
$W$
$W_{0}$
$W_{\text {empty }}$
$W_{\text {fuel }}$
$W_{\text {payload }}$
$\omega$
$\omega_{\text {max }}$
$X$
$\bar{y}$
$y^{+}$

Fluctuating velocity

$\mathrm{m} / \mathrm{s}$

Airspeed

$\mathrm{m} / \mathrm{s}$

Kinematic viscosity

$\mathrm{m}^{2} / \mathrm{s}$

Cruise speed

$\mathrm{m} / \mathrm{s}$

Volume of the fuel

$\mathrm{m}^{3}$

Amount of fuel burned

lbs

Loiter speed $\mathrm{m} / \mathrm{s}$

Maximum speed $\mathrm{m} / \mathrm{s}$

Velocity during minimum turning radius $\mathrm{ft} / \mathrm{s}$

Stall speed $\mathrm{m} / \mathrm{s}$

Velocity during maximum turning rate $\mathrm{ft} / \mathrm{s}$

Corner velocity $\mathrm{ft} / \mathrm{s}$

Weight $\mathrm{kg}$

Aircraft take off gross weight $\quad \mathrm{kg}$

Aircraft empty weight $\quad \mathrm{kg}$

Aircraft fuel weight $\quad \mathrm{kg}$

Aircraft payload weight $\quad \mathrm{kg}$

Turn rate $\mathrm{rad} / \mathrm{s}$

Maximum turning rate $\mathrm{rad} / \mathrm{s}$

Kinematic viscosity ratio -

Mean aerodynamic chord spanwise position m

Dimensionless wall distance parameter 


\section{GREEK SYMBOLS}

$\begin{array}{llc}\text { Symbol } & \text { Description } & \text { Unit } \\ \Lambda & \text { Wing sweep angle } & \circ \\ \lambda & \text { Wing taper ratio } & - \\ \lambda_{H T} & \text { Horizontal tail taper ratio } & - \\ \lambda_{V T} & \text { Vertical tail taper ratio } & - \\ \eta & \text { Propeller efficiency } & - \\ \mu & \text { Dynamic viscosity } & \mathrm{kg} / \mathrm{m} . \mathrm{s} \\ \mu_{t} & \text { Turbulent viscosity } & \mathrm{Pa.s} \\ \phi & \text { General flow variable } & - \\ \rho & \text { Air density } & \mathrm{kg} / \mathrm{m}^{3} \\ \lambda_{H T} & \text { Horizontal tail taper ratio } & - \\ \theta_{\text {static taildown }} & \text { Static taildown angle } & \circ \\ \theta_{\text {tipback }} & \text { Tipback angle } & \circ\end{array}$




\section{LIST OF ABBREVIATIONS}

ABBREVIATIONS

$\begin{array}{ll}\text { UAV } & \text { Unmanned Aerial Vehicle } \\ \text { TUAV } & \text { Tactical Unmanned Aerial Vehicle } \\ \text { HLG } & \text { High lift generating fuselage } \\ \text { TOP } & \text { Take off parameter } \\ \text { CAD } & \text { Computer aided design } \\ \text { CFD } & \text { Computational fluid dynamics } \\ \text { SST } & \text { Shear Stress Transport } \\ \text { RSM } & \text { Reynolds Stress Model } \\ \text { LES } & \text { Large eddy simulation }\end{array}$




\section{CHAPTER 1}

\section{INTRODUCTION}

\section{Introduction to the Aircraft Design}

Aircraft design is an engineering technique of creating a flying object by considering balance between defined specifications, aspects and requirements. Aerodynamics, structures, weight, payload for a certain mission, production, cost, propulsion systems, stability and control are the main topics in aircraft design process.

The aircraft design process is a progressive procedure which can be described crudely as aircraft sizing and simple weight improvement, analysis, preliminary design and a more detailed optimization process, determination of requirements as well. Figure 1.1 describes the process. These processes incorporates crude subtitles, which are conceptual design, preliminary design and detailed design, given in figure 1.2.

At the first step, requirements setting for a mission profile as well as competitors study has been performed. After determining requirements, which can also be called as conceptual design phase, initial outer body of the aircraft is drafted. Preliminary design is the most crucial step owing to including advanced aerodynamic, structural and stability analyses. The preliminary design is followed by detailed design, including the design of subparts of the aircraft such as ribs, skins and other parts. Additionaly, cost and production tasks should also be considered. 


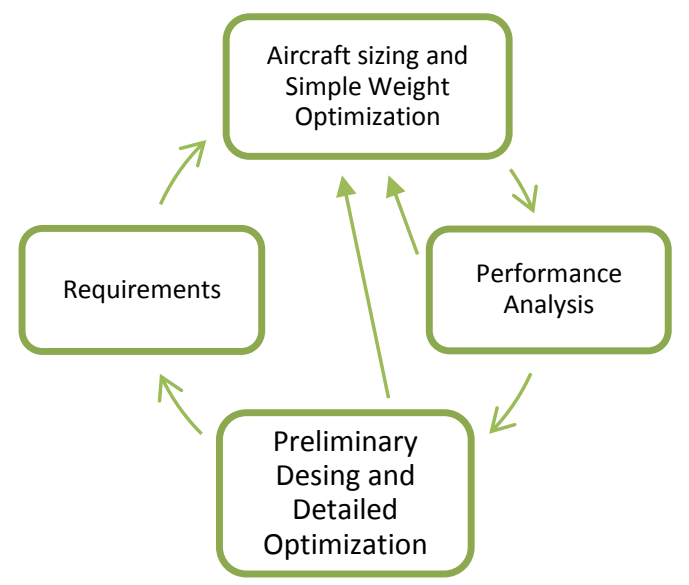

Figure 1.1 Aircraft Design Cycles

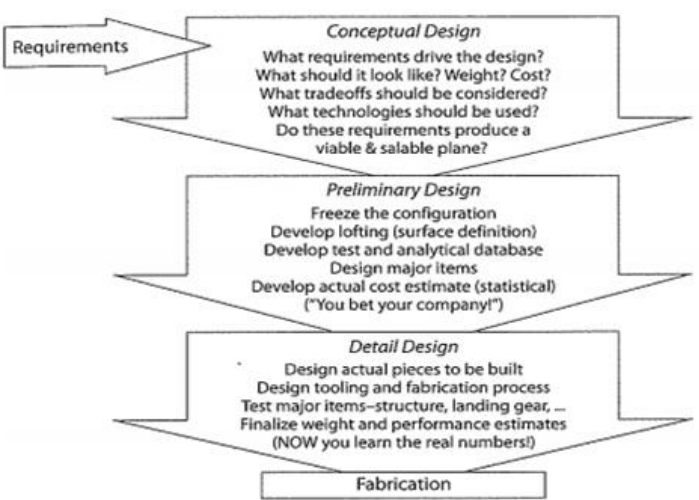

Figure 1.2 Three Phases of Aircraft Design (Taken from Ref. [23] Fig.2.2)

\section{Unmanned Aerial Vehicle and their Classification}

An unmanned aerial vehicle, commonly referred as a drone, is an aircraft without a human pilot on board. Flight is performed either autonomously or by a remote control of the ground station. A lot of UAV types, configurations, sizes and shapes are available. UAV application areas are given in table 1 . The success of UAV mission is highly dependent on the UAV's performance and reliability during flight. Recently, with the aid of improvements in autonomous control technology, UAV market is continiously growing, in both civilian and military sector. 
Table 1.1 Various UAV Applications

\begin{tabular}{|l|}
\hline Remote Sensing \\
\hline Commercial Aerial Surveillance \\
\hline Commercial and Motion Picture Film \\
\hline Domestic policing \\
\hline Oil, gas and mineral exploration and production \\
\hline Disaster relief \\
\hline Scientific research \\
\hline Armed attacks \\
\hline Aerial target exercice for training purpose \\
\hline Search and rescue \\
\hline Conservation \\
\hline Maritime patrol \\
\hline Forest fire detection \\
\hline Archaeology \\
\hline
\end{tabular}

The Tactical Unmanned Aerial vehicle is used for reconaissance, surveillance and target acquisition, even in adverse weather conditions. Aim of a TUAV is to gain superiority over the opposite site by enhanced enemy situational awareness, target acquisition ability, battle damage assesment and optimized battle management ability. Combination of depicted advantages contributes to the commander's situational awareness by allowing him to locate the squads much more effectively [32]. Classification of military UAV's can be seen in figure 1.3.

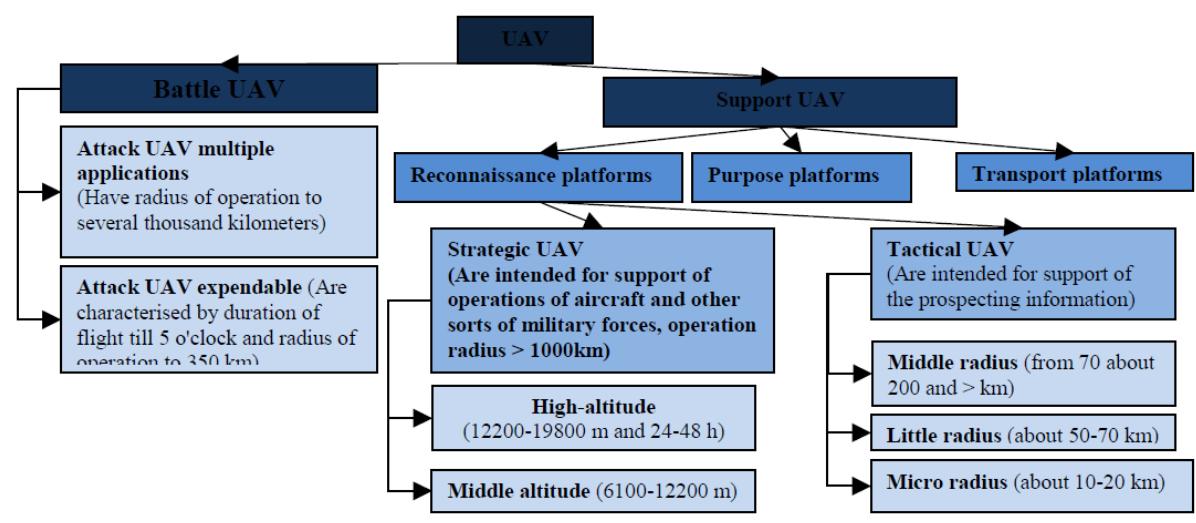

Figure1.3 Classification of Military Purpose UAV's (Taken from Ref.[32]) 


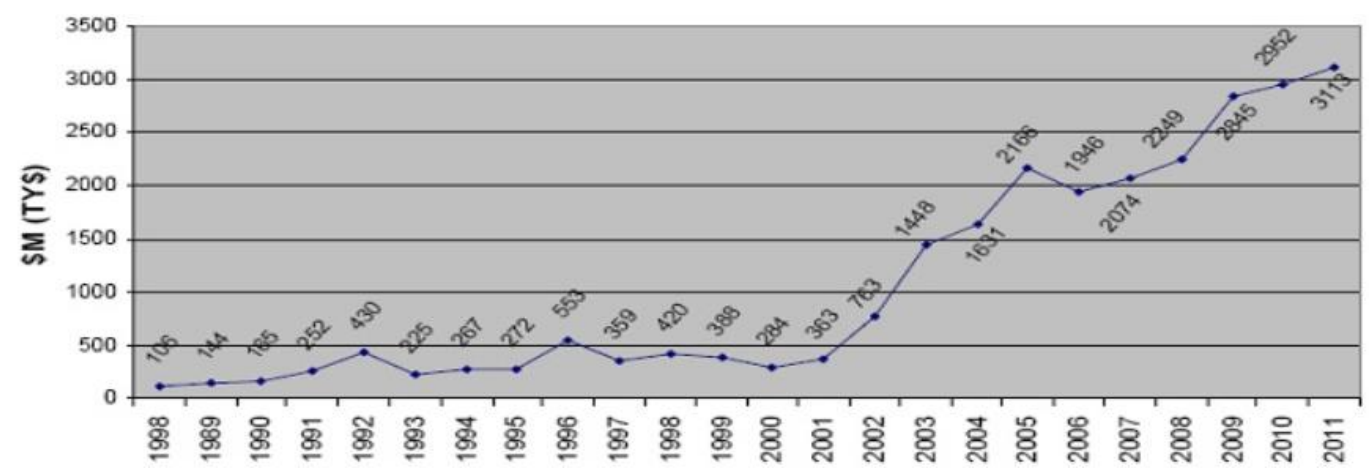

Figure 1.4 Annual Rise in US UAV Market (Taken from Ref.[27])

\section{UAV Market in Turkey}

Turkey's Vision in Unmanned systems is to design and produce genuine products so as to achieve national needs, and compete globally as well. Strategic goals are defined as followings [33];

-Producing genuine unmanned land, sea and aerial platforms to meet needs of Turkish Armed Forces, as well as being able to have maintanence capability.

-Collecting unmanned land, sea and aerial platforms in a single infrastructure in order not to allow any deviation from a mission or program.

-Gaining technological background in stealth, propulsion, fuel, material science and long endurance subtitles.

-Enhancing University and Industry collaboration.

-Being able to produce highly valuable products. Therefore, expectations are not only limited to satistfy Turkey's security needs but are also targeted towards exporting.

\section{Literature Survey}

On the other hand, desired main specifications in this study and mean values coming from the competitors study are given in the next table. 


\begin{tabular}{|c|c|}
\hline Altitude & $+3500 \mathrm{~m}(11500 \mathrm{ft})$ \\
\hline Endurance & $10-12 \mathrm{hrs}$ \\
\hline Range & $\approx 150 \mathrm{~km}$ \\
\hline Payload & $60 \mathrm{~kg}$ \\
\hline Wing span & $8-10 \mathrm{~m}$ \\
\hline
\end{tabular}

Table 1.3 Competitors Study Results

\begin{tabular}{|c|c|}
\hline Propulsion & Propeller \\
\hline Motor & Opposed Cylinder \\
\hline Engine Power (hp) & 70 \\
\hline Takeoff \& Landing & Runway \\
\hline Takeoff Gross Weight $(\mathbf{k g})$ & 500 \\
\hline Payload $(\mathbf{k g})$ & 70 \\
\hline Wing Span $(\mathbf{m})$ & 10.5 \\
\hline Fuselage Lenght $(\mathbf{m})$ & 6.5 \\
\hline Maximum Speed $(\mathbf{k m} / \mathbf{h})$ & 160 \\
\hline Endurance $(\mathbf{h r s})$ & +20 \\
\hline Range $(\mathbf{k m})$ & 150 \\
\hline Ceiling $(\mathbf{f t})$ & 22500 \\
\hline
\end{tabular}

\section{Conceptual Considerations}

At the beginning of conceptual design phase, the UAV planform area variables, which are taper ratio, aspect ratio, airfoil type, wing span, wing plan planform area and wing sweep requires great concern during the design phase. According to mission requirements, the UAV must have a high aspect ratio and a large span due to the high endurance performance requirement of the aircraft. It's known that high aspect ratio wings foster higher lift coefficient, compared to low aspect ratio wings at the same airspeed. The reason is the reduction of tip vortex generation. However, due to increased effective angle of attack at tips, stall will be encountered at a lower angle of attack, compared to low aspect ratio wings.

In addition, wing configuration selection is another fundametal aspect which should be considered during aircraft design process. However, some variables can be selected by the designer, such as the taper ratio. During the processes, taper ratio of 0.45 is preferred owing to generating elliptical lift distribution [23]. As a result, induced drag can be slightly lowered. Besides, tail configuration is another aspect that should be considered seriously. 


\section{CHAPTER 2}

\section{TACTICAL UAV DESIGN}

\section{Design Procedure}

Design process is harmonized by offering an input output analysis method. Input design parameters are range, lift to drag ratio, endurance, cruising altitude, payload weight, cruise speed and the aspect ratio. In addition, cruise speed is chosen by considering optimum takeoff gross weight and cruise speed. Depicted step is an iterative process greatly affecting the aircraft's final configuration. The configuration can be simply explained as airfoil type, wing loading, thrust to weight ratio, engine selection, wing and control surface geometries, landing gear selection, performance parameters and performance coefficients.The design process is handled by generating an excel file in which the design parameters cruise speed, aspect ratio, endurance, range, etc. are included.

Performance calculations are made by an iterative weight calculation method. Initial performance improvement was performed by optimizing the takeoff gross weight and cruise speed by conventional methods. Weight has a strong effect on cruise speed, ceiling, climb rate and maneuvrability of an aircraft [21]. During this step, cruise speed versus weight comparisons were performed. Methodology of design is summarized as a flow chart and is given below. 


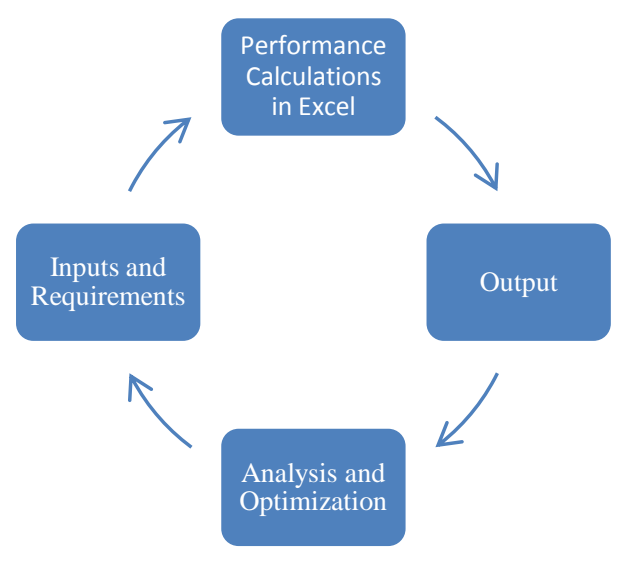

Figure 2.1 Design Methodology Flow Chart

\section{Specifying the Inputs: Design Parameters}

The initial step before any weight estimation is to define the design parameters, such as the wing and tail shape, wing configuration, engine specifications, mission profile parameters and requirements so as to reveal a stable and efficient aircraft.

\subsection{Aircraft and Wing Parameters}

The aircraft fuselage is initially conceived as a blended wing-fuselage configuration due to inducing up to $\% 40$ higher lift to drag ratio [8]. However, due to complexity and cost considerations, ellyptical shape fuselage, which has similar characteristics to blended type is chosen. Such configuration allows smoother airflow around the aircraft. In addition, elliptical fuselage shapes can also be assessed as similar to HLG characteristics due to having a shape of an airfoil. However, fuselage having a rough elliptical shape will deteriorate the drag beyond transonic region [31]. During the design process, the aft fuselage cross section reduction has not exceeded $10^{\circ}$ [23]. As depicted previously, according to desired performance, taper ratio has been chosen manually by the user's will. 
Table 2.1 Aircraft Wing Parameters

\begin{tabular}{|c|c|}
\hline $\boldsymbol{C}_{\boldsymbol{L} \text { max }}$ & Maximum lift coefficient of the wing \\
\hline$\left(\begin{array}{c}\boldsymbol{t} \\
\boldsymbol{c}\end{array}\right)_{\text {wing }}$ & Thickness to chord ratio of wing airfoil \\
\hline $\boldsymbol{C}_{\boldsymbol{L}_{\boldsymbol{\alpha}}}$ & Lift curve slope of the aircraft \\
\hline $\boldsymbol{A}$ & Wing sweep \\
\hline $\boldsymbol{c}_{\boldsymbol{r}}$ & Wing root chord \\
\hline $\boldsymbol{c}_{\boldsymbol{t}}$ & Wing tip chord \\
\hline $\boldsymbol{b}$ & Wing span \\
\hline $\boldsymbol{C}_{\boldsymbol{l} \mathbf{0}}$ & Airfoil lift coefficient at zero angle of attack \\
\hline $\boldsymbol{C}_{\boldsymbol{m} \mathbf{0}}$ & Airfoil moment coefficient at zero angle of \\
& attack \\
\hline $\boldsymbol{A R}$ & Wing aspect ratio \\
\hline $\boldsymbol{\lambda}$ & Wing taper ratio \\
\hline
\end{tabular}

\subsection{Tail Parameters}

Tail paramaters consist of geometric characteristics of the tail.

Table 2.2 Aircraft Tail Parameters

\begin{tabular}{|c|c|}
\hline$C_{r H T}$ & Horizontal tail root chord \\
\hline$C_{t H T}$ & Horizontal tail tip chord \\
\hline$C_{r V T}$ & Vertical tail root chord \\
\hline$C_{t V T}$ & Vertical tail tip chord \\
\hline$A R_{V T}$ & Vertical tail aspect ratio \\
\hline$A R_{H T}$ & Horizontal tail aspect ratio \\
\hline$\lambda_{H T}$ & Horizontal tail taper ratio \\
\hline$\lambda_{V T}$ & Vertical tail taper ratio \\
\hline$L_{H T}$ & Horizontal tail length \\
\hline$L_{V T}$ & Vertical tail length \\
\hline
\end{tabular}




\subsection{Mission Profile Parameters}

Mission profile inputs contain a lot of parameters. However, one can implicitly conclude that cruise time is the essential factor affecting the take off gross weight, compared to other parameters.

Table 2.3 Aircraft Mission Profile Parameters

\begin{tabular}{|c|c|}
\hline $\boldsymbol{t}_{\text {cruise }}$ & Cruising time \\
\hline $\boldsymbol{t}_{\text {loiter }}$ & Loitering time \\
\hline$(\boldsymbol{L} / \boldsymbol{D})_{\text {cruise }}$ & Cruise lift to drag ratio \\
\hline$(\boldsymbol{L} / \boldsymbol{D})_{\text {loiter }}$ & Loiter lift to drag ratio \\
\hline $\boldsymbol{V}_{\text {cruise }}$ & Cruise speed \\
\hline $\boldsymbol{V}_{\text {loiter }}$ & Loiter speed \\
\hline $\boldsymbol{c}_{\text {cruise }}$ & Cruise specific fuel consumption coefficient \\
\hline $\boldsymbol{c}_{\text {loiter }}$ & Loiter specific fuel consumption coefficient \\
\hline
\end{tabular}

\subsection{Landing Gear Parameters}

Table 2.4 Aircraft Landing Gear Parameters

\begin{tabular}{|c|c|}
\hline $\boldsymbol{F}_{\boldsymbol{m}}$ & Total force acting on the main landing gears \\
\hline $\boldsymbol{F}_{\boldsymbol{n}}$ & Total force acting front landing gear \\
\hline
\end{tabular}

\section{Geometric Model}

Prior to design, aircraft wing configuration models have been discussed. The different types of wing configurations have several advantages and disadvantages that make it suitable for certain flight operations, but unsuitable for other kinds of missions. Mid wing configuration has been selected due to possessing the advantages of both low and high wing configurations.

At the beginning of design, AR and taper ratio were selected according to previous designs and theoretical considerations. For instance, some researches reveal AR of 17.5 gives the best performance, in both L/D and stability manner for flows having such a Re number [16]. 
However, high aspect ratio comes with additonal cost, which leads the designer to find a compromise between cost and aerodynamic efficiency. Therefore, AR of 12 was selected according to literature survey and optimum performance-cost relationship. In addition, taper ratio of 0.45 has been selected due to depicted factors at chapter 1 .

The calculation of other specifications are given in the following equations [4].

The wing area;

$S_{\text {wing }}=\frac{\left(c_{r}+c_{t}\right) \cdot b}{2}$

The wing aspect ratio;

$A R_{\text {wing }}=\frac{b^{2}}{S_{\text {wing }}}$

The taper ratio;

$\lambda=\frac{c_{t}}{c_{r}}$

The mean aerodynamic chord;

$\bar{c}=\frac{2}{3} c_{r} \frac{1+\lambda+\lambda^{2}}{1+\lambda}$

The position of mean aerodynamic chord in spanwise direction;

$\bar{y}=\frac{b}{6} \frac{1+2 \lambda}{1+\lambda}$

\subsection{Tail Geometry}

Geometric specifications for both horizontal and vertical tails are given in formulas. Tail volume coefficients and tail moment coefficients are selected according to sailplane assumptions. 


\subsubsection{Horizontal Tail}

According to ref.[23], leading edge sweep angle of the horizontal tail for subsonic airplanes should be $5^{\circ}$ greater than the wing leading edge sweep. Therefore, horizontal tail leading edge sweep was selected as $5^{\circ}$. In addition, twist and dihedral were not included. Related equations are given below [23].

The horizontal tail surface area;

$S_{H T}=\frac{C_{H T} \bar{c} S_{W}}{L_{H T}}$

The horizontal tail aspect ratio;

$A R_{H T}=\frac{l_{H T}^{2}}{S_{H T}}$

In the horizontal tail moment arm equation the term of 0.65 comes from the sailplane assumption;

$L_{\mathrm{HT}}=0.65 .\left(l_{\text {fuselage }}\right)$

The horizontal tail mean aerodynamic chord;

$\overline{C_{H T}}=\left(\frac{2}{3}\right) C_{H T \operatorname{root}}\left(\frac{1+\lambda+\lambda^{2}}{1+\lambda}\right)$

The taper ratio of horizontal tail;

$\lambda_{H T}=\frac{c_{T, H T}}{c_{R, H T}}$

\subsubsection{Vertical Tail}

According to ref.[23], leading edge sweep angle of the vertical tail for subsonic airplanes is usually $20^{\circ}$. Related equations are given below [23];

The vertical tail surface area; 
$S_{V T}=\frac{C_{V T} \bar{c} S_{W}}{L_{V T}}$

The vertical tail aspect ratio;

$A R_{V T}=\frac{l_{V T}^{2}}{S_{V T}}$

The vertical tail moment arm of 0.65 term comes from sailplane assumption;

$L_{\mathrm{VT}}=0.65 .\left(l_{\text {fuselage }}\right)$

The vertical tail mean aerodynamic chord;

$\overline{C_{V T}}=\left(\frac{2}{3}\right) C_{V T \operatorname{root}}\left(\frac{1+\lambda+\lambda^{2}}{1+\lambda}\right)$

The taper ratio of vertical tail;

$\lambda_{V T}=\frac{c_{T, V T}}{c_{R, V T}}$

\section{Weight Model}

According to historical trends and experiences, the weight estimation process is the starting point of the conceptual design phase. During this step, conventional and widely employed weight estimation method [23] was employed. During these estimations, some constants are assumed according to prop-engine airplane, such as addition of $V_{\text {loiter }}$ and $(L / D)_{\text {loiter }}$ .During estimations, effect of AR and $V_{\text {cruise }}$ are considered, but payload effect was not analyzed since the payload is constant and can not be varied for the aircraft. In short, flowchart is given as in Fig.1.1.

The total weight is found by summation of fuel weight, internal component weights, empty weight and payload. Related formula is given below.

$W_{0}=W_{\text {payload }}+W_{\text {fuel }}+W_{\text {empty }}$ 


\section{Aerodynamics}

This section includes the calculation methods of fundamental aerodynamic coefficients and specifications of an aircraft.

\subsection{Lift Curve Slopes}

Lift curve slope is the relationship between lift coefficient and angle of attack, which is calculated for aircraft fuselage, wing and tails. For thin airfoil assumption, it can be assumed to be as $2 \pi$, however, for the whole aircraft design, the lift curve slope has a more complex relationship given as follows [24];

$C_{L_{\alpha}}=C_{L_{\alpha w i n g}}+C_{L_{\alpha H \cdot T}} \cdot \eta_{H} \cdot \frac{S_{H}}{S}\left(1-\left(\frac{d \varepsilon}{d \alpha}\right)_{\text {downwash }}\right)$

Lift curve slope of the wing is as following;

$C_{L_{\alpha \text { wing }}}=\frac{2 \cdot \pi \cdot A R_{\text {wing }}}{2+\sqrt{4+\frac{A R_{\text {wing }}^{2} \beta^{2}}{\eta^{2}}\left(1+\frac{\tan ^{2} \Lambda_{C / 2}}{\beta^{2}}\right)}} \cdot \frac{S_{\text {exposed }}}{S_{\text {ref }}} \cdot F$

$\beta^{2}=1-M^{2}$

$M=\frac{\mathrm{v}}{a}$

$\eta=\frac{C_{l \alpha}}{2 \pi / \beta}$

$F=1.07\left(1+\frac{d}{b}\right)^{2}$

$(2.23)$

Where $d$ and $b$ are the fuselage diameter and length respectively.

Lift curve slope for horizontal tail is given as follows [24]; 
$C_{L_{\alpha H . T}}=\frac{2 . \pi \cdot A R_{H . T}}{2+\sqrt{4+\frac{A R_{\text {wing }}^{2} \beta^{2}}{\eta^{2}}\left(1+\frac{\tan ^{2} \Lambda_{c / 2}}{\beta^{2}}\right)}} \cdot \frac{S_{\text {exposed }}}{S_{\text {ref }}} \cdot F$

Downwash factor is found from;

$$
\begin{aligned}
& \left(\left.\frac{d \varepsilon}{d \alpha}\right|_{M}\right)_{\text {downwash }}=\left.\frac{d \varepsilon}{d \alpha}\right|_{M=0} \cdot \frac{\left.C_{L_{\alpha \text { wing }}}\right|_{M}}{\left.C_{L_{\alpha \text { wing }}}\right|_{M=0}} \\
& \left.\frac{d \varepsilon}{d \alpha}\right|_{M=0}=4.44\left[K_{A} K_{\lambda} K_{H} \sqrt{\cos \Lambda_{\frac{c}{4}}}\right]^{1.19} \\
& K_{A}=\frac{1}{A R_{\text {wing }}}-\frac{1}{1+\left(A R_{\text {wing }}\right)^{1.7}} \\
& K_{\lambda}=\frac{10-3 \lambda}{7} \\
& K_{H}=\frac{1-\frac{h_{\text {tail }}}{b}}{\left(\frac{2 l_{\text {tail }}}{b}\right)^{1 / 3}}
\end{aligned}
$$

\subsection{Maximum Lift Coefficient}

Maximum theoretical lift coefficient is given as [23];

$C_{L \max }=(0.9) C_{l \max }\left(\cos \Lambda_{c / 4}\right)$

\subsection{Parasitic Drag Coefficient Estimation}

Component Build up Method is used [23] to give the parasitic darg coefficient;

$$
\begin{aligned}
& C_{D 0}=\frac{\sum\left(C_{f c} F F_{c} Q_{c} S_{w e t c}\right)}{S_{r e f}}+C_{D 0 \text { misc }}+C_{L \& P} \\
& \left(C_{D 0}\right)_{c}=\frac{\sum\left(C_{f c} F F_{c} Q_{c} S_{w e t c}\right)}{S_{r e f}}
\end{aligned}
$$


$C_{D 0 \text { misc }}=C_{D 0 \text { flap }}+C_{D 0 L G}$

Term "c" refers to the specified component (eq.3.32). The miscellaneous drag is defined as the drag contribution due to air speed around the aircraft components such as: flaps, landing gears, upswept aft fuselage, and base area, are then estimated and added to the total, along with estimated contributions for leakages and proturberances " $\mathrm{C}_{\mathrm{DL} \& \mathrm{P}}$ ". For turbulent flow, which happens in most cases, the flat-plate skin friction coefficient should not be neglected [23]. Note that the second term in the denominator is the Mach number (compressibility) correction and it approaches unity for low-subsonic flight.

$C_{f}=\frac{0.455}{\left(\log _{10} R\right)^{2.58}\left(1+0.144 M^{2}\right)^{0.65}}$

As component form factor, following equation can be used for both wing and tails [23];

$$
\begin{aligned}
& F F=\left[1+\frac{0.6}{\left(\frac{x}{c}\right)_{m}}\left(\frac{t}{c}\right)+100\left(\frac{t}{c}\right)^{4}\right]\left[1.34 M^{0.18}\left(\cos \Lambda_{m}\right)^{0.28}\right] \\
& S_{\text {wet }}=S_{\text {exposed }}\left[1.977+0.52\left(\frac{t}{c}\right)\right]
\end{aligned}
$$

As for the form factor, FF, the following equation can be used for both wing and tails [23];

$$
\begin{aligned}
& f=1.07\left(1+\frac{d}{b}\right)^{2} \\
& F F=\left(1+\frac{60}{f^{3}}+\frac{f}{400}\right)
\end{aligned}
$$

Landing gear parasitic drag coefficient has been found by [23];

$$
C_{D 0 L G}=\frac{\left(\frac{D}{q_{\infty}}\right)}{S_{w i n g}}
$$

Flap parasitic drag coefficient has been found by [23]; 
$\Delta C_{D 0 \text { flap }}=F_{\text {flap }} \frac{c_{f}}{c} \frac{S_{\text {flapped }}}{S_{\text {ref }}}\left(\delta_{\text {flap }}-10^{0}\right)$

\section{Performance}

Performance calculations are as follows: L/D, $V_{\text {stall }}$, power required and power available values, rate of climb, time to climb, speed\&load factor parameters, minimum turn radius and maximum turn rate.

\subsection{L/D Ratio Calculation}

Theoretical L/D ratio has been calculated as follows [4];

$$
\left(\frac{L}{D}\right)_{\text {cruise }}=\frac{C_{L}}{C_{D}}=\frac{C_{L}}{C_{D 0}+K C_{L}^{2}}
$$

\subsection{Stall Velocity}

Stall is defined as reduction in lift coefficient due to flow detachment as a result of high angle of attack. Theoretical $V_{\text {stall }}$ has been calculated using the following equation [4];

$V_{\text {stall }}=\sqrt{\frac{2\left(\frac{W}{S}\right)}{\rho C_{L \text { max }}}}$

\subsection{Power Required}

Initially, owing to the piston-prop engine configuration, one should find the power by equating thrust to drag [4].

$T=\frac{\eta P}{V}$ 
$D=T=\frac{1}{2} \rho V^{2} S C_{D}$

\subsection{Rate of Climb}

Maximum rate of climb is given as follows [4];

$\left(\frac{R}{C}\right)_{\max }=\frac{\text { Excess power }}{\text { Weight }}=\frac{P_{\text {available }}-P_{\text {required }}}{\text { Weight }}=\frac{\left(T_{A} \max -D\right) \times V_{\text {inf }}}{W}$

Maximum altitude can be found by equating rate of climb to zero.

\subsection{Time to Climb}

Area under $\left(\frac{R}{C}\right)^{-1}$ vs altitude gives us time to climb to maximum attainable altitude.

\subsection{Load Factor}

The definition of load factor is the ratio of lift to weight. Expicitly, the ratio varies during maneuvers. Equations for both load factor and maximum load factor are given below [4];

$n=\frac{L}{W}=\frac{1}{2} \rho V^{2} C_{L} \frac{S}{W}$

Maximum load factor will occur when $C_{L}=C_{L \text { max }}$;

$n_{\max }=\frac{L}{W}=\frac{1}{2} \rho V^{2} C_{L \max } \frac{S}{W}$

Maximum load factor constraint with $T_{A}$;

$n=\left[\frac{\frac{1}{2} \rho V^{2}}{K\left(\frac{W}{S}\right)}\left[\left(\frac{T}{W}\right)-\frac{1}{2} \rho V^{2} \frac{C_{D 0}}{\left(\frac{W}{S}\right)}\right]\right]^{1 / 2}$

Later on the thrust term with be replaced by the equation 3.43 given for prop-engine aircraft, one can find; 
$n=\left[\frac{\frac{1}{2} \rho V^{2}}{K\left(\frac{W}{S}\right)}\left[\left(\frac{\eta P}{W V}\right)-\frac{1}{2} \rho V^{2} \frac{C_{D 0}}{\left(\frac{W}{S}\right)}\right]\right]^{1 / 2}$

Calculations were performed by considering both $C_{L \text { max }}$ and $P_{A \text { max }}$ factors.

\subsection{Turn Performance}

Turning performance is an essential factor while calculating the aircraft performance parameters. These are minimum turn radius, velocity and load factor during this maneuver, maximum turning rate, velocity, load factor during the action and corner speed. Equations for these parameters are given below [4];

Minimum turn radius is defined as;

$R_{\text {min }}=\frac{4 K\left(\frac{W}{S}\right)}{g \rho\left(\frac{T}{W}\right) \sqrt{1-\frac{4 K C_{D 0}}{\left(\frac{T}{W}\right)^{2}}}}$

Velocity during minimum turn radius;

$V_{R_{\text {min }}}=\sqrt{\frac{4 K\left(\frac{W}{S}\right)}{\rho\left(\frac{T}{W}\right)}}$

Load factor during minimum turn radius;

$n_{R_{\min }}=\sqrt{2-\frac{4 K C_{D 0}}{\left(\frac{T}{W}\right)^{2}}}$

Maximum turn rate;

$\omega_{\max }=g \sqrt{\frac{\rho}{W / S}\left[\frac{T / W}{2 K}-\left(\frac{C_{D 0}}{K}\right)^{1 / 2}\right]}$

Velocity during maximum turn rate;

$V_{\omega \max }=\left[\frac{2\left(\frac{W}{S}\right)}{\rho}\right]^{1 / 2}\left[\frac{K}{C_{D 0}}\right]^{1 / 4}$ 
Load factor during maximum turn rate;

$n_{\omega \max }=\left(\frac{T / W}{\sqrt{K C_{D 0}}}-1\right)^{1 / 2}$

Corner velocity;

$V^{*}=\sqrt{\frac{2 n_{\max } W}{\rho C_{L \max } S}}$

Although critical pull up and pull down maneuvers are not essential for an intelligence, and reconnaisance UAV, it's worth to consider the followings [4];

Equations for pull up maneuver;

Turn radius;

$R=\frac{V^{2}}{g(n-1)}$

Turn rate;

$\omega=\frac{g(n-1)}{V}$

Equations for pull down maneuvers;

Turn radius;

$R=\frac{V^{2}}{g(n+1)}$

Turn rate;

$\omega=\frac{g(n+1)}{V}$

\section{Mission Profile}

Mission profile includes take off, climb, cruise, loiter, descend, and landing. Initial weight estimation by Raymer method as well as by Mission profile are described below. 


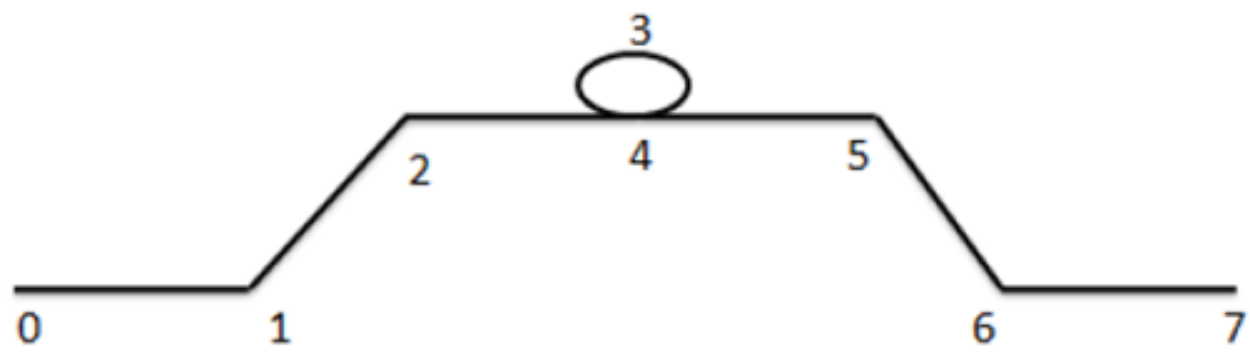

Figure 2.2 Mission Profile of the Aircraft

\subsection{Takeoff Phase}

Takeoff is the phase of flight in which air vehicle goes from the ground to flying in the air. Initial weight estimation for takeoff phase 1-2 is defined as [23];

$\frac{W_{1}}{W_{0}}=0.97$ to 0.99

Takeoff distance can be found by [23];

$\frac{W}{S}=T O P \sigma \frac{C_{l \max }}{1.21}\left(\frac{h p}{w}\right)$

Where takeoff paramater is found from Fig 2.5;

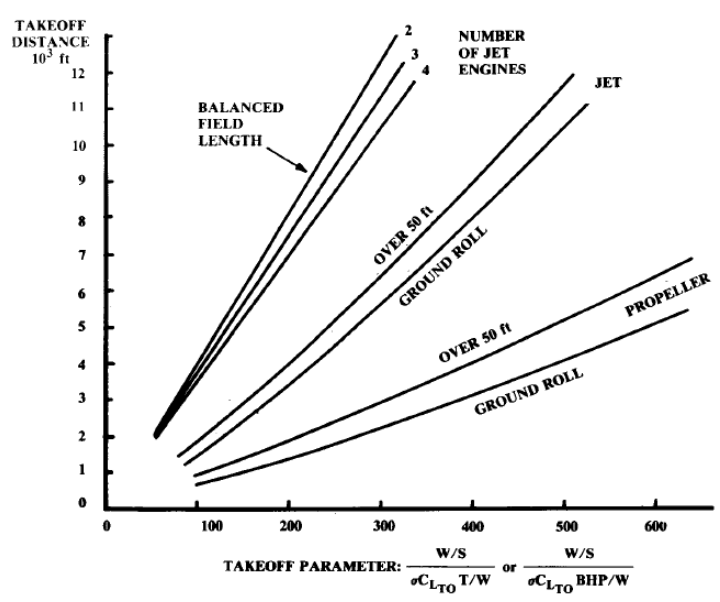

Figure 2.3 TOP vs Takeoff Distance(Taken from Ref. [23] Fig.5.4) 


\subsection{Climb Phase}

Climbing is the phase to reach cruising altitude. Due to the fact that Mach number is not high enough for statistical climb equations, weight estimation were based on historical values.

Equation related with the phase 1-2 are given [23];

$\frac{W_{2}}{W_{1}}=0.985$

\subsection{Cruise Phase}

Cruise is the flight phase where the aircraft fuel efficiency is the highest. Achieved by reduction in dynamic pressure, which is a result of either diminishing density or velocity.

Equation related with the phase 2-3 and 4-5 are given respectively [23];

$$
\begin{aligned}
& \frac{W_{3}}{W_{2}}=\exp \left[\frac{-R C_{b h p}}{550 \eta_{p}\left(\frac{L}{D}\right)_{\max }}\right] \\
& \frac{W_{5}}{W_{4}}=\exp \left[\frac{-R C_{b h p}}{550 \eta_{p}\left(\frac{L}{D}\right)_{\max }}\right]
\end{aligned}
$$

\subsection{Loiter Phase}

Loiter is defined as cruising certain amount of time over a small territory. Equation related with this phase 3-4 is given below [23];

$$
\begin{aligned}
& \frac{W_{4}}{W_{3}}=\exp \left[\frac{-E V C_{b h p}}{550 \eta_{p}\left(\frac{L}{D}\right)}\right] \\
& \left(\frac{L}{D}\right)=0.866 .\left(\frac{L}{D}\right)_{\max }
\end{aligned}
$$




\subsection{Descent Phase}

Descent is the phase prior to landing. Weight estimation for the phase is based on historical values. Equation related with the phase 5-6 is given below [23];

$\frac{W_{6}}{W_{5}}=0.995$

\subsection{Landing Phase}

Landing is the phase in which aircraft returns to the ground. Weigh estimation for the phase is based on historical values.

Equation related with the phase 6-7 is given below [23];

$\frac{W_{7}}{W_{6}}=0.992$ to 0.997 


\section{CHAPTER 3}

\section{THE INITIAL DESIGN AND CALCULATIONS}

\section{Airfoil Selection}

An airfoil is a 2-D profile of a wing. During the movement of airfoil shaped body, aerodynamic forces, called as lift and drag are generated. However, airfoil profile has a vital effect on the aircraft performance and should be selected carefully. During airfoil selection process, $\mathrm{Re}, \mathrm{M}$ and $C_{l \text { design }}$ parameters were considered.

$$
\begin{aligned}
& R e=\frac{U \times \bar{c}}{v} \\
& M=\frac{u}{a} \\
& C_{l \text { design }}=\frac{w}{S_{\text {ref } q}}
\end{aligned}
$$

According to Re, M, $C_{l \text { design }}$ and t/c parameters, similar airfoils were compared in the table 3.1. In addition, XLFR5 and Javafoil were used to compare airfoil performance parameters. However, Javafoil tool benefits not to calculate only airfoil performance parameters but also wing parameters using variables AR and sweep angle. In short, Eppler 562 airfoil profile has been selected by considering defined parameters. 
Table 3.1 Various Airfoils Comparison Table

\begin{tabular}{|l|l|l|l|}
\hline Airfoils & Max(t/c) & \multicolumn{1}{|c|}{$\mathbf{C l}_{\boldsymbol{\alpha}=\mathbf{0}}$} & $\left(\frac{\mathbf{L}}{\mathbf{D}}\right)_{\max }$ \\
\hline Eppler 562 & 15 & 0.62 & 85.3 \\
\hline Eppler 591 & 15.7 & 0.9 & 85.5 \\
\hline Eppler 657 & 15.6 & 0.61 & 48.4 \\
\hline Eppler 855 & 15.7 & 0.52 & 71.3 \\
\hline Fx 60-160 & 15.6 & 0.48 & 63.8 \\
\hline Glenn Martin 4 & 15.5 & 0.39 & 74.4 \\
\hline
\end{tabular}

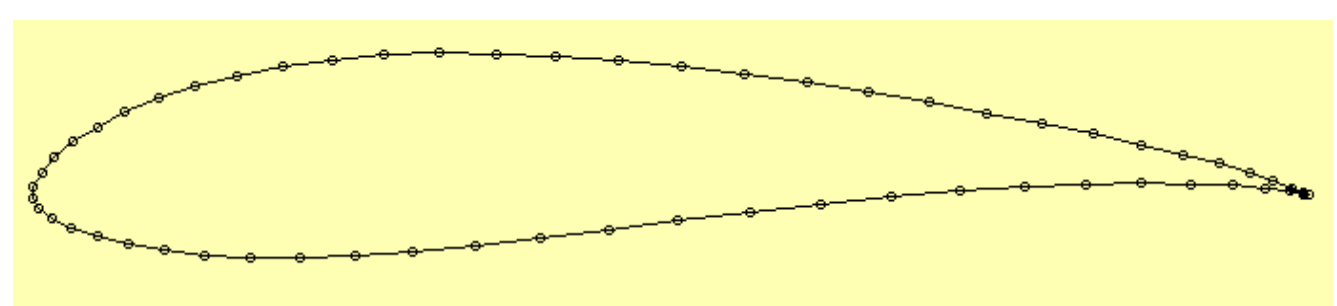

Figure 3.1 Eppler 562 Airfoil Profile

\section{Calculation of Wing Loading}

Wing loading should be found by considering stall velocity, cruise speed and landing distance. Lowest value should be taken after calculations.

\subsection{Stall Velocity Constraint}

Theoretical $V_{\text {stall }}$ has been calculated as following [4];

$V_{\text {stall }}=\sqrt{\frac{2\left(\frac{W}{S}\right)}{\rho C_{L \max }}}$ 


\subsection{Cruise Speed Constraint}

The parameter has been calculated as follows [25];

$\frac{L}{D}=\left(\frac{\rho V^{2} C_{D 0}}{2\left(\frac{W}{S}\right)}+\frac{2 K}{\rho V^{2}} \times \frac{W}{S}\right)^{-1}$

\subsection{Landing Run Constraint}

The parameter has been calculated as follows [23];

$S_{\text {landing }}=80\left(\frac{W}{S}\right)\left(\frac{1}{\sigma C l_{\max }}\right)+S_{a}$

Where $S_{a}$ is defined as obstacle clearance distance.

Wing loading should be found by considering takeoff distance, cruise and maximum speed. The highest value should be taken afterwards calculations.

\section{Calculation of Power to Weight Ratio}

\subsection{Takeoff Distance Constraint}

The parameter has been calculated using the following formula [23];

$\frac{W}{S}=T O P \sigma \frac{C_{l \max }}{1.21}\left(\frac{h p}{w}\right)$

\subsection{Cruise Speed Constraint}

The parameter has been calculated with following [25] equation; 
$\left(\frac{P}{W}\right)_{\text {cruise }}=\frac{1}{(L / D)_{\text {cruise }}}$

\subsection{Maximum Speed Constraint}

The parameter has been calculated using [4];

$V_{\text {max }}=\left\{\frac{\left[\frac{T_{A \max }}{W}\right]\left(\frac{W}{S}\right)+\left(\frac{W}{S}\right) \sqrt{\left[T_{A \max } / W\right]^{2}-4 C_{D 0} K}}{\rho C_{D 0}}\right\}$

$T_{A \max }=\frac{\eta P_{A \max }}{V}$

\section{Engine Selection}

During engine selection process, consideration was based on engine power consistency with the selected P/W ratio; in addition, involment of turbocharger is an asset. According to cited criterion, HKS $700 \mathrm{~T}$ engine has been selected. Specifications are given below [11]. Technical drawing is given in the appendix section.

Table 3.2 Specifications of HKS 700 T Engine (Taken from Ref.[11])

\begin{tabular}{|l|l|}
\hline Configuration & $\begin{array}{l}\text { 2 cylinder 4 stroke engine with horizontally opposed cylinders, 4 valves per } \\
\text { cylinder, turbocharger with intercooler }\end{array}$ \\
\hline Bore x stroke & $85 \mathrm{~mm}$ x $62.5 \mathrm{~mm}$ \\
\hline Displacement & $709 \mathrm{cc}$ \\
\hline Compression ratio & $8.8: 1$ \\
\hline Power output & $\begin{array}{l}77 \mathrm{hp}(57.4 \mathrm{~kW}) \text { at } 4900 \mathrm{rpm} \text { (continuous); } 80 \mathrm{hp}(59.7 \mathrm{~kW}) \text { at } 5300 \mathrm{rpm}(3 \\
\text { min./take off })\end{array}$ \\
\hline Torque max. & $11 \mathrm{~kg} . \mathrm{m}$ at $4600-5200 \mathrm{rpm}$ \\
\hline Max RPM & $5300 \mathrm{rpm}$ \\
\hline TBO & 500 hours (expected higher TBO with fleet experience) \\
\hline Gearbox & C type with ratio 2.13 \\
\hline Weight & $57.5 \mathrm{~kg}$ \\
\hline
\end{tabular}




\section{Propeller Selection}

According to gearbox ratio of the selected engine, widely used c type blade 4/64 having 1.62 $\mathrm{m}$ diameter has been selected. Detailed analysis has been performed by the employement Javafoil software in which blade numbers, revolution per minutes, diameter, free stream velocity and airfoil type are defined during the analysis.

\begin{tabular}{|c|c|c|c|}
\hline Propeller & & & \\
\hline $\mathrm{V} /(\mathrm{nD})$ & 1.481 & $\mathrm{v}(\mathrm{( \Omega R})$ & 0.472 \\
\hline Efficiency $\eta$ & $76.574 \%$ & loading & low \\
\hline Thrust $\mathrm{T}$ & $640.9 \mathrm{~N}$ & $\mathrm{Ct}$ & 0.0519 \\
\hline Power $\mathrm{P}$ & $77 \mathrm{~kW}$ & $\mathrm{Cp}$ & 0.1003 \\
\hline Torque $\mathrm{Q}$ & $319.7 \mathrm{Nm}$ & $\mathrm{Cs}$ & 2.3464 \\
\hline$\beta$ at $75 \% \mathrm{R}$ & $36.1^{\circ}$ & Pitch $\mathrm{H}$ & $2.79 \mathrm{~m}$ \\
\hline
\end{tabular}
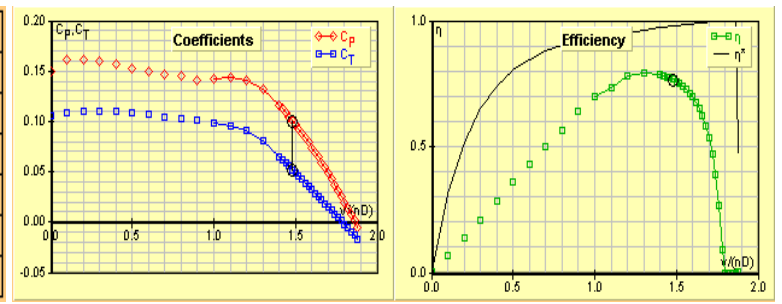

Figure 3.2 Propeller Specifications

\section{Wing and Fuselage Design}

\subsection{Wing Design}

The wing parameters, such as taper ratio, aspect ratio, span, wing vertical location, wingtip, twist, sweep and dihedral angle have vital effect on the aircraft performance.

Taper ratio, $\lambda$, is the ratio between root and tip chord. Typically, most wings of low sweep angle have a taper ratio about 0.4-0.5. Taper ratio affects seriously the lift distribution along the span. Prandtl lifting line theory states lowest induced drag is obtained while lift is distributed elliptically. Production of a wing having elliptical shape is difficult and expensive. Instead of elliptical wing shape, a rectangular wing with a taper ratio of 0.45 is chosen since such a design provides the same lift distribution as that of an elliptic wing [23].

Wing twist is implemented to prevent tip stall as well as approximating the lift distribution to that of an elliptical wing type. "Geometric twist" changes the airfoil incidence angle. When the wing tip airfoil has a lower incidence angle compared to the root airfoil is called as "wash out". However, improvement of lift distribution by twisting will be only effective at a single lift coefficient. In short, the more is the twist so as to obtain elliptical lift distribution, the worse is the effectiveness of wing at different angles of attacks [23]. 
Wing dihedral is the wing angle with respect to the horizontal axis when the aircraft is seen from the front, which is directly related with the stability and roll characteristics. Roughly speaking, the higher is the dihedral angle, the better is the stability with subsequent reduction in maneuverability [25].

Tail is a small lifting and control surface located at behind of the main lifting surfaces. $\mathrm{T}$ tail configuration provides compatible and satisfactory results in UAV applications due to inducing good pitch control, uniform flow around the tail and above average glide ratio due to the fact that the horizontal tail is not affected by flow coming from the wing. Yet, greater amount of bending moment at the root section of vertical tail needs a stronger structural desing.

\subsection{Fuselage Design}

The fuselage is an aircraft's main body which carries the crew and the passengers or payload. For certain types of aircraft, fuselage dimensions are in a strict design rules interval. For instance, for a passenger aircraft, most of the fuselage length is dedicated for the passenger compartment.

The fuselage length can be found by using the formula [23];

$l_{f}=a \cdot W_{0}^{c}$

Where a and $\mathrm{c}$ are coefficients depending upon aircraft type and $\mathrm{W}_{0}$, the takeoff gross weight in lbs.

In addition, during the fuselage design, elliptical shape has been chosen according to considerations detailed in chapter 2 .

\subsection{Winglet Geometry Selection}

Winglets are vertical extentions of wingtips used for improving the fuel efficiency, lift to drag ratio and cruise range by reducing the induced drag. Reduction in induced drag is achieved by diminishing the strengths of wingtip vortices and secondary flow, besides has a great impact on increasing the effective aspect ratio. In addition, winglet devices also improve handling characteristics, safety, climbing performance and ceiling height [30]. Moreover, small amount of thrust is obtained with the aid of flow impingement. Sharp winglet shapes intensify the adverse pressure gradient formation, leading flow separation 
risk and rise in drag. The given situation can be partially eliminated with blended type winglets.

\section{Fuel Space Calculation}

Initially, trapped fuel should be calculated by using the following equation [23];

$\frac{W_{f}}{W_{0}}=1.06\left(1-\frac{W_{x}}{W_{0}}\right)$

Then, fuel volume has been found by;

$V_{f}=\frac{W_{f}}{\rho_{f}}$

\section{Landing Gear Locating and Sizing}

Landing gear is a supporting structure while the aircraft is not flying; employed during landing, take off or taxiing stage.

Tricycle landing gear configuration has one wheel at the front, two or more main wheels located in the behind of landing gear. Due to the ease of operation, the configuration is widely used and is also selected for our aircraft. Tipback angle should be at least $15^{\circ}$ to prevent the aircraft tail from tipping back. In order to locate and size correctly the landing gears, taildown and tipback angles must be found as follows [23];

$$
\begin{aligned}
& \tan \theta_{\text {static taildown }}=\frac{\mathrm{H}_{2}}{x_{\text {main landing gear }}} \\
& \tan \theta_{\text {tipback }}=\frac{x_{\text {cg aircraft }}-x_{\text {main landing gear }}}{H_{1}} \\
& x_{n}=x_{c g \text { wing }}-x_{\text {nose gear location }} \\
& x_{m}=x_{\text {main landing gear }}-x_{c \text { g aircraft }}
\end{aligned}
$$




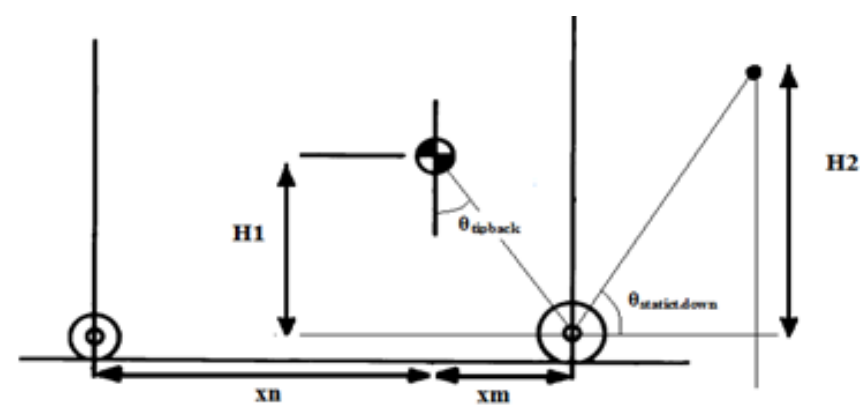

Figure 3.3 Location of Landing Gears

For nose landing gear sizing, the following equation is used;

$F_{n}\left(x_{n}+x_{m}\right)=W_{0}\left(x_{c g \text { wing }}-x_{\text {cg aircraft }}-x_{m}\right)$

For main landing gear sizing, the following equation is used;

$2 F_{m}\left(x_{n}+x_{m}\right)=W_{0}\left(x_{\text {cg aircraft }}-x_{\text {nose gear location }}\right)$

Wheel diameter and width of the nose landing gear;

$D_{\text {nose }}=A\left(W_{n}\right)^{B}$

Wheel diameter and width of the main landing gear;

$D_{\text {main }}=A\left(W_{m}\right)^{B}$

Where A and B coefficients are selected according to the general aviation assumption.

Electrically controlled retractable type landing gear is selected owing to ease of operation and cost. Due to given considerations, product of aerotelemetry for UAV's is chosen. Retracting the landing gear in a similar size UAV reduces drag coefficient up to \%17 [3]. 


\section{Aerodynamic Analysis}

The aerodynamic specifications of the aircraft are represented in this section. Step by step calculations are in the appendix section.

\subsection{Outer Geometry Calculations}

Table 3.3 Aircraft Geometrical Specifications

\begin{tabular}{|c|c|c|c|}
\hline Taper Ratio & 0.45 & Fuselage Width(m) & 0.6 \\
\hline Wing Span (m) & 10 & Fuselage Length(m) & 5.3 \\
\hline Aspect Ratio & 12 & Wing Loading (lb/ft' $\left.{ }^{2}\right)$ & 11.97 \\
\hline Sweep Angle ( $\left.{ }^{\circ}\right)$ & 0 & $S_{\text {wing with } 10^{\circ} \text { flap }}\left(\mathrm{ft}^{2}\right)$ & 4.24 \\
\hline $\begin{array}{l}\text { Vertical Tail Root } \\
\text { Chord (m) }\end{array}$ & 0.74 & $S_{\text {wet }}\left(\mathrm{ft}^{2}\right)$ & 187.51 \\
\hline $\begin{array}{l}\text { Vertical Tail Tip } \\
\text { Chord (m) }\end{array}$ & 0.59 & $S_{\text {exp.wing }}\left(\mathrm{ft}^{2}\right)$ & 34.027 \\
\hline $\begin{array}{c}\text { Vertical Tail Span } \\
(\mathbf{m})\end{array}$ & 0.9 & $S_{\text {exp.V.T }}\left(\mathbf{f t}^{2}\right)$ & 7.17 \\
\hline $\begin{array}{l}\text { Horizontal Tail } \\
\text { Root Chord (m) }\end{array}$ & 0.45 & $S_{\text {exp.H.T }}\left(\mathrm{ft}^{2}\right)$ & 3.53 \\
\hline $\begin{array}{l}\text { Vertical Tail Tip } \\
\text { Chord (m) }\end{array}$ & 0.225 & $\begin{array}{c}\text { Horizontal Tail Sweep } \\
\left({ }^{\circ}\right)\end{array}$ & 5 \\
\hline Wing Dihedral $\left({ }^{\circ}\right)$ & 9 & Vertical Tail Sweep $\left(^{\circ}\right)$ & 20 \\
\hline
\end{tabular}




\subsection{Lift Curve Slope Values and Aerodynamic Parameters}

Table 3.4 Aircraft Aerodynamic Specification Values

\begin{tabular}{|c|c|c|c|c|c|}
\hline$C_{L \alpha \text { wing }}\left(\operatorname{deg}^{-1}\right)$ & 0.11 & $\mathrm{C}_{\mathrm{lmax} \text { plain }}$ & 1.552 & $C_{\text {D 0 miscellaneous }}$ & 0.091 \\
\hline$C_{L \alpha H . T}\left(\operatorname{deg}^{-1}\right)$ & 0.38 & $C_{l \text { max } 10^{0} \text { flap }}$ & 1.63 & $\mathrm{C}_{\mathrm{DO}}$ & 0.104 \\
\hline Downwash $\left(\frac{\partial \varepsilon}{\partial \alpha}\right)$ & 0.175 & $\mathrm{C}_{\text {D0 L.G }}$ & 0.042 & $C_{\text {D cruise }}$ & 0.0254 \\
\hline $\mathbf{M}_{\text {cruise }}$ & 0.1323 & $C_{\text {Do flap }}$ & 0.043 & $\mathrm{C}_{\mathrm{L} \text { cruise }}$ & 0.62 \\
\hline$C_{\text {l design }}$ & 0.72 & $C_{\text {Do c }}$ & 0.0128 & $\mathbf{V}_{\text {Stall }}(\mathrm{m} / \mathbf{s})$ & 28.1 \\
\hline$V_{\max }(\mathrm{m} / \mathrm{s})$ & 79.24 & $V_{\text {cruise }}(\mathrm{m} / \mathrm{s})$ & 79.24 & $\left(\mathrm{C}_{\mathrm{L}} / \mathrm{C}_{\mathrm{D})_{\text {max }}}\right.$ & 24.4 \\
\hline$\left(C_{L} / C_{D}\right)_{\text {cruise }}$ & 22 & & & & \\
\hline
\end{tabular}

\section{Performance}

In the section, performance parameters such as stall velocity, climb rate, maximum velocity, turn rate, turn radius and load factor are calculated.

\subsection{Power Available vs Power Required, Climb Rate and Climbing Time}

In order to find the power available, one should equate the drag to thrust. After that, thrust should be converted into power using the following equation.

$T=\frac{\eta P}{V}$

Rate of climb is defined as the aircraft's vertical speed or change in altitude. Area below the curve $(\mathrm{R} / \mathrm{C})^{-1}$ versus altitude gives the time to climb.

\subsection{Load factor}

The load factor is described as the lift to weight ratio and signifies the stress to which the aircraft body is subjected to. The ratio increases while the lift coefficient rises. According to UAV certification standarts, positive and negative load factors should be greater than 2 and 
0.5 respectively [26]. Therefore, by selecting $n_{\text {positive }}, n_{\text {negative }}$ as 2.5 and -1 respectively, compromise between safety and cost is achieved. $n_{\text {positive ultimate }}$ and $n_{\text {negative ultimate }}$ values are one and a half times of the standart $n$ values for both positive and negative loading cases.

Then, the aircraft corner speed is calculated [4];

$V^{*}=\sqrt{\frac{2 n_{\max } W}{\rho C_{L \max } S}}$

The loading factor versus airspeed is given below;

\subsection{Performance Results}

Results are tabulated below.

Table 3.5 Aircraft Performance Values

\begin{tabular}{|c|c|c|c|c|c|}
\hline $\mathrm{V}_{\text {corner at }} \mathrm{n}_{\text {positive }}\left(\frac{\mathrm{ft}}{\mathrm{s}}\right)$ & 205.79 & $\begin{array}{l}\text { n at } R_{\min } \text { at } \\
\text { h=0ft }\end{array}$ & 0.3523 & \begin{tabular}{|l} 
\\
$\omega_{\text {max }}$ at \\
$h=10000 f t$ \\
$(f t / s)$
\end{tabular} & 178.45 \\
\hline 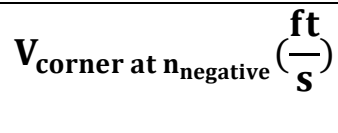 & 221.7 & $\begin{array}{l}\mathrm{n} \text { at } R_{\min } \text { at } \\
\mathrm{h}=10000 \mathrm{ft}\end{array}$ & 0.3523 & $\begin{array}{l}n \\
\omega_{\text {max }} \text { at } \\
h=0 \mathrm{ft}\end{array}$ & 0.25 \\
\hline $\begin{array}{l}\begin{array}{l}\text { Time } \\
\text { (sec) }\end{array} \\
\text { to Climb }\end{array}$ & 3900 & $\begin{array}{l}R_{\min } \\
h=0 \mathrm{ft}\end{array}$ & 1120 & $\begin{array}{l}n \\
\omega_{\max } \text { at } \\
h=10000 \mathrm{ft}\end{array}$ & 0.236 \\
\hline $\begin{array}{l}\mathrm{V} \text { at } R_{\min } \text { at } \mathrm{h}=\mathbf{0 f t} \\
(\mathrm{ft} / \mathrm{s})\end{array}$ & 190.24 & $\begin{array}{l}R_{\min } \text { at } \\
h=10000 f t\end{array}$ & 1611 & $\begin{array}{l}\omega_{\text {max }} \text { at } \\
h=0 f t \\
(\mathrm{rad} / \mathrm{s})\end{array}$ & 0.15 \\
\hline $\begin{array}{l}\text { V at } R_{\min } \text { at } \\
\mathrm{h}=10000 \mathrm{ft}(\mathrm{ft} / \mathrm{s})\end{array}$ & 228.10 & $\begin{array}{l}V \\
\omega_{\max } \text { at } \\
h=0 \mathrm{ft}(\mathrm{ft} / \mathrm{s})\end{array}$ & 148.84 & $\begin{array}{l}\omega_{\max } \text { at } \\
\mathrm{h}=10000 \mathrm{ft} \\
(\mathrm{rad} / \mathrm{s})\end{array}$ & 0.088 \\
\hline
\end{tabular}

\section{Mission Profile}

Mission profile analysis has been performed so as to find the takeoff gross weight, amount of fuel burned and the optimum cruise speed selection. Mission profile is given at fig.3.4. 
Finally, better weight estimation process has been employed. Simplified results are given below.

\subsection{Takeoff Phase}

$\frac{W_{1}}{W_{0}}=0.97$

$W_{\text {fuel burned } 0-1}=26.04 \mathrm{lbs}$

\subsection{Climb Phase}

$\frac{W_{2}}{W_{1}}=0.985$

$W_{\text {fuel burned } 1-2}=12.63 \mathrm{lbs}$

\subsection{Cruise Phase}

$$
\begin{aligned}
& C_{\text {bhp cruise }}=0.0001111 \mathrm{l} / \mathrm{sec} \\
& \frac{W_{3}}{W_{2}}=\exp \left[\frac{-R C_{b h p}}{550 \eta_{p}\left(\frac{L}{D}\right)_{\max }}\right]=0.996 \\
& W_{\text {fuel burned } 2-3}=2.81 \mathrm{lbs} \\
& \frac{W_{5}}{W_{4}}=\exp \left[\frac{-R C_{b h p}}{550 \eta_{p}\left(\frac{L}{D}\right)_{\max }}\right]=0.996 \\
& W_{\text {fuel burned } 4-5}=2.56 \mathrm{lbs}
\end{aligned}
$$




\subsection{Loiter Phase}

$C_{\text {bhp loiter }}=C_{\text {bhp cruise }} \times 1.25=0.000139 \mathrm{l} / \mathrm{sec}$

$(L / D)=(L / D)_{\max } \cdot 0.866$

$\frac{W_{4}}{W_{3}}=\exp \left[\frac{-E V C_{b h p}}{550 \eta_{p}\left(\frac{L}{D}\right)}\right]=0.910$

$W_{\text {fuel burned } 3-4}=66.93 \mathrm{lbs}$

\subsection{Descent Phase}

$\frac{W_{6}}{W_{5}}=0.995$

$W_{\text {fuel burned } 5-6}=3.747 \mathrm{lbs}$

\subsection{Landing Phase}

$\frac{W_{7}}{W_{6}}=0.997$

$W_{\text {fuel burned } 6-7}=2.238 \mathrm{lbs}$

In short;

$\frac{W_{f}}{W_{0}}=0.144$

$W_{\text {TOGW }}=715.15 \mathrm{lbs}$

$W_{\text {fuel burned }}=117.01 \mathrm{lbs}$

In addition, cruise speed improvement for conceptual design has been performed and given in fig.3.4. Cruise speed improvement is performed with respect to attainable maximum 
cruise speed without a significant rise in the weight. High cruise speed indicates the condition of being far from the stall point. According to the considerations detailed, a cruise speed of $150 \mathrm{ft} / \mathrm{s}$ is chosen. Improvement for payload has not been performed since the payload amount is fixed and can not be altered for the given UAV.

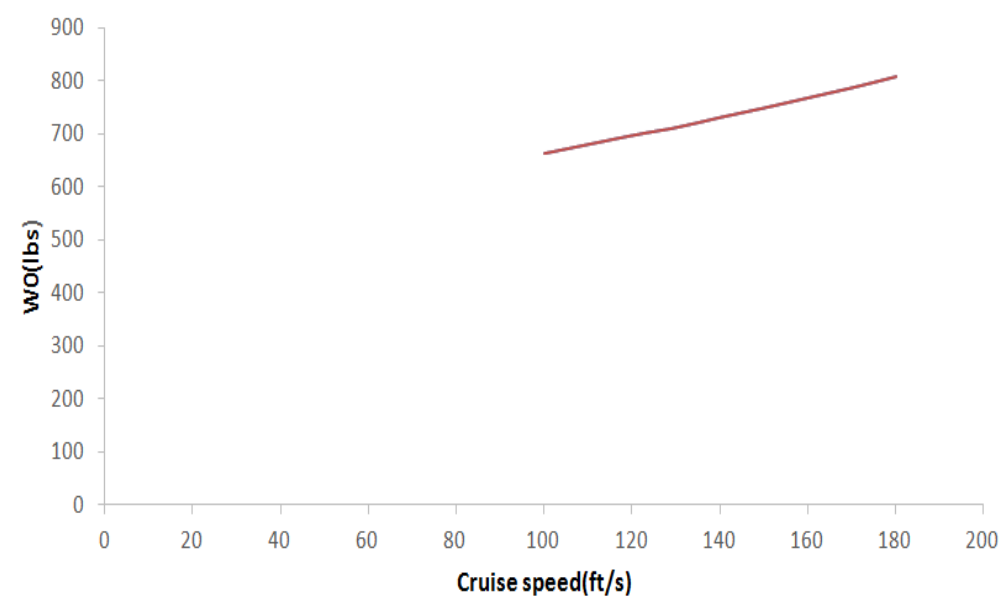

Figure 3.4 Cruise Speed Improvement Process 


\section{CHAPTER 4}

\section{COMPUTATIONAL APPROACH, RESULTS AND IMPROVEMENT}

In this chapter of the thesis, CFD analysis of designed aircraft, as well as outer body geometry improvements in order to obtain better aerodynamic characterisctics will be explained in details.

\section{Computational Techniques Using CAD and CFD Analysis}

In the recent years, the computational approach has been widely used in order to design, analyze and optimize the desired products. The computer aided tools contribute in waste time reduction, product optimization, facilitation in modeling and reduction in cost. However, people having strong background in both computational tools and technical knowlege are required so as to gather proper and accurate results.

In the first step, the geometric model has been designed in CATIA V5 in details, saved in stp format so as to import it into ANSYS geometry design modeler. However, one should pay attention not to create unrequired sharp corners, overlapping of lines in order not to have error message during meshing process. Sometimes, precautions even such as virtual topology or pinch control may not be enough.

In the second step, the sharp angles, slivers, spikes, faces have been repaired for accurate meshing and computational results. Then, the control volume should be sized by considering the flow not to reach the enclosure boundaries. In short, assuming that the aircraft is located in the center by considering vertical direction, control volume size should be at least 10 times greater than the aircraft length in all directions. Explicitly, the greater is the control volume size, the more confidential is the result. Eventhough there is not strict rule in computation domain sizing; flow velocity, body geometry, viscosity, turbulence model and mesh type plays a significant role. However, an optimum point should be attanined during computation with inferior computers. Also the control domain size in vertical plane has been halfed to reduce computation time. For instance, the flow around train simulation does not 
require huge domain in the backward due to body being streamlined [7]; notwithstanding, large domain is required in left and right side due to including side wind effects. Another example can be given for flow analysis around tractor body. In the given study, width and height of the flow domain is chosen as big enough since the shape of the tractor is like a bluff body and the flow velocity is very high for such a shape [6]. As in meshing process, fine meshing combined with inflation layers have been employed so as to obtain $y^{+}$values at an acceptable interval and capture the near wall flow. In addition, orthogonal quality and skewness were seriously observed in each meshing process and re-meshing were performed for meshing process having poor quality meshes. Sample generated mesh for the study is given in figure 4.2 .

In the third step, Fluent software has been implemented in order to get results for different configurations and angle of attack values. 3-D Navier Stokes coupled with turbulence model has been employed during the processes. Inlet boundary condition has been defined as velocity inlet in which the inlet velocity is defined. Outlet boundary condition has been defined as pressure outlet in which the outlet pressure is defined as zero gage pressure. Iterations have been continued until desired residuals have been reached. Sides of the control volume have been defined as symmetry boundary condition. Afterward postprocessing the results, slight geometrical modifications to the main wing geometry has been employed to get desired performance values.

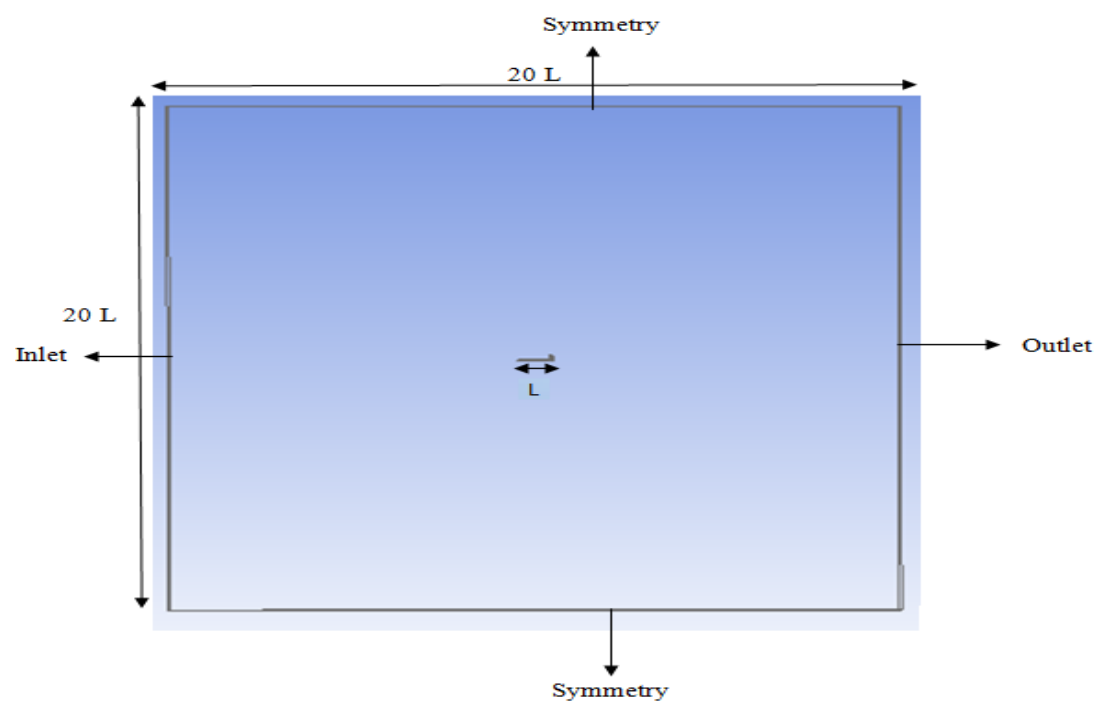

Figure 4.1 Control Volume Size With Respect to Aircraft Dimensions 


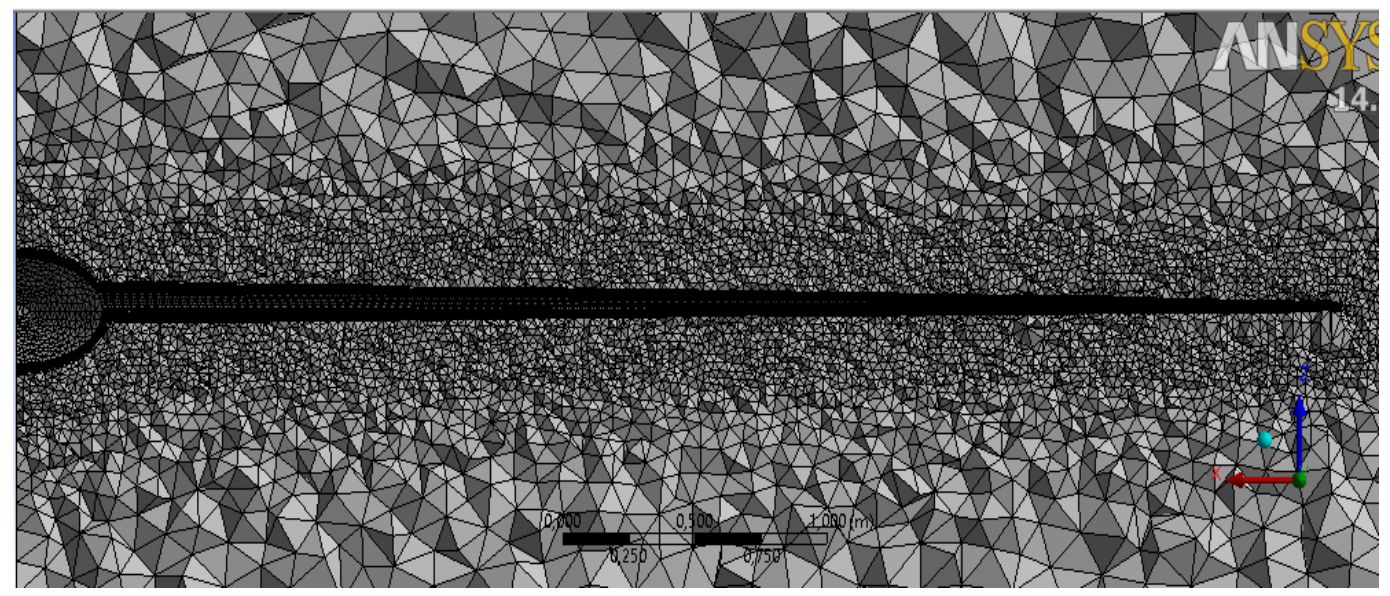

Figure 4.2 Aircraft Surfaces Afterwards Meshing

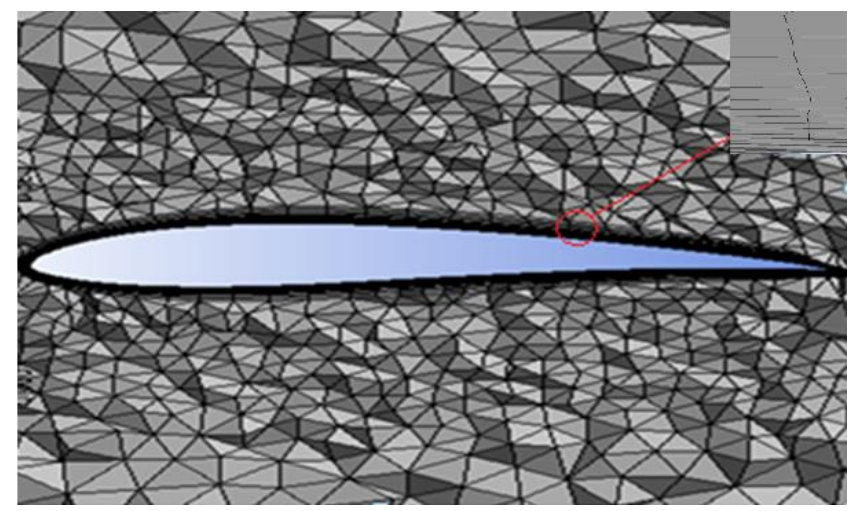

Figure 4.3 Aircraft Wing Afterwards Meshing and Detail View of Inflation Layers

\section{Numerical Methods for External Aerodynamic Analysis of the Aircraft}

CFD analysis is a well estabished technique for a wide range of applications, such as external flow, flow combined with heat transfer, fluid structural interaction, internal flow problems and etc. Especially CFD analysis plays a significant role in demonstrating the performance and improvement of a new aircraft design. The major advantage of a CFD process is the ability to inexpensively generate a desired amount of simulations inducing to understand the performance of the designed geometry. However, deep knowledge about the CFD tool, methods and post processing is required to gather correct results. Otherwise, gathered results might be evaluated as true although they are semi or fully incorrect.

Actual flows encountered in daily life are usually turbulent, such as exit flow from an air conditioning device or flow around an automobile [22]. Turbulent flow is a flow type characterized by chaotic characteristic changes including high momentum convection, low 
momentum diffusion and fast altering in both pressure and velocity. As a result, unsteady vortices are generated and they might interact with each other; hence, rise in drag is inevitable. Intermediate stage between laminar and turbulent flow is called as laminar to turbulent transition. In laminar flow, kinetic energy of the fluid is such low that chaotic changes encountered in turbulent flow are not available. The way to differ flow types of laminar and turbulent is performed by the Reynolds number where $U$ is the flow velocity, $\bar{c}$ is the mean chord length and $v$ is kinematic viscosity. Re number is usually referred as the ratio of inertial to viscous forces. The expression is given in equation 4.1.

$R e=\frac{U \times \bar{c}}{v}$

Turbulence model is a computational way to approximate the mean flow equations. Most of the engineering applications do not need to deal with the details of turbulent fluctuations. Turbulent model theories are based on Boussinesq theorem stating that reynolds stresses are directly related with the mean deformation rate [22].

CFD simulation is an useful tool in order to simulate the desired model or case without need of costly experimentations. However, a compromise between solution accuracy and computation time should be estabished. Solution accuracy increases with models having higher number of equations; however, the benefit comes with deterioration in CPU time. Hence, the essential point must be to select appropriate equation type by considering the application, accuracy and computation effort.

The accuracy of CFD predictions for turbulent flow, in particular 3D simulations, is highly dependent on the quality of the turbulence modeling whose flow characteristics include 3D boundary layers with strong streamline curvature, separation and strong vortices. Three turbulence models are recommended for transport simulations; Realizable k- $\mathcal{E}$ turbulence model, LES and RSM. However, by considering computation effort and satisfactory solution accuracy, k-E model coupled with standart wall functions has been employed during the CFD analyses.

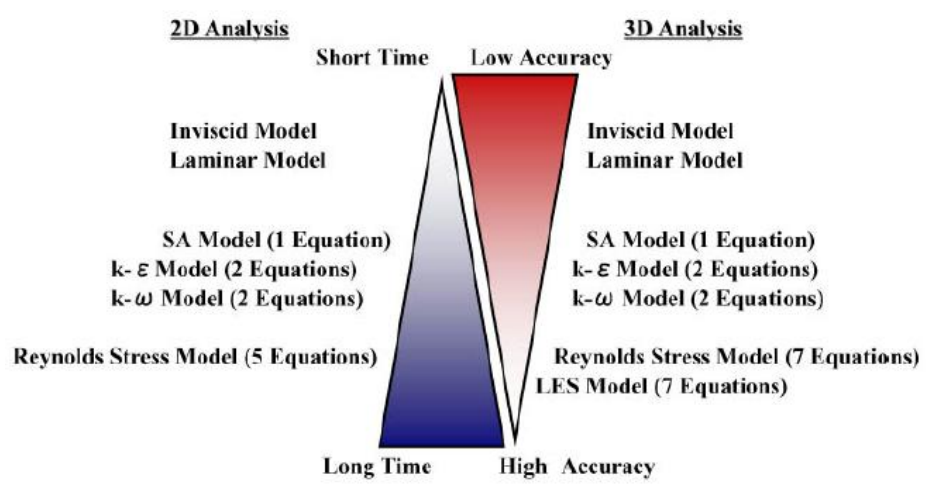

Figure 4.4 Relationship Between CPU Time and Accuracy (Taken from Ref.[12] Fig.3.14) 


\section{Mesh Independency Test and Boundary Conditions}

Mesh independency test is the comparison of results gathered by using different mesh configurations. Mesh independency, also known as grid convergence, have been investigated by comparing results from all level of meshes. Whether the grid independence is reached, the solutions from the two finest meshes should be identical and a finer mesh configuration would not improve the results. Explicitly; higher is the mesh number, better is the numerical accuracy. However, a compromise between numerical accuracy and computation time should be satisfied. In addition, mesh quality assesment procedure should also be included. In short, mesh independency process is the refinement of meshes until the difference between results are very similar [15]. All of the configurations employed in the thesis includes 20 inflation layers to calculate accurately the near wall flow. The figure below shows different mesh numbers and L/D at zero incidence angle of the baseline geometry results of the aircraft. The test results have guided the author in meshing process for other geometrical configurations and angle of attacks.

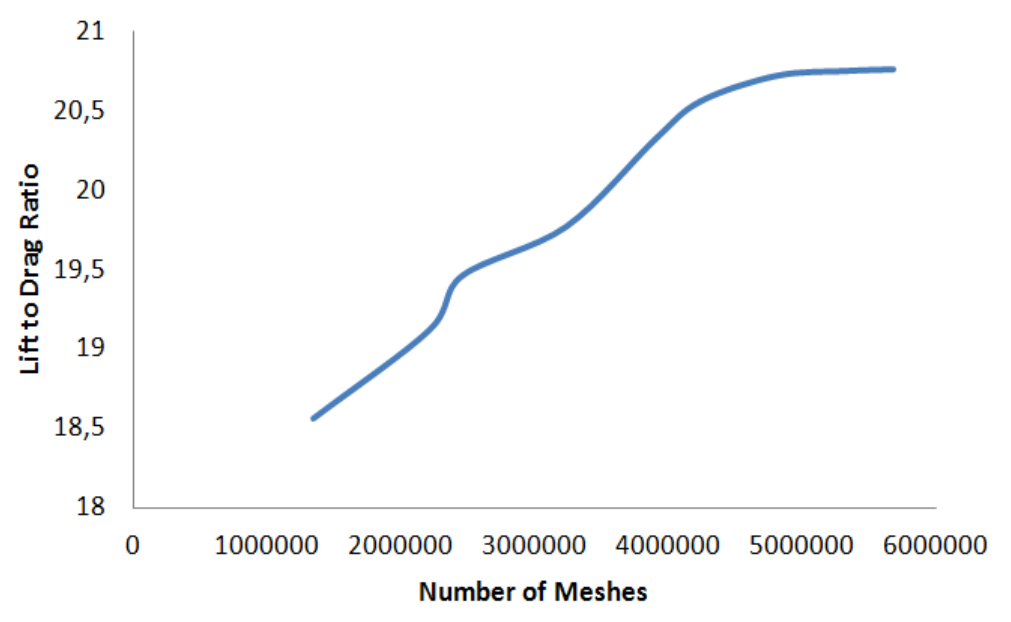

Figure 4.5 Mesh Independence Study Results

Results show that the mesh number beyond 5000000 will be unnecessary. Besides, further increase in mesh quantity will not induce more accurate results after some point [13]. In addition, $y^{+}$values were the greatest concern of mesh quality assesment process. The parameter value of below unity is desired; however, one must find a compromise between solution accuracy and compuation time. The $y^{+}$value less or close to unity is strongly recommended for applications incorporating fluid flow and heat transfer [5]. On the other hand, an interval of $5<y^{+}<30$ will be satisfactory for the majority of flows including near wall flow [29]. Moreover, one should consider that proper $y^{+}$range is highly dependend on the Re number [5]. In the study, variation of $y^{+}$is in acceptable range according to ref.[29]. In addition, one of the deductions is that optimum mesh number provides better convergence rate and stability. Depicted mesh numbers guide us how to mesh accurately for the remaining aircraft configurations and angle of attacks. 
Mesh quality is described by various parameters, such as orthogonal quality, skewness, aspect ratio, jacobian ratio, warping factor, parallel deviation and maximum corner angle. However, orthogonal quality and skewness are the most essential parameters in quality assesment. Orthogonal quality is computed for cells using the vector from the cell centroid to each of it's faces, the corresponding face area vector and the vector from the cell centroid to the centroids of each of the adjacent cells [18]. The value should be as maximum as possible close to unity to get desired results. Aspect ratio is a measure of the stretching of the cell. It should be avoided from sudden changes in aspect ratio in the flowfield. Skewness is defined as the difference between the shape of the cell and the shape of an equilateral cell of equivalent volume. Highly skewed cells can reduce accuracy and convergence tendency. The value should be as maximum as possible close to zero to get desired results. In short, a CFD user should avoid using meshes having orthogonal quality and skewness values below 0.01 and 0.1 respectively, and such poor quality cells can be improved before the analysis.

So far, mesh quality has been discussed. Next is the boundary conditions. 3-D CFD study using Navier Stokes equations has been performed. Solver is chosen as pressure based, instead of density based due to the fact that cruise speed is in the interval of incompressible region. At the inlet, velocity inlet boundary condition has been chosen. As for the walls of control volume, symmetry condition is the most suitable selection. At the outlet, pressure outlet boundary condition has been chosen. Turbulent intensity, which is the ratio of fluctuating velocity to main velocity, is difficult to calculate. Instead, experimental values of turbulent intensity for desired flow velocities is taken from experimental studies [19]. Hydraulic diameter can be calculated easily from formulas. Related formulas are given below

$I \equiv \frac{u^{\prime}}{U}$

$u^{\prime} \equiv \sqrt{\frac{1}{3}\left(u_{x}^{\prime 2}+u_{y}^{\prime 2}+u_{z}^{\prime 2}\right)}$

$D_{H}=\frac{4 A}{P}$

Details of the boundary conditions for zero angle of attack condition are given in the next table. 


\begin{tabular}{|c|c|c|}
\hline Boundary & Name & Value \\
\hline Velocity Inlet & Velocity & $45 \mathrm{~m} / \mathrm{s}$ \\
\hline & Temperature & $300 \mathrm{~K}$ \\
\hline & Turbulence Intensity & 0.5 \\
\hline & Hydraulic Diameter & $66.66 \mathrm{~m}$ \\
\hline & Gauge Pressure & $0 \mathrm{~Pa}$ \\
\hline Pressure Outlet & Temperature & $300 \mathrm{~K}$ \\
\hline & Turbulence Intensity & $\% 0.5$ \\
\hline & Hydraulic Diameter & $66.66 \mathrm{~m}$ \\
\hline & & \\
\hline
\end{tabular}

Convergence is another important issue to assess results of an analysis to be satisfactory or not. Computation tools run successive iterations until the residuals of the variables fall below a desired value. However, this does not signify that the results of the analysis has converged, more iteration might be needed. In the study, the convergence criteria are assumed as $10^{-3}$ for the continuity and $10^{-7}$ for the momentum equations. Authorities state that convergence criteria of $10^{-6}$ for velocity components are enough [17]. These depicted criterion require at least 400 iterations in this study. On the other hand, one can deduce that higher is the mesh number and quality, better is the convergence rate. In addition, second order discretization sheme selection is a must for such a study due to the fact that flow is not straight in some regions.

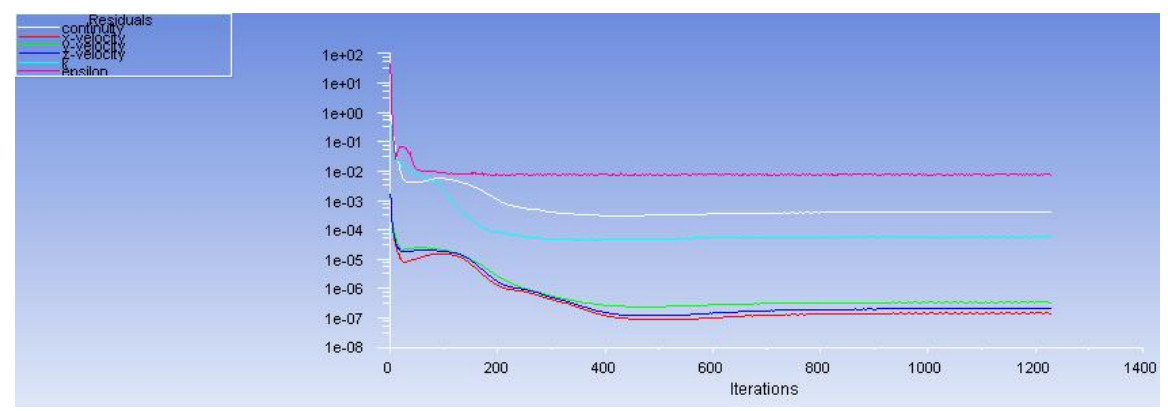

Figure 4.6 Residuals versus Number of Iterations

Furthermore, the employement Navier Stokes Equations with a turbulence model is a must in such an analysis which possesses some separation locations in the flowfield. As known from undergraduate courses, friction drag contribution can not be neglected in drag prediction calculations. 


\section{Aerodynamic Design and Improvement}

Aerodynamics is a branch of dynamics dealing with air motion, especially while air interacts with a solid body. Understanding air motion around a solid body enables scientists to find forces and moments acting on the body.

The definition of aerodynamic shapes of modern aircraft are based essentially on computational simulations and calculations to evaluate many alternative designs. The conventional way to evaluate a new aircraft design is performed by a wind tunnel testing, which confirms both aerodynamic and structural design of an aircraft. However, the entension of aircraft speeds into compressible, even in supersonic and hypersonic range requires the need of cheap and confident testing methods. The use of computational simulation provides engineers to verify alternative designs, but it still suffers the identification of the best possible configuration. Explictly, CFD will never exactly replace wind tunnel testing, but gives a much more cheaper alternative and supports the experimental datas. Application of CFD has following profits [2].

- Increase in design span. Higher number of configurations can be investigated by using CFD tools.

- The guarantee of compatibilty of derived similar vehicles.

- Reproducability, transparency and standartization of the overall design process can be achieved.

- Reduction of design risk.

- Results are not dependent on personal skill, dependent only to theoretical and the effective use of CFD tool.

Aerodynamic computation codes used in aircraft industry can be divided into three main categories. These are empirical and cheap methods, advanced higher order and highest level. Empirical methods are simple, cheap, fast and easy to apply. These are simple linear first order singularity methods, like linear first order panel and vortice lattice methods. Advanced higher order potential flow codes considers vortical separated flow, nonlinear wake interactions and corrections for boundary layer development. Highest level codes includes fully potential flow solutions, euler and navier stokes codes [2]. 


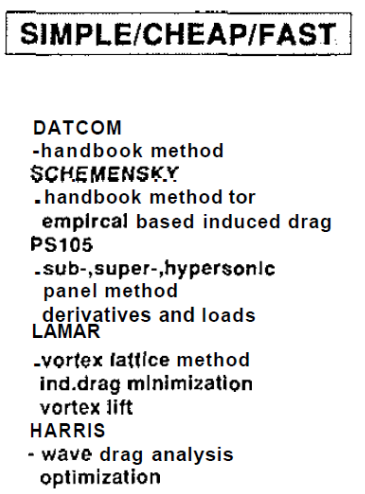

\section{ADVANCED HIGHEST LEVEL}

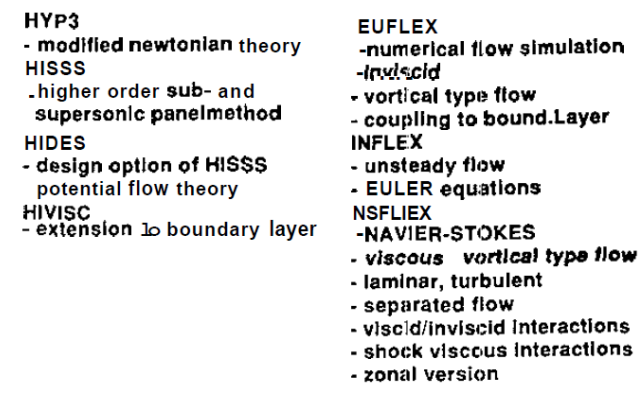

Figure 4.7 Comparison of Various CFD Methods (Taken from Ref.[2] Fig.4)

Optimization is maximizing or minimizing some parameters, values or functions relative to some defined parameters. These allows correlation of the different choices to decide which might adapt better to desired set values. The maxima or minima of the functon represent an important feature of the choices and it's maximum performance under desired case [10]. Nowadays aircraft designs require optimization processes in various aspects so as to surpass it's adverseries.

Shape improvement is the process of reaching an optimal design after performing iterations over parameters. The process introduces the geometry and computational analysis tool iteratively to generate optimum design according to desired constraints [10]. Aerodynamic improvement processes are usually based on altering planform area variables, which are taper ratio, aspect ratio, airfoil type, span, area and sweep [28].

On the other hand, highly sophisticated methods; which are boundary layer ingestion, very high aspect ratio, win box design, open rotor concept for turbofan engines, delaying boundary layer transition, different separation control technologies are also available; however, the costs and the unemployement of these methods in small size aircrafts make them unattractive [1].

The performed improvement process is targeting reduction in power requirements and enhancing endurance by improving the lift to drag ratio. As stated, although aerodynamic improvement is based on altering planform area variables, structural integrity of the aircraft is another great concern. Therefore, by fixing AR and span, the process is based on increasing span efficiency by comparing various types of winglets. Similar studies have proven their cheap and effective approach in UAV design improvement [9]. However, the most efficient way is the multidisciplinary aerodynamic-structural optimization process which employs gradient based genetic algorithms by the world's well known aircraft companies since 1970's [20]. By considering cost and effectiveness, various wingtip devices were tested for cruise conditions in terms of force and moment parameters. Blended airfoil wingtip airfoil has been selected as Psu 90-125, which is widely used in sailplanes. Figures of compared wingtip geometries are given below. 

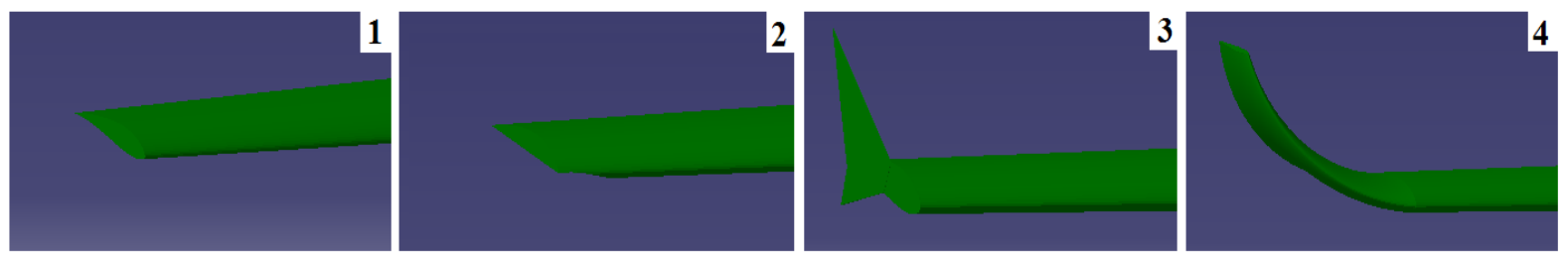

Figure 4.8 Various Wingtip Geometries.(From left to right: 1) Without Wingtip Device, 2) Hoerner Type Wingtip Device, 3) Shifted Downstream Type Wingtip Device and 4) Blended Type Wingtip Device)

\subsection{Forces for Different Wintip Geometries}

As depicted previously, the main aim of the wintip devices is to increase lift to drag for higher endurance and performance of an aircraft. While comparing with the results in ref.[14], one can see the similiarity between results.

While comparing lift coefficient results, blended type winglet has proven it's efficiency. Shifted downstream type provides an above average lift rise. Unfortunately, both hoerner and simple type wingtip devices are not able to increase lift as high as blended and shifted downstream type. Whereas, simple and hoerner type devices can be chosen due to their simplicity.

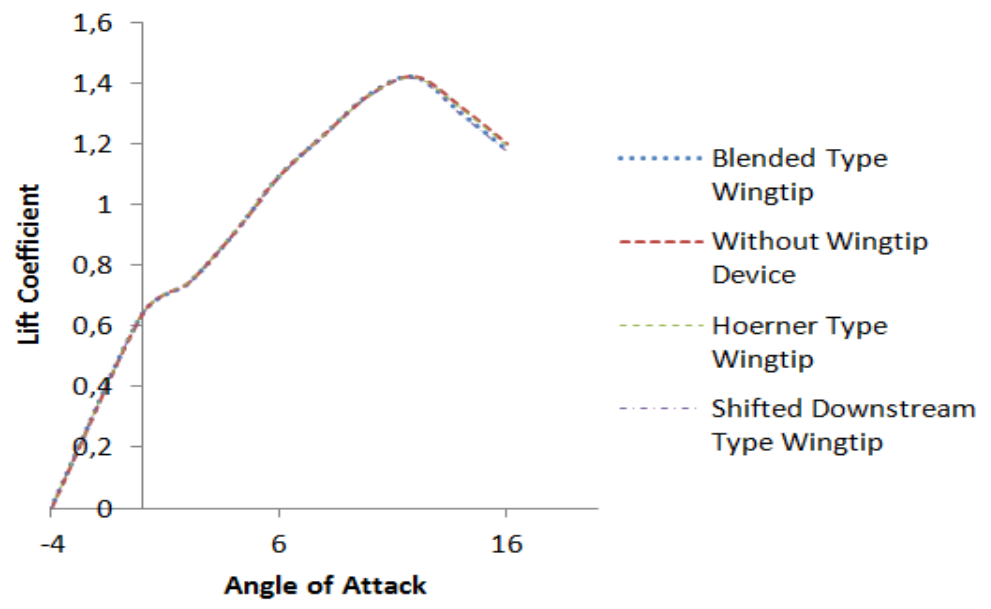

Figure 4.9 Lift Coefficient versus Angle of Attack

Blended type wingtip device offers the lowest drag coefficient due to reduction in induced drag, which is a result of diminish in vorticity around the tip of the wing. In short, significant reduction in drag and rise in lift coefficient has been obtained with the employement of blended type winglet, compared to aircraft having without a wingtip device. 


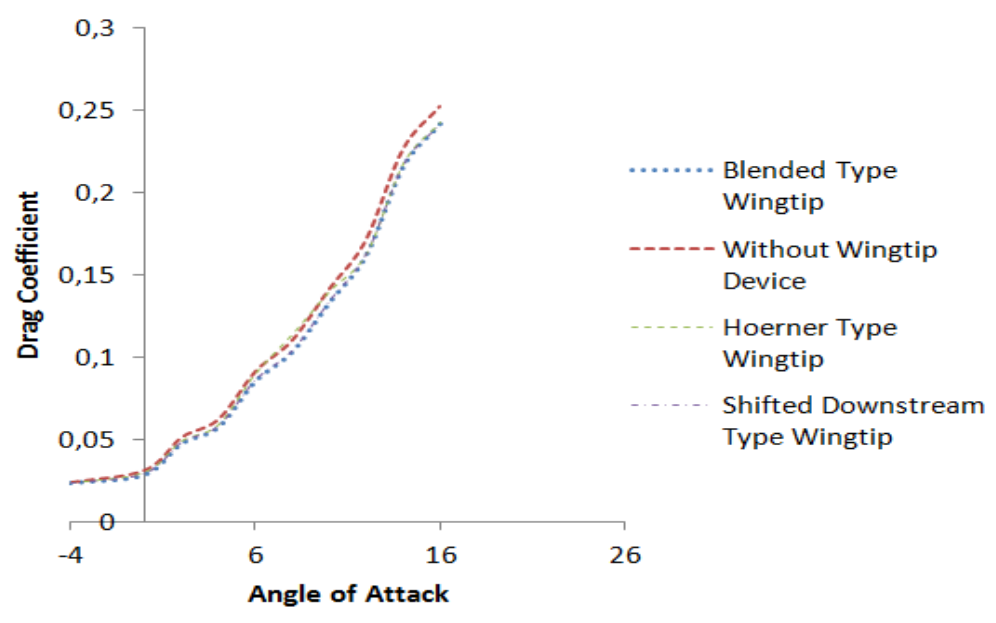

Figure 4.10 Drag Coefficient versus Angle of Attack

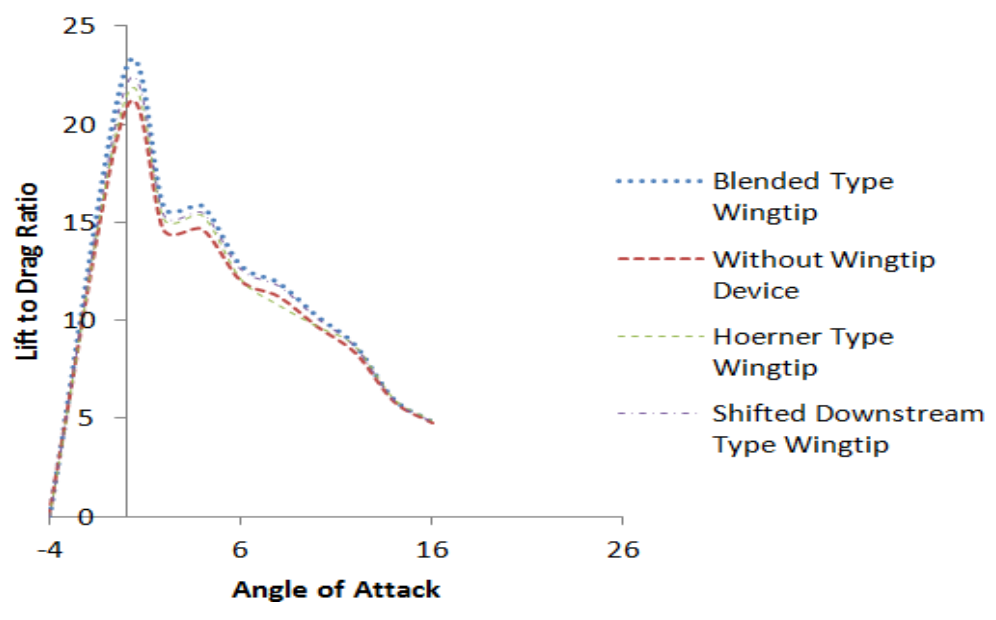

Figure 4.11 Lift to Drag Ratios versus Angle of Attack

\subsection{Moments for Different Wingtip Geometries}

Addition of winglets has several unfavorable effects in moment rise. The first and the most essential effect is the increase in root pithing moment due to rise in span efficiency. The second one is winglet develops additional lift in the same direction as the wing lift [14]. As expected, the pitching moment rises with the angle angle of attack due to increase in amount of lift. Therefore, any design including a wingtip geometry should be performed with additional pitching moment consideration. Neverthless, the study guide us to compare bending moments for different wingtip geometries. In short, $\% 5$ rise in the moment is observed for the blended winglet configuration, compared to without wingtip device type. Details are given in the figures below. 


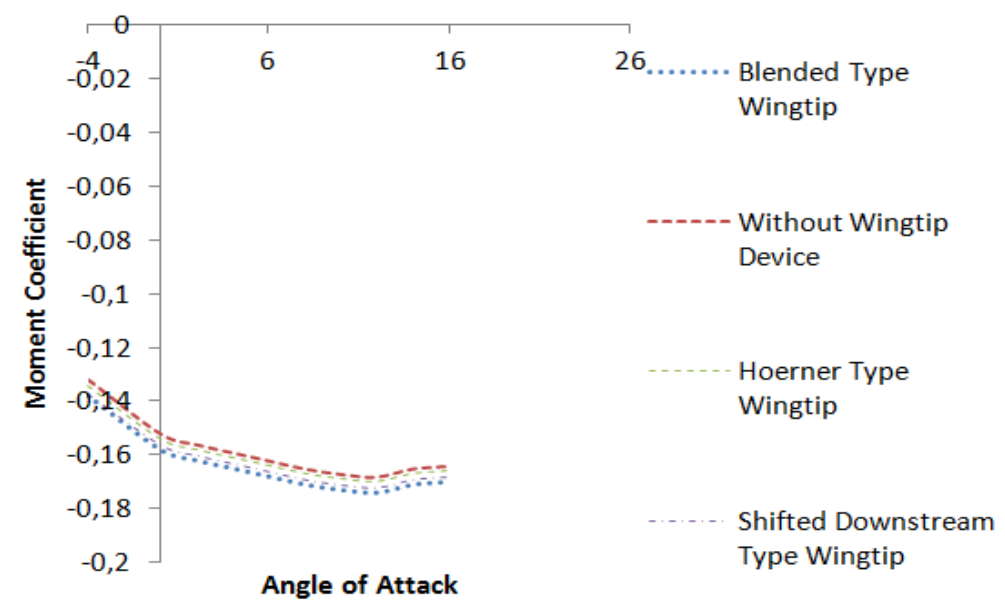

Figure 4.12 Pitching Moment Comparison for Different Wingtip Geometries

\section{Selection of the Optimum Wingtip Geometry}

In agreement with gathered results, the best choice for aerodynamic efficiency is the blended type wingtip geometry. Configurations including shifted downstream and blended wingtip devices provide lower amount of pressure at the locations closer to the mid chord of the suction side. On the other hand, suction side pressure differences between hoerner type wingtip device and baseline geometry are implicit. Explicitly, higher is the pressure difference between suction and pressure side of the wing, better lift to drag rations are gathered. The efficiency of wingtip devices are proven by both wing pressure contours and pressure coefficient in chordwise direction figures. Although the wing pressure contours includes the entire span, pressure coefficient plots were taken $0.1 \mathrm{~m}$ far away from the tip of the wing. In short, greater pressure between suction and pressure side of the wing are gathered by the emploment of wingtip devices. In addition, the improvement in lift to drag ratio has lead slight reduction in the takeoff gross weight and burned fuel amount. Besides, slight improvements in rate of climb, time to climb, power required and load factor are also observed.

Table 4.2 Final Results of the UAV

\begin{tabular}{|c|c|c|c|}
\hline & $\begin{array}{c}\text { Conceptual } \\
\text { Design Results }\end{array}$ & $\begin{array}{c}\text { Baseline Design } \\
\text { Results }\end{array}$ & $\begin{array}{c}\text { Improved Design } \\
\text { Results }\end{array}$ \\
\hline Fuel Burned (lbs) & 117,01 & 129 & 121,64 \\
\hline $\begin{array}{c}\text { Take-off Gross Weight } \\
\text { (lbs) }\end{array}$ & 715,15 & 770,62 & 735,60 \\
\hline
\end{tabular}

In the following figures, one can observe the change in power with respect to air speed. Due to the fact that the aircraft is driven by a propeller engine power train, power available is 
constant; however, power required is directly related with the air speed. Reduction in power required in improved design is a result of diminish in drag coefficient. Besides, slight improvement in rate of climb is a result of reduction in drag coefficient. However, wingtip devices are not able to generate significant differences in load factors since the lift coefficients for baseline and improved geometries are very close.

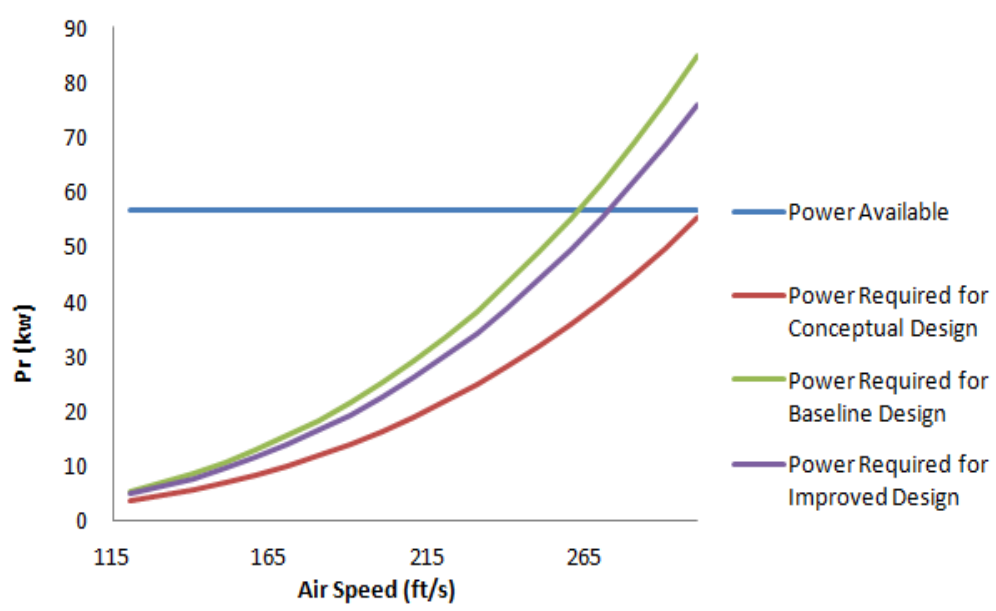

Figure 4.13 Pr versus Airspeed

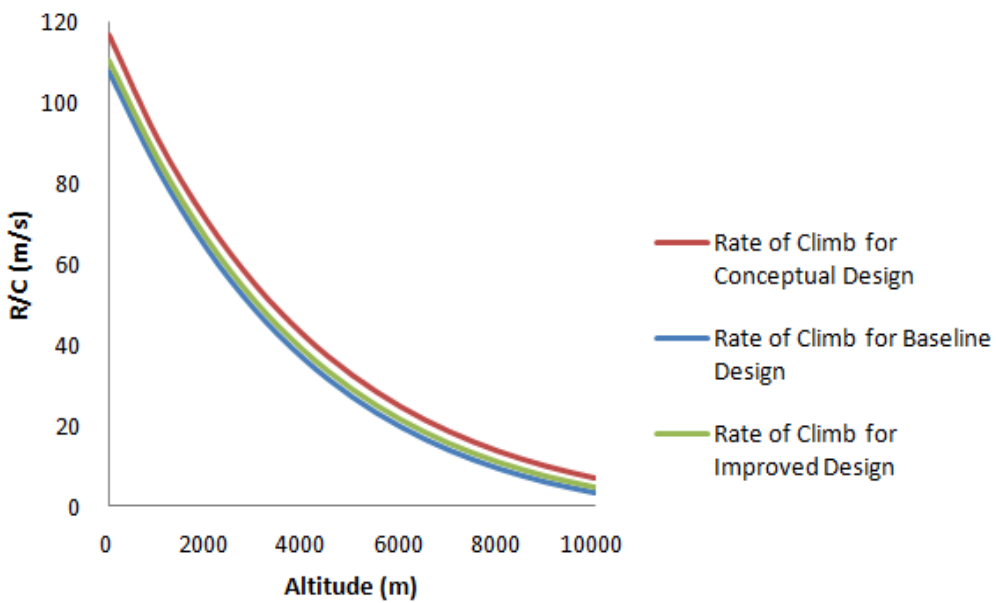

Figure 4.14 R/C versus Altitude 


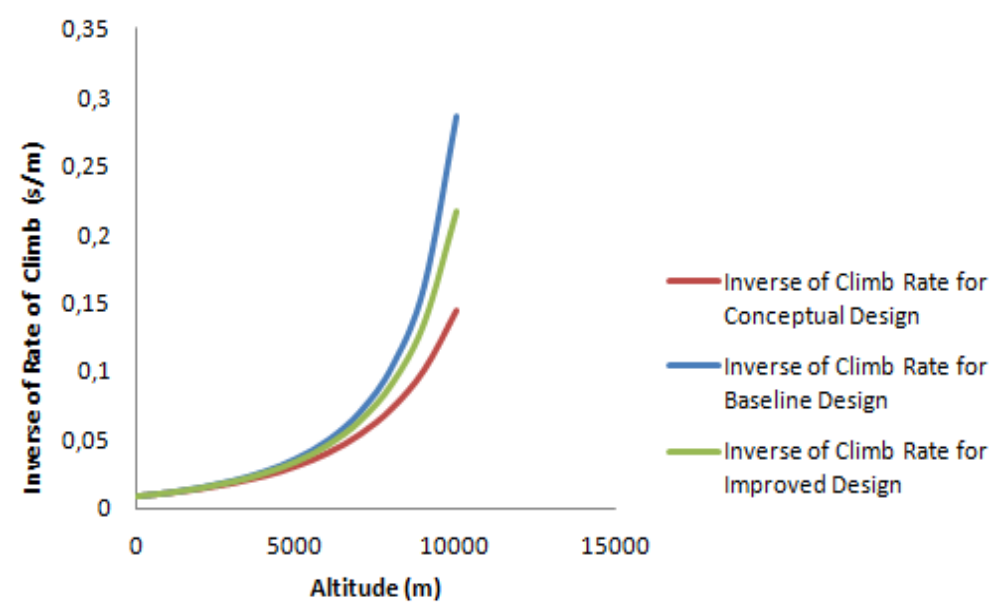

Figure $4.15(R / C)^{-1}$ versus Altitude

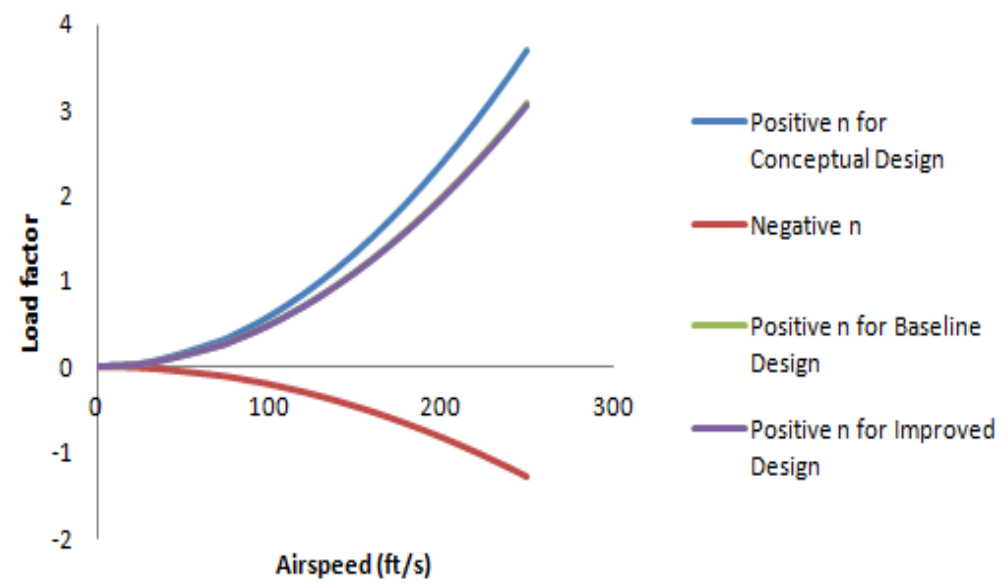

Figure 4.16 Load Factor versus Airspeed 


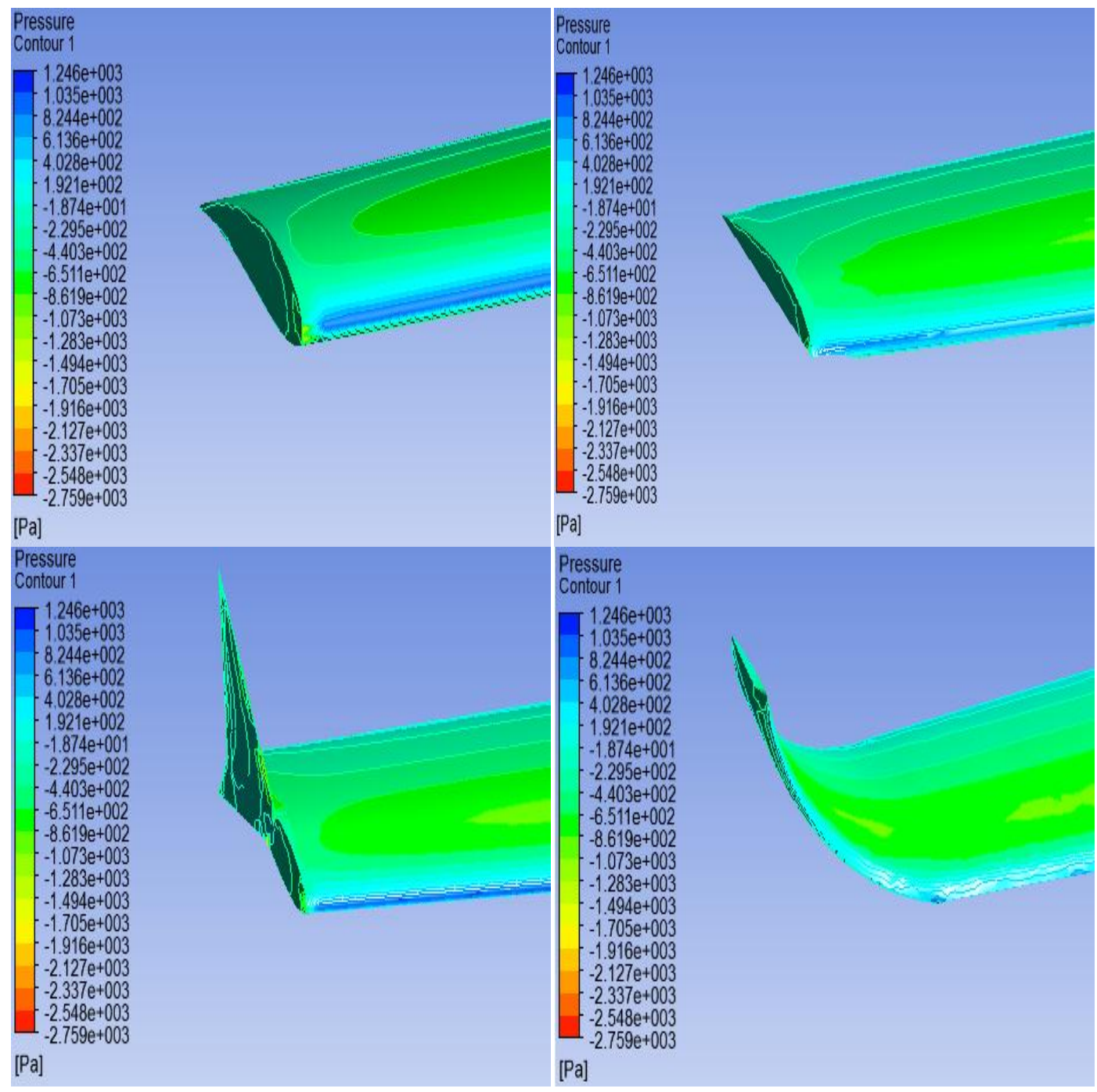

Figure 4.17 Comparison of Wing Pressure Contours for Different Wingtip Geometries at $-4^{\circ}$ Incidence Angle. (From left to right: Without Wingtip Device, Hoerner Type Wingtip Device, Shifted Downstream Type Wingtip Device, and Blended Type Wingtip Device) 


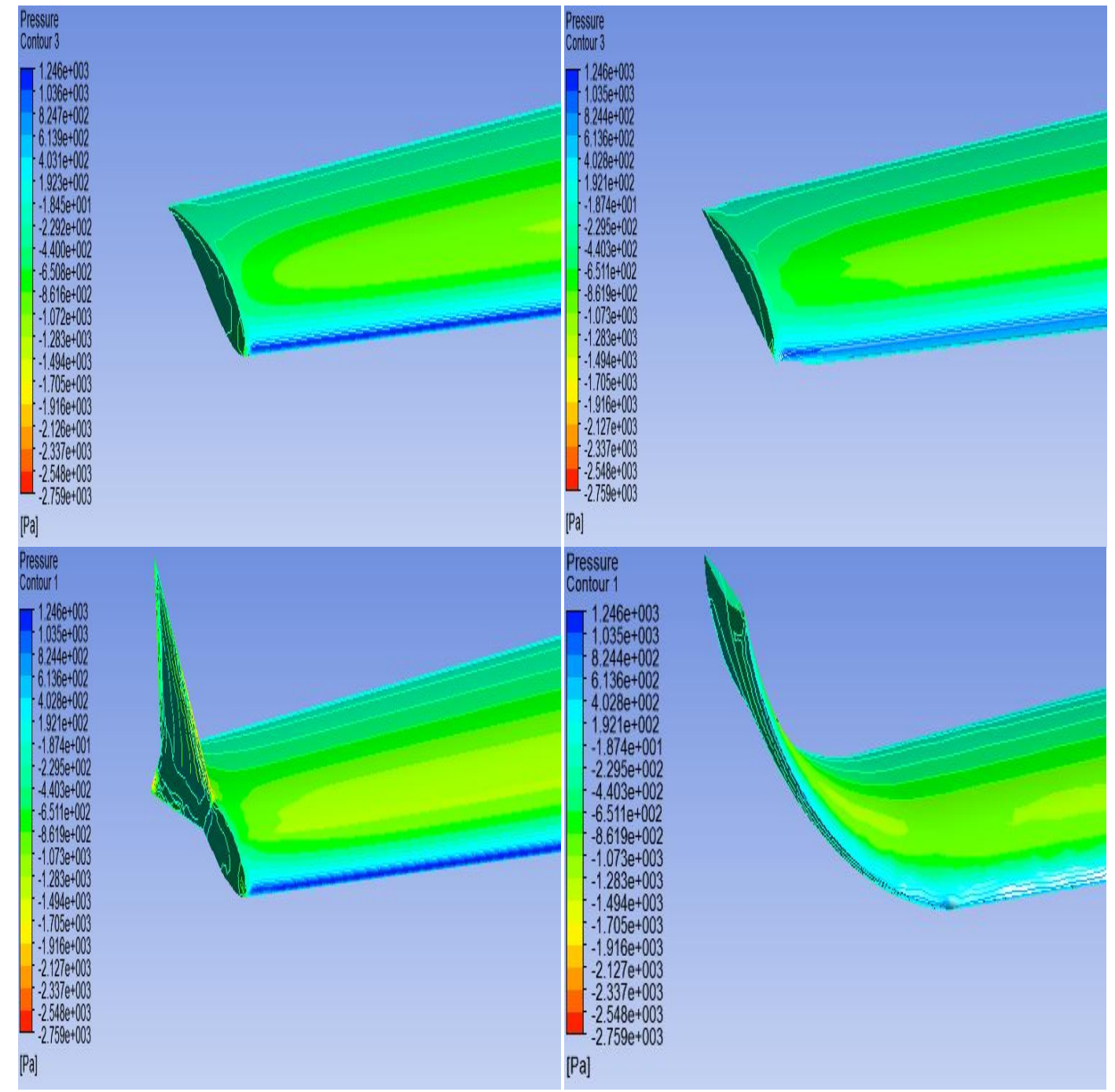

Figure 4.18 Comparison of Wing Pressure Contours for Different Wingtip Geometries at $0^{\circ}$ Incidence Angle. (From left to right: Without Wingtip Device, Hoerner Type Wingtip Device, Shifted Downstream Type Wingtip Device, and Blended Type Wingtip Device) 


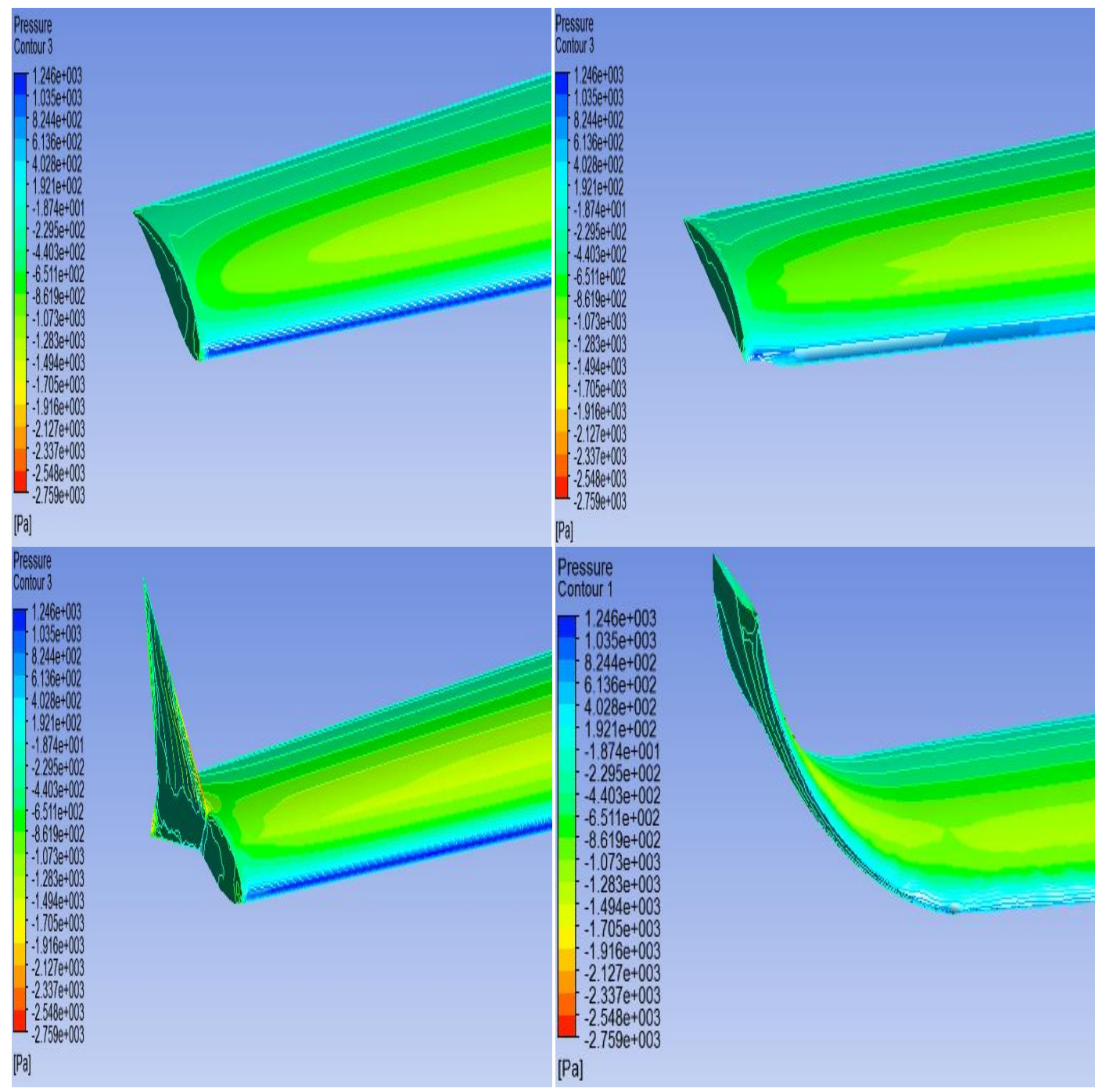

Figure 4.19 Comparison of Wing Pressure Contours for Different Wingtip Geometries at $2^{\circ}$ Incidence Angle. (From left to right: Without Wingtip Device, Hoerner Type Wingtip Device, Shifted Downstream Type Wingtip Device, and Blended Type Wingtip Device) 


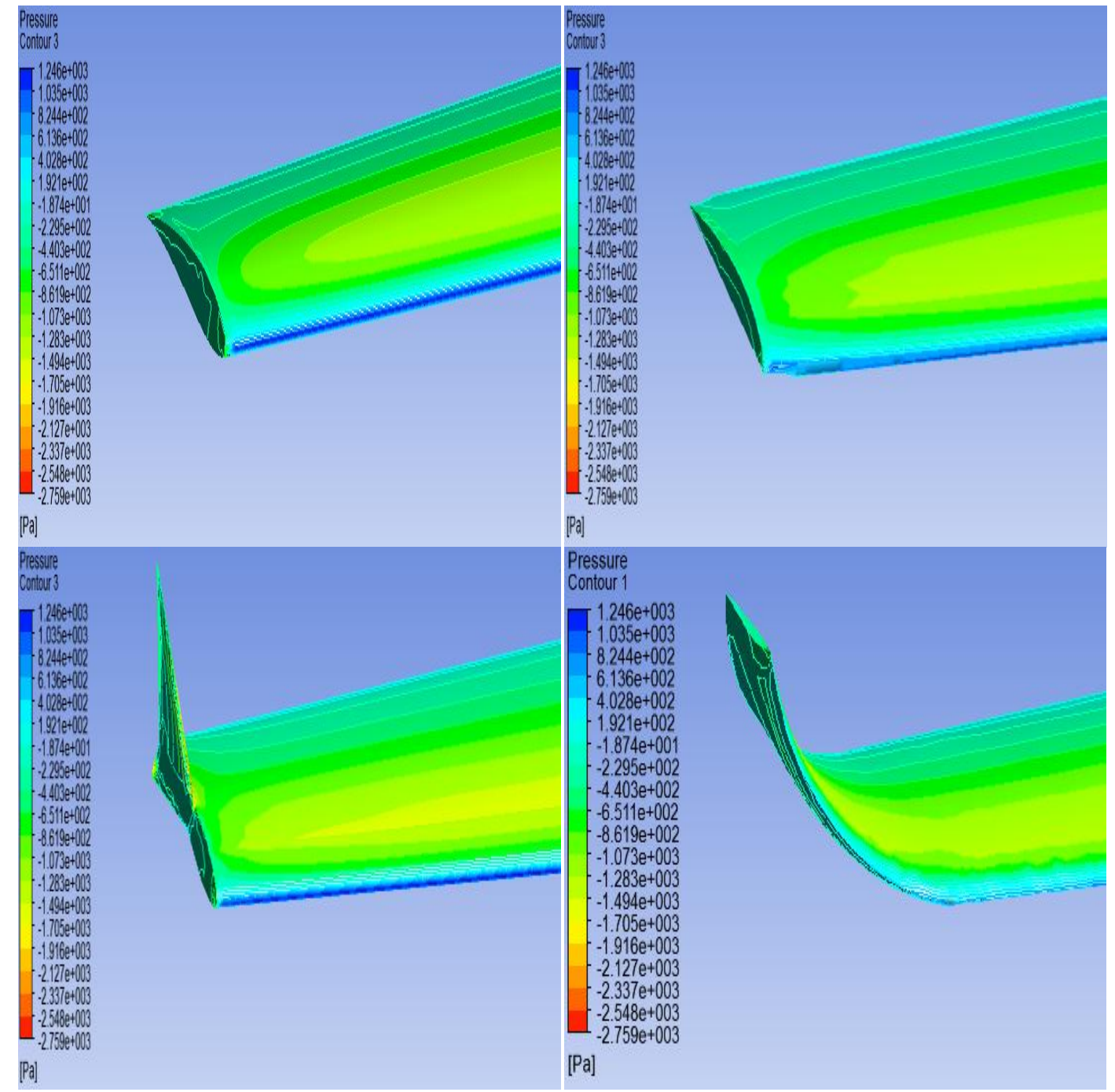

Figure 4.20 Comparison of Wing Pressure Contours for Different Wingtip Geometries at $4^{\circ}$ Incidence Angle. (From left to right: Without Wingtip Device, Hoerner Type Wingtip Device, Shifted Downstream Type Wingtip Device, and Blended Type Wingtip Device) 


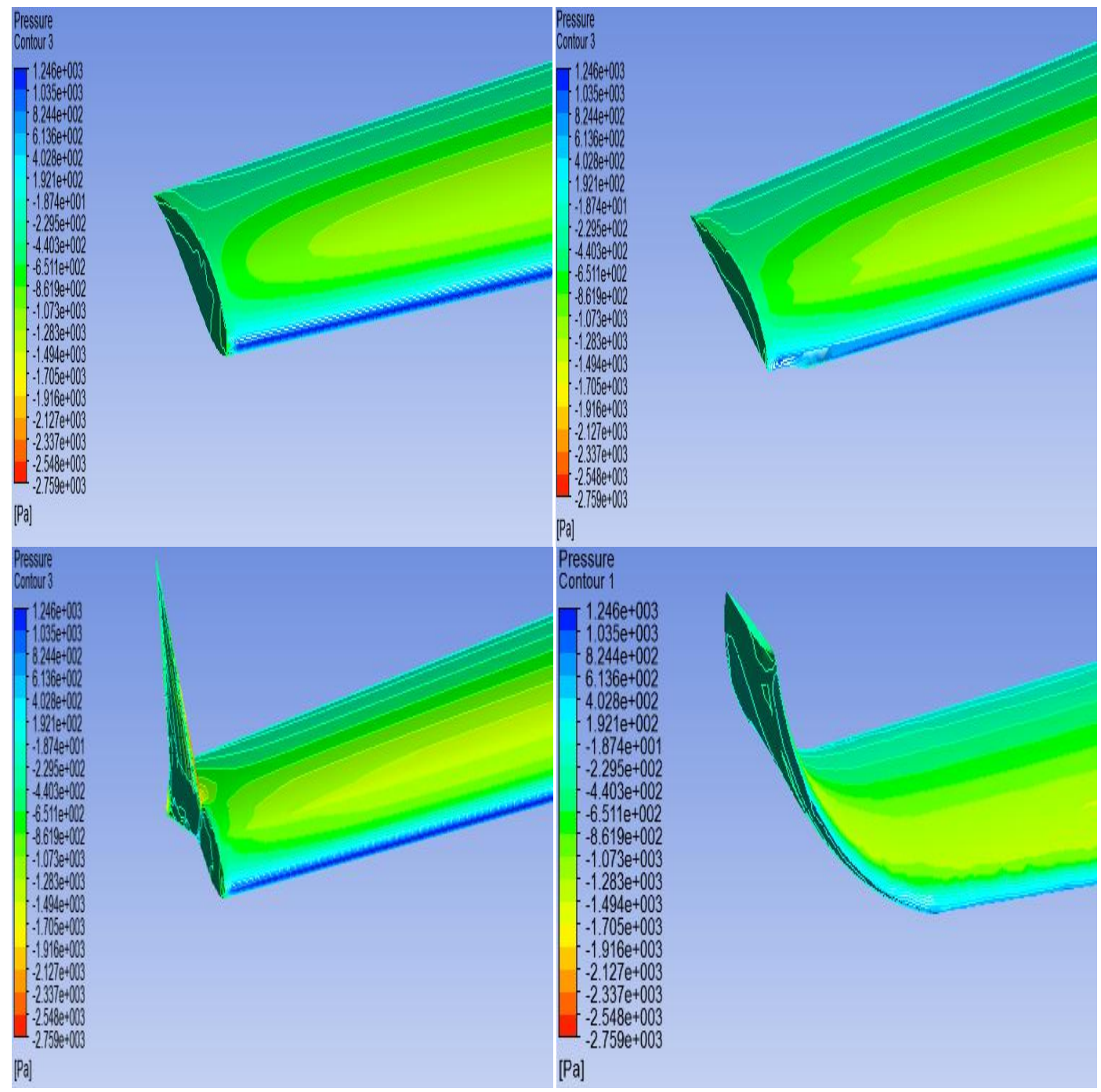

Figure 4.21 Comparison of Wing Pressure Contours for Different Wingtip Geometries at $6^{\circ}$ Incidence Angle. (From left to right: Without Wingtip Device, Hoerner Type Wingtip Device, Shifted Downstream Type Wingtip Device, and Blended Type Wingtip Device) 


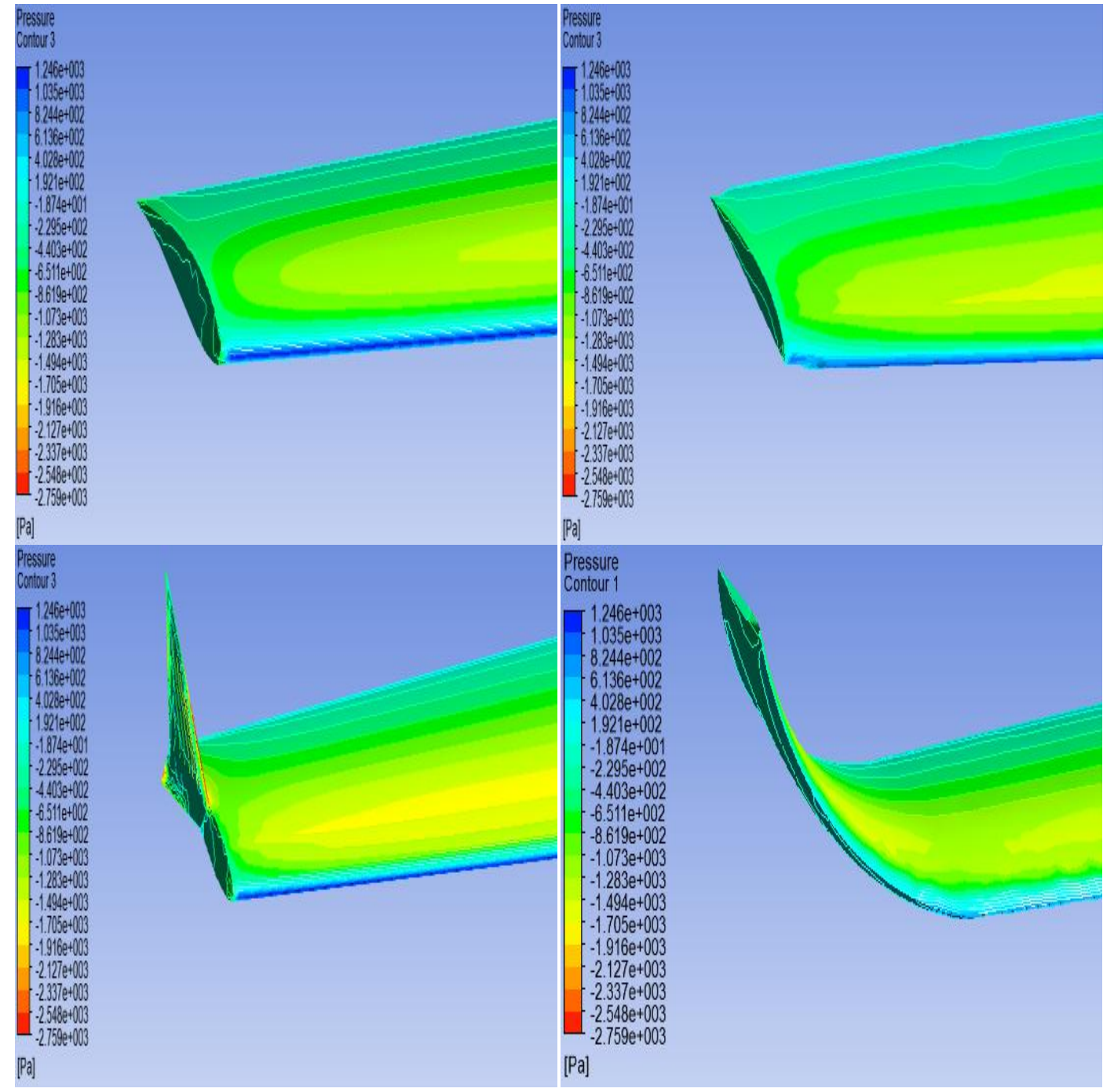

Figure 4.22 Comparison of Wing Pressure Contours for Different Wingtip Geometries at $8^{\circ}$ Incidence Angle. (From left to right: Without Wingtip Device, Hoerner Type Wingtip Device, Shifted Downstream Type Wingtip Device, and Blended Type Wingtip Device) 


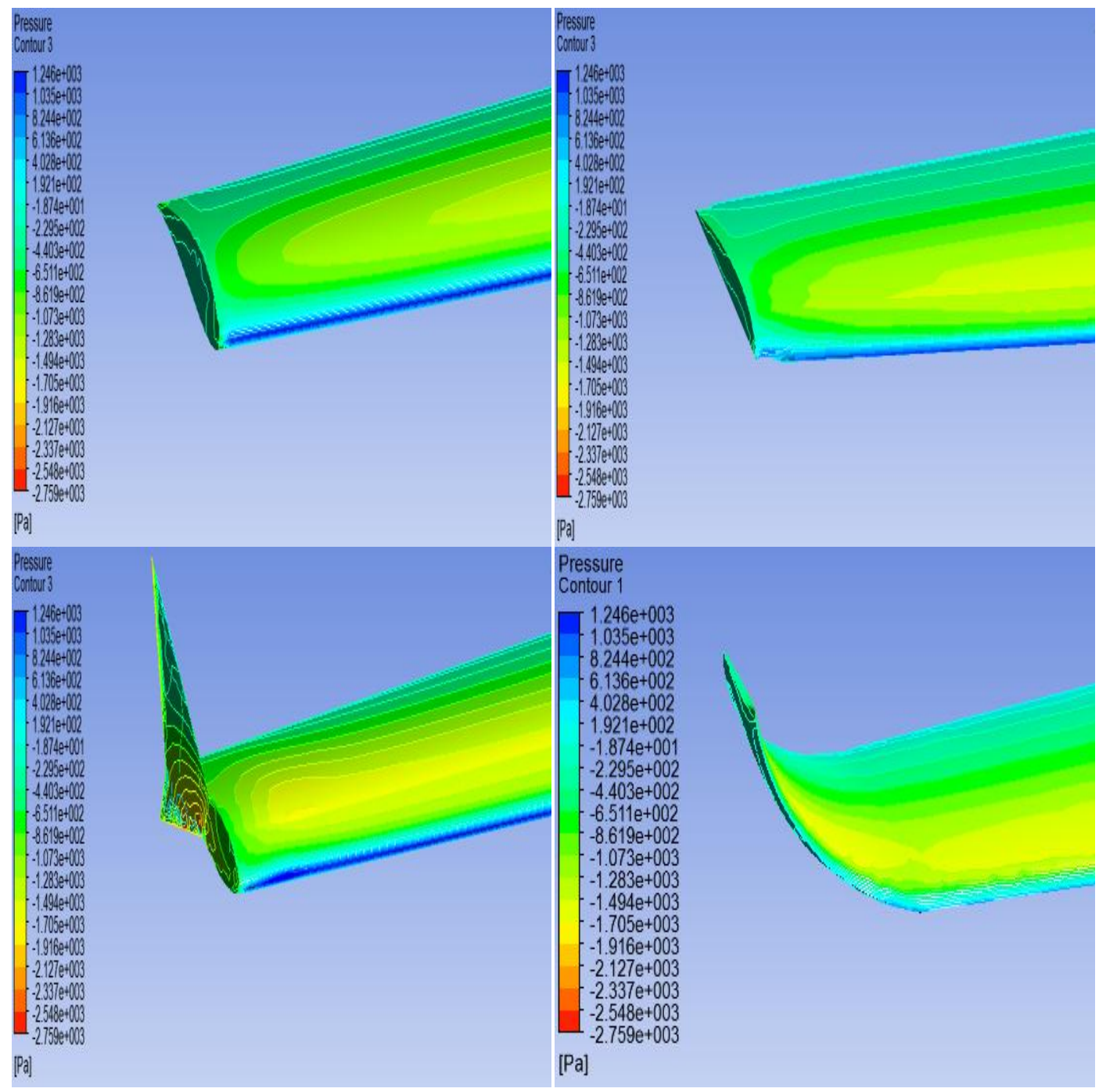

Figure 4.23 Comparison of Wing Pressure Contours for Different Wingtip Geometries at $10^{\circ}$ Incidence Angle. (From left to right: Without Wingtip Device, Hoerner Type Wingtip Device, Shifted Downstream Type Wingtip Device, and Blended Type Wingtip Device) 


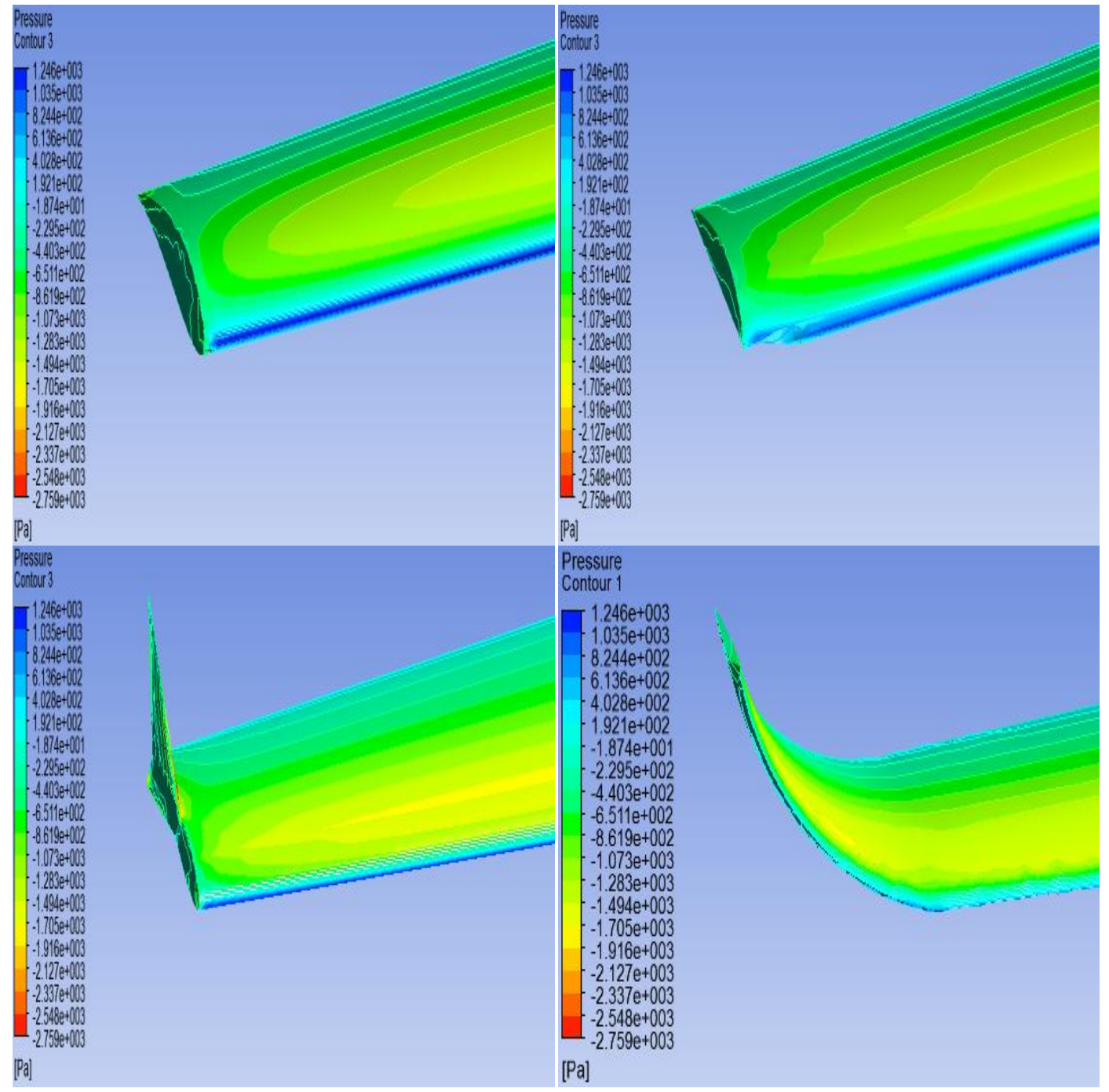

Figure 4.24 Comparison of Wing Pressure Contours for Different Wingtip Geometries at $12^{\circ}$ Incidence Angle. (From left to right: Without Wingtip Device, Hoerner Type Wingtip Device, Shifted Downstream Type Wingtip Device, and Blended Type Wingtip Device) 


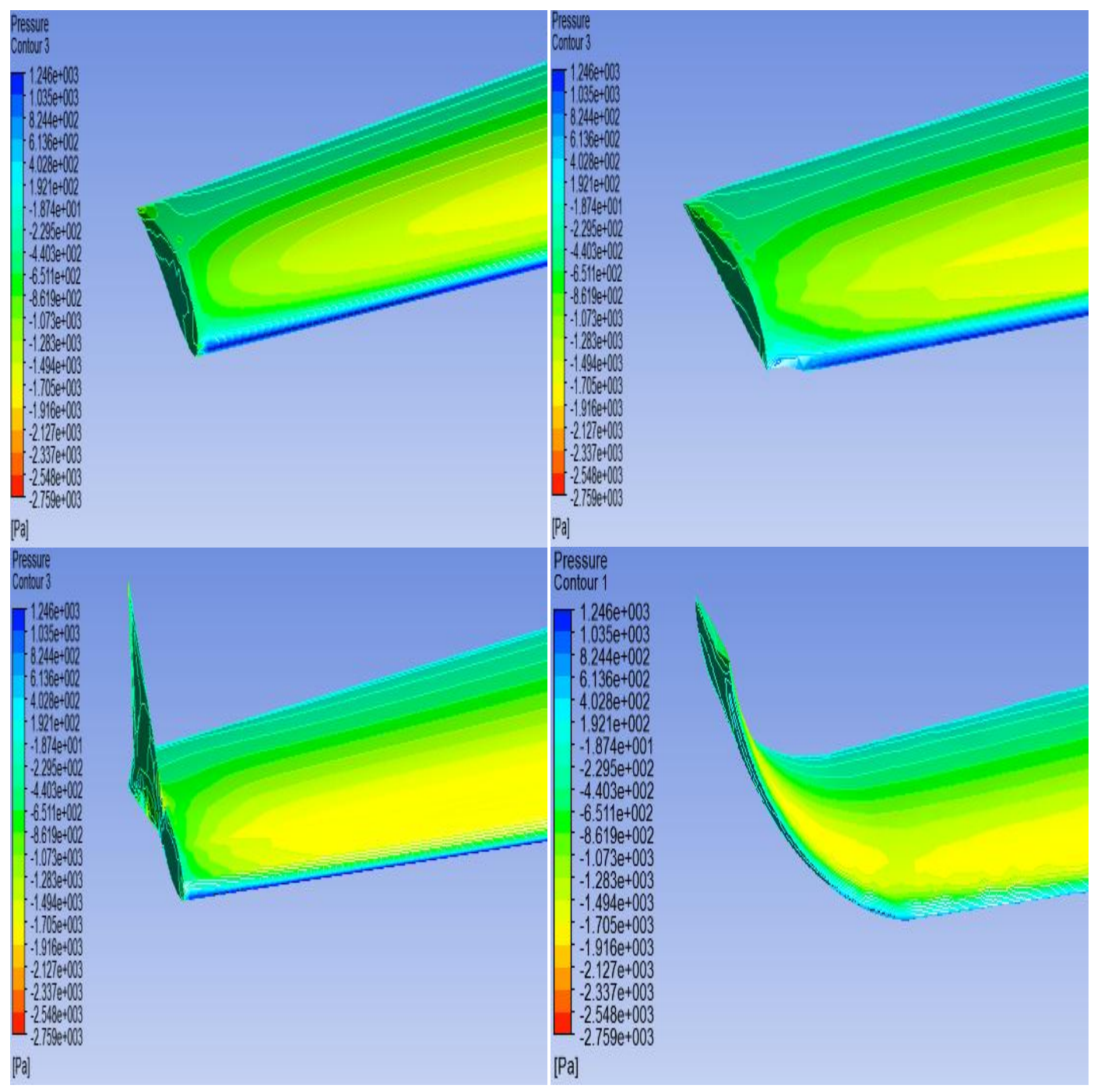

Figure 4.25 Comparison of Wing Pressure Contours for Different Wingtip Geometries at $14^{\circ}$ Incidence Angle. (From left to right: Without Wingtip Device, Hoerner Type Wingtip Device, Shifted Downstream Type Wingtip Device, and Blended Type Wingtip Device) 


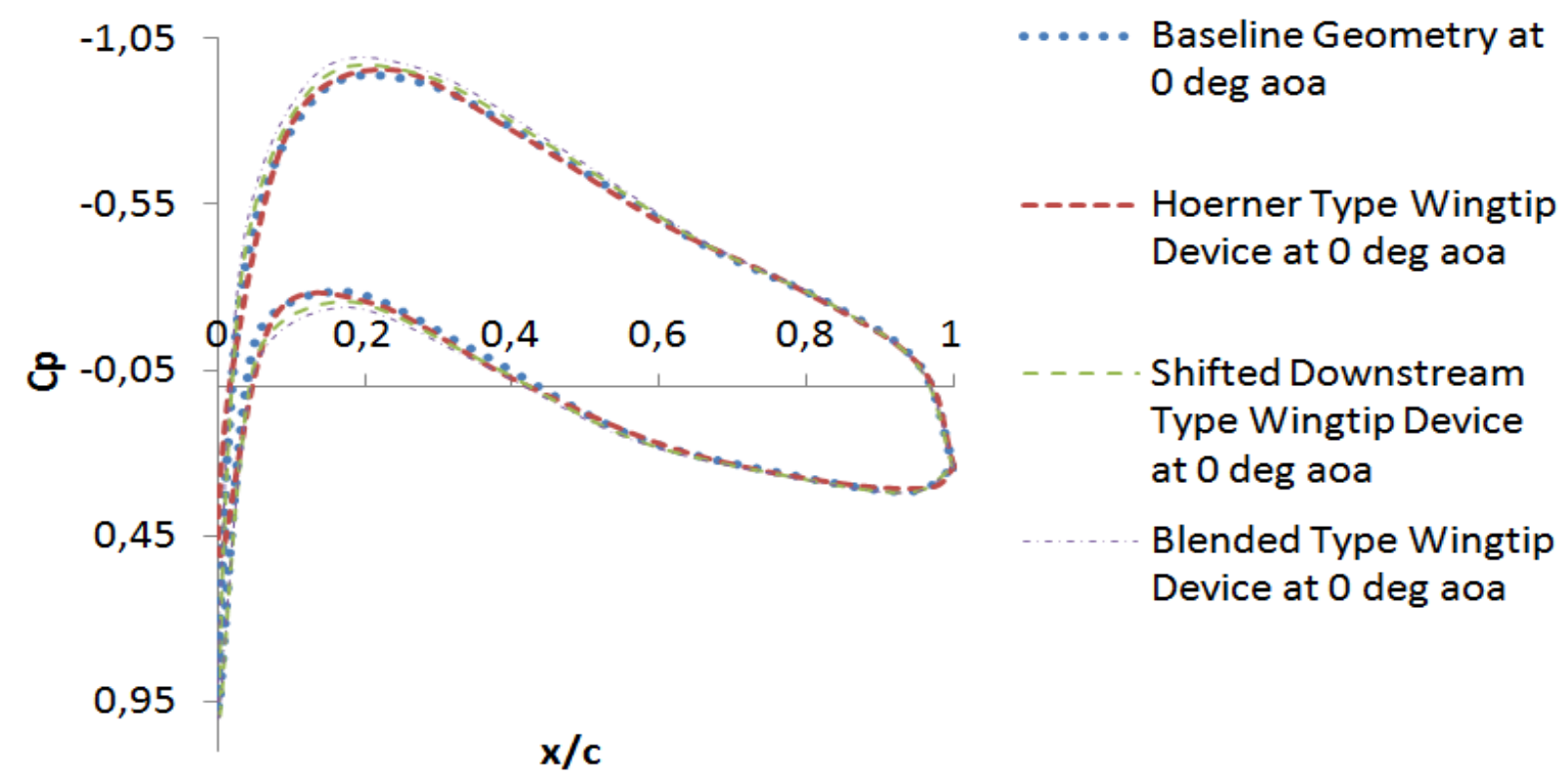

Figure 4.26 Wingtip Geometry Effect on Pressure Distribution at $0^{\circ}$ Incidence Angle

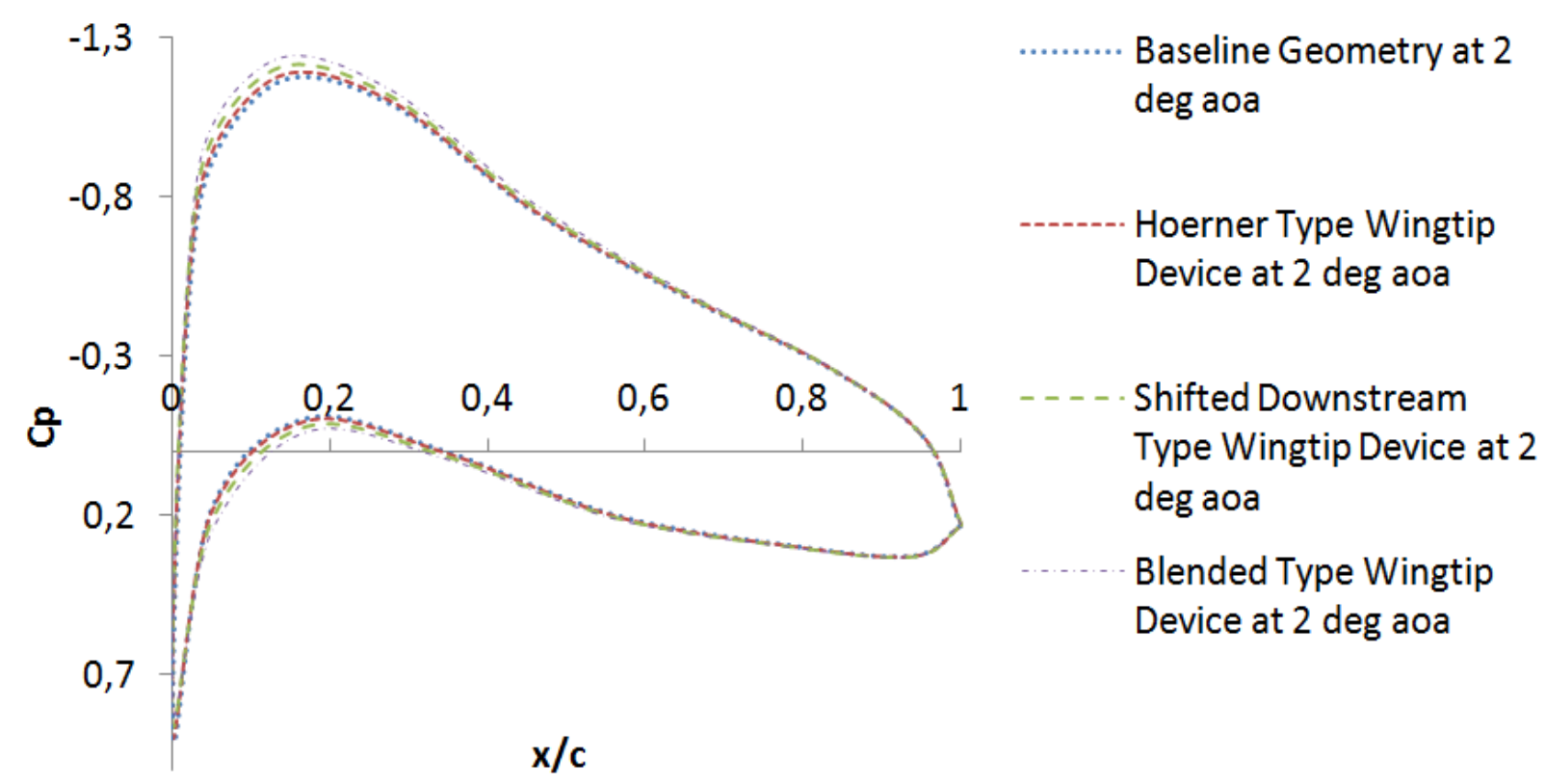

Figure 4.27 Wingtip Geometry Effect on Pressure Distribution at $2^{\circ}$ Incidence Angle 


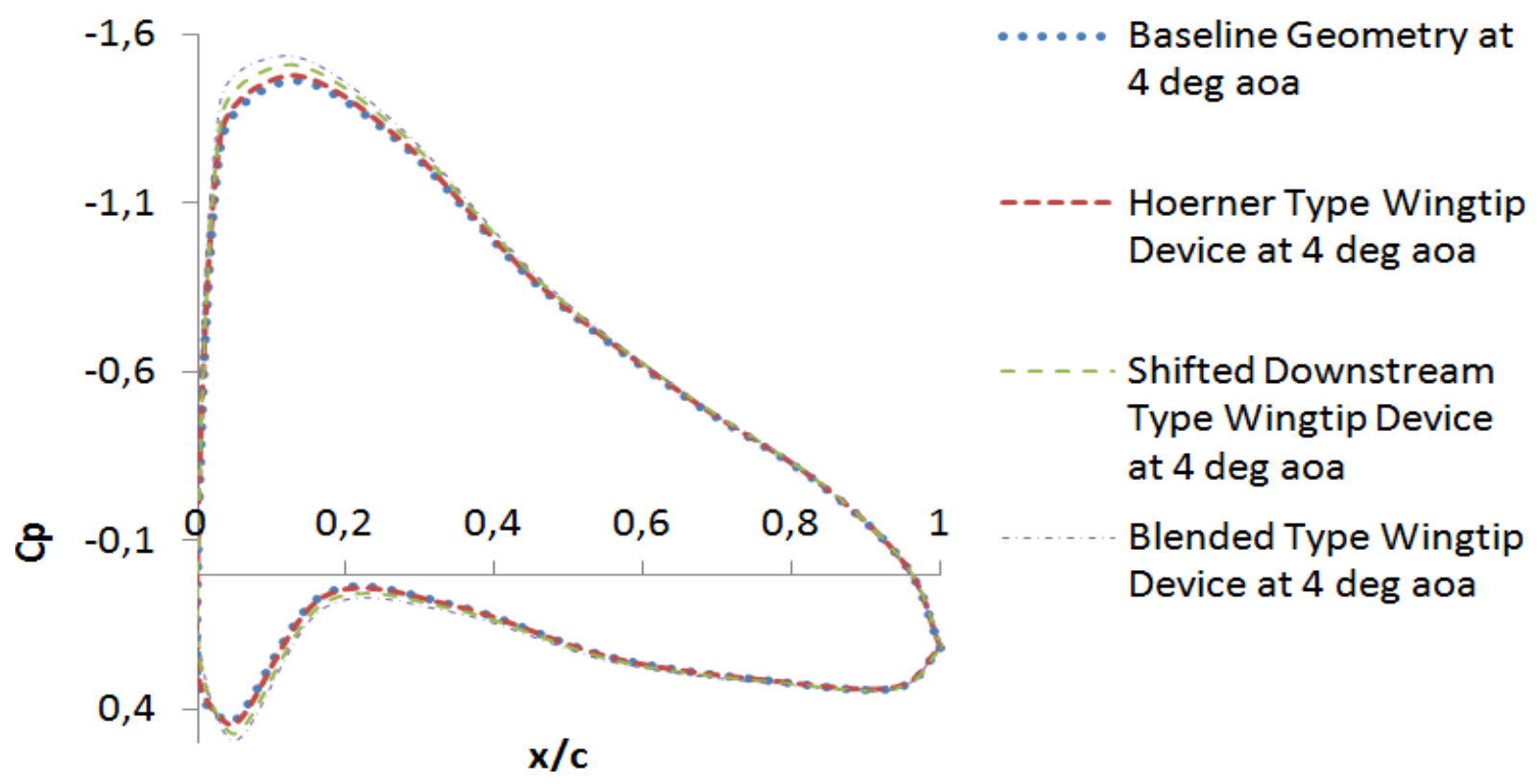

Figure 4.28 Wingtip Geometry Effect on Pressure Distribution at $4^{\circ}$ Incidence Angle

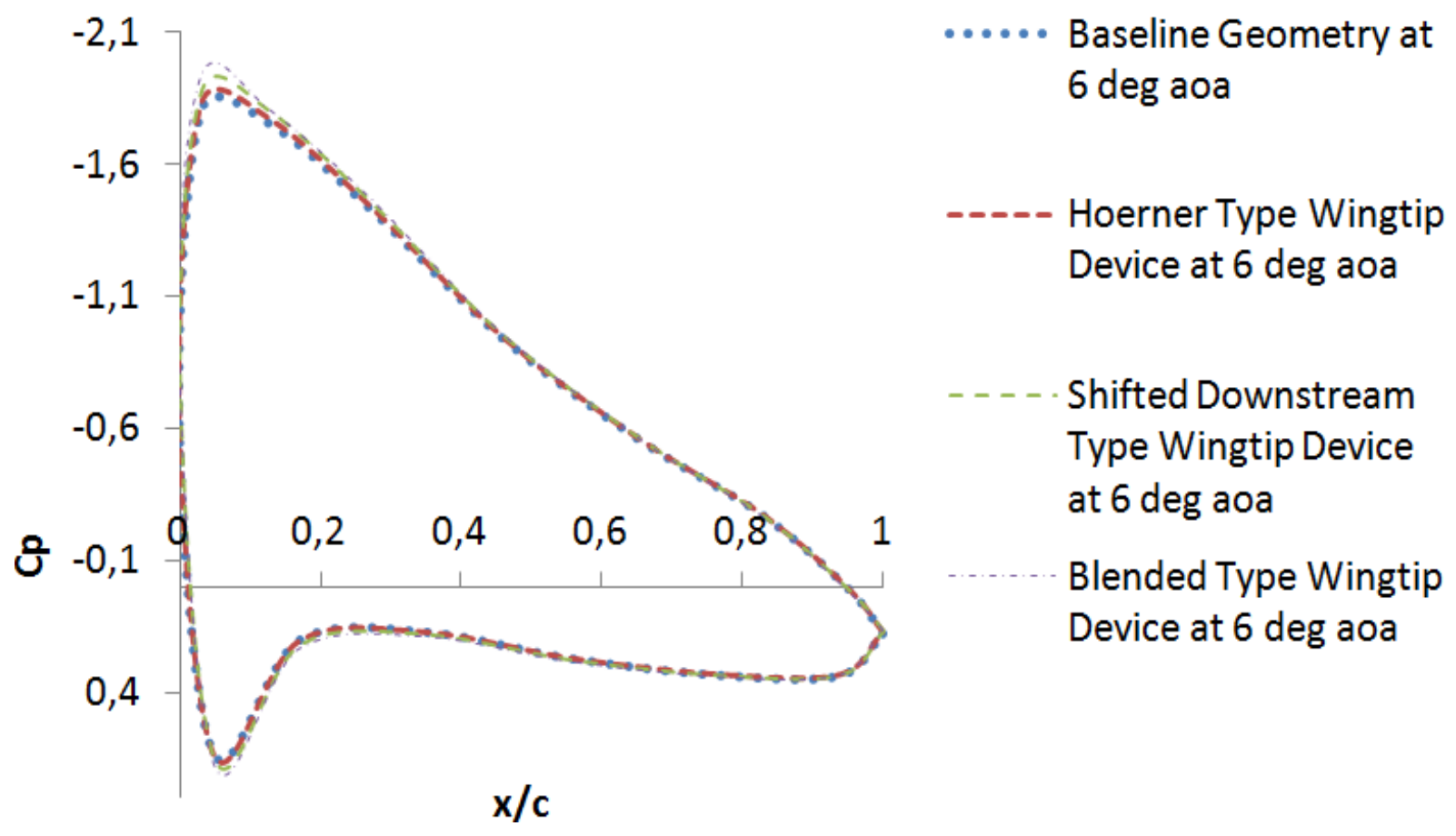

Figure 4.29 Wingtip Geometry Effect on Pressure Distribution at $6^{\circ}$ Incidence Angle 


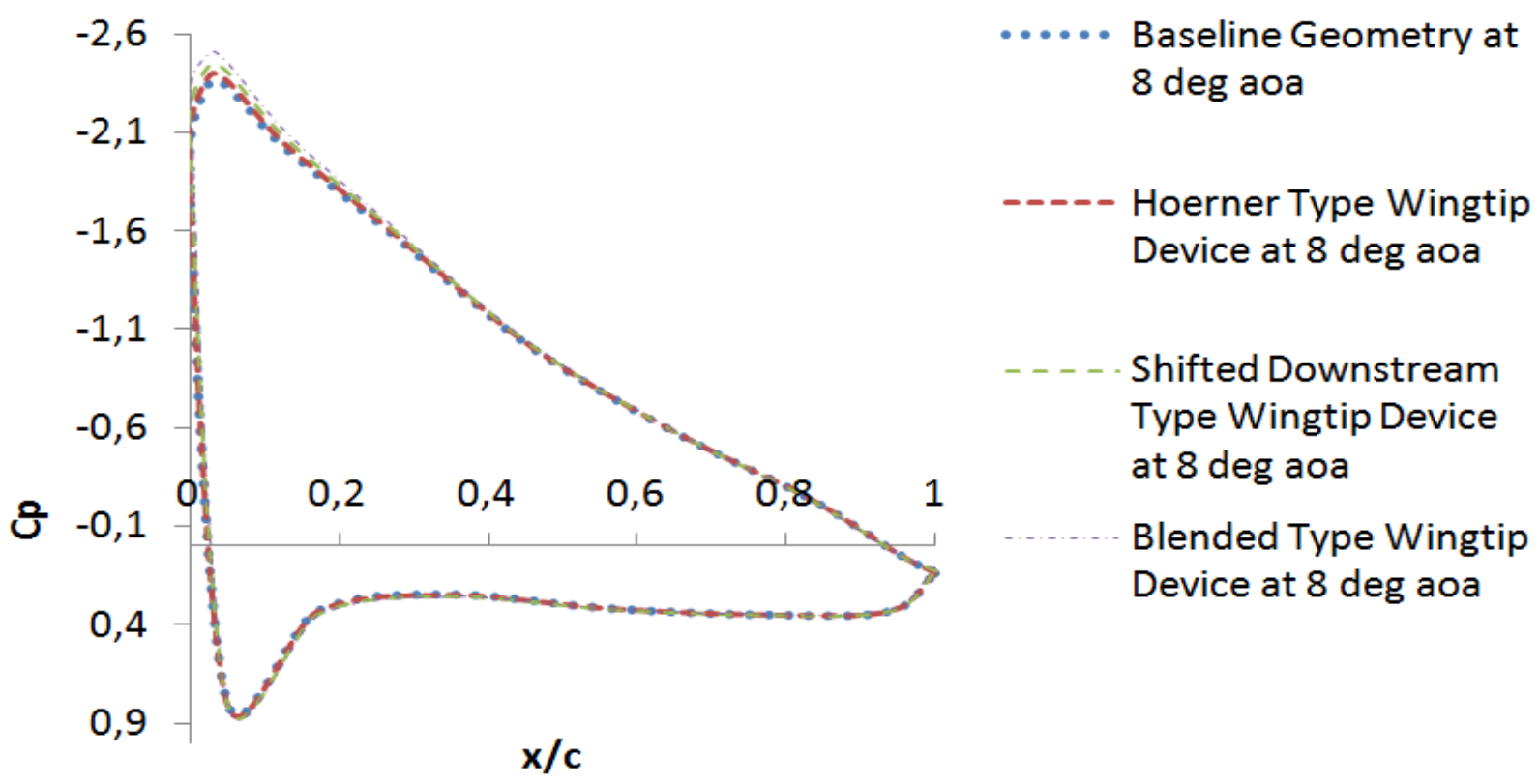

Figure 4.30 Wingtip Geometry Effect on Pressure Distribution at $8^{\circ}$ Incidence Angle

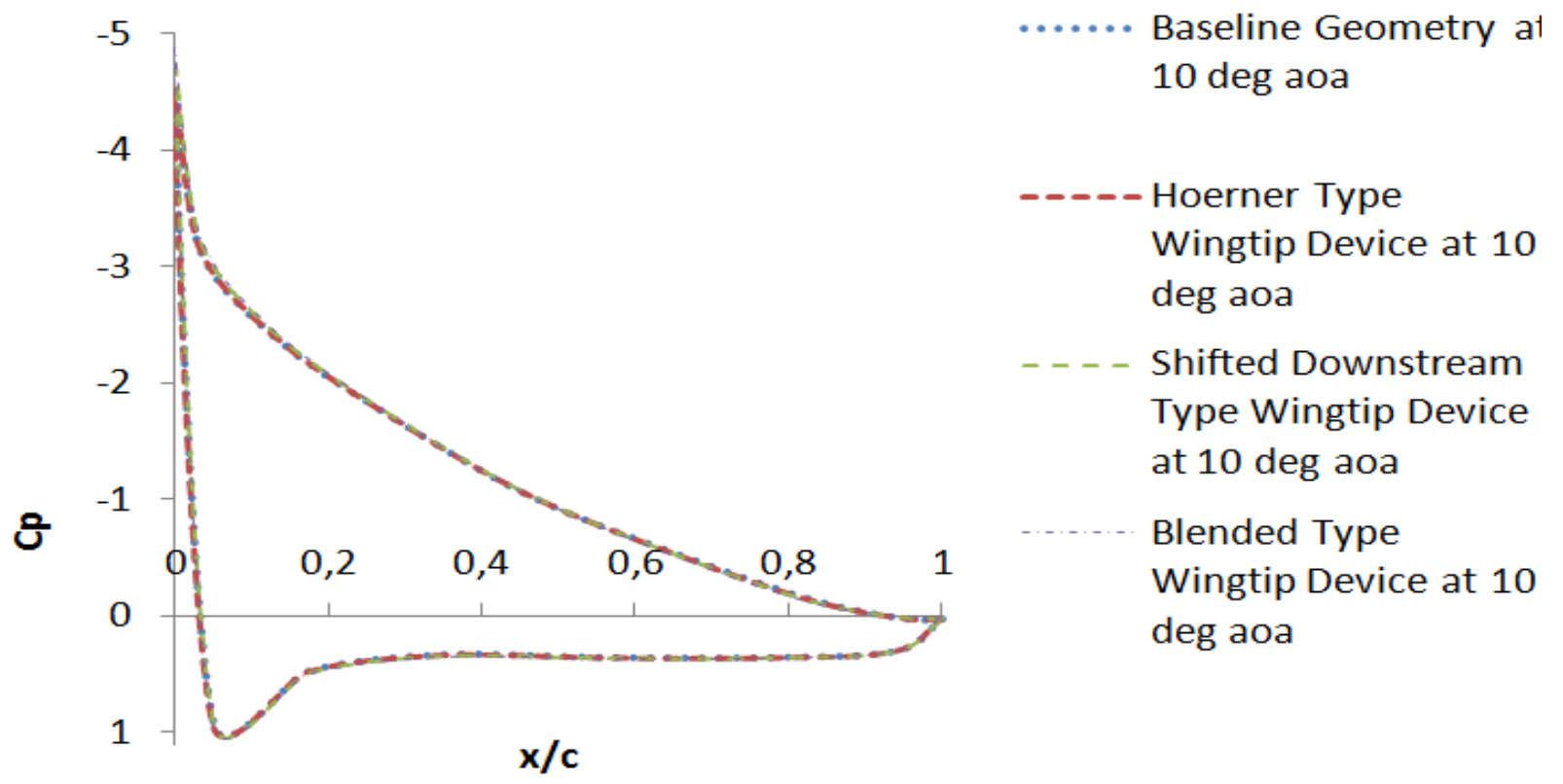

Figure 4.31 Wingtip Geometry Effect on Pressure Distribution at $10^{\circ}$ Incidence Angle 


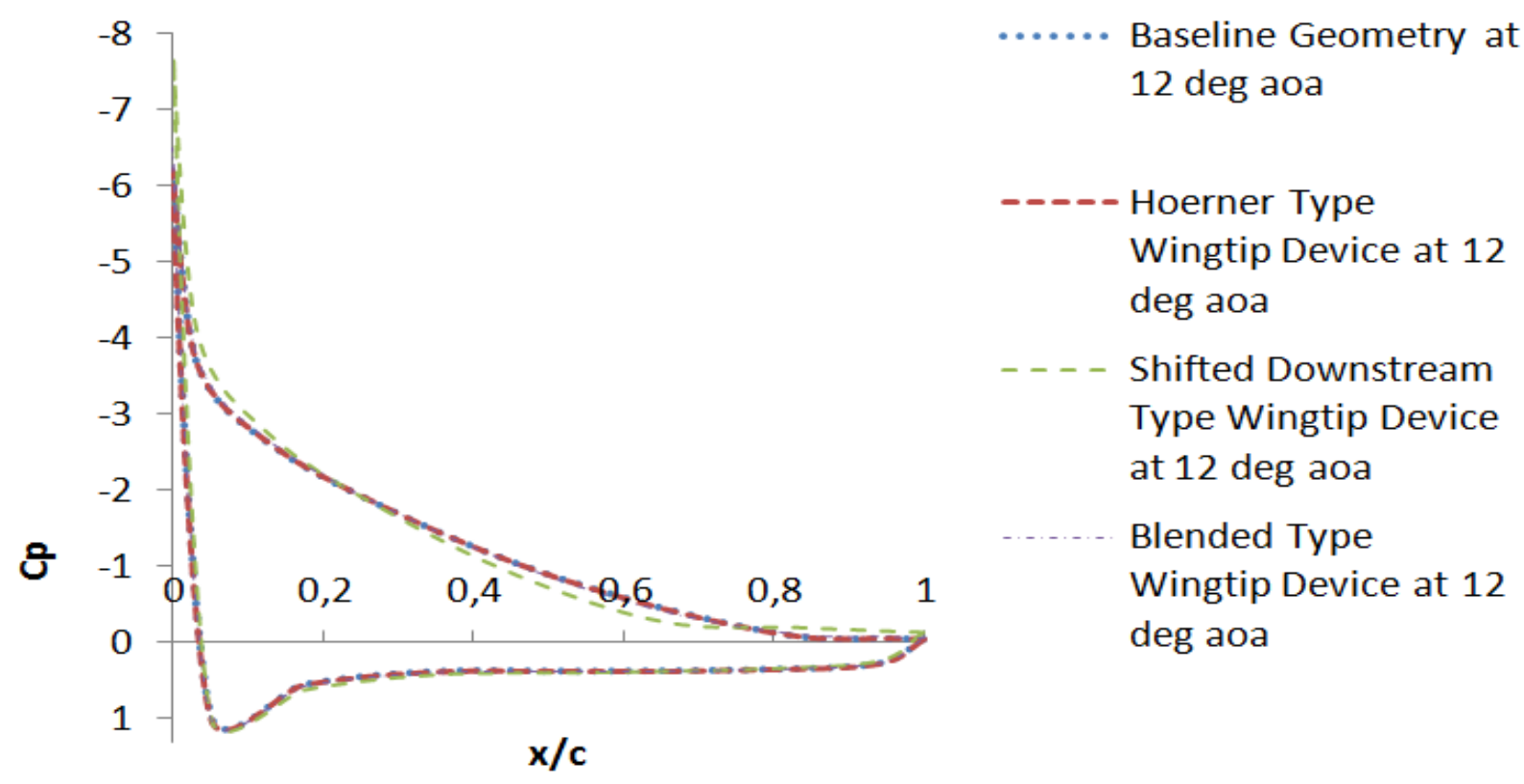

Figure 4.32 Wingtip Geometry Effect on Pressure Distribution at $12^{\circ}$ Incidence Angle

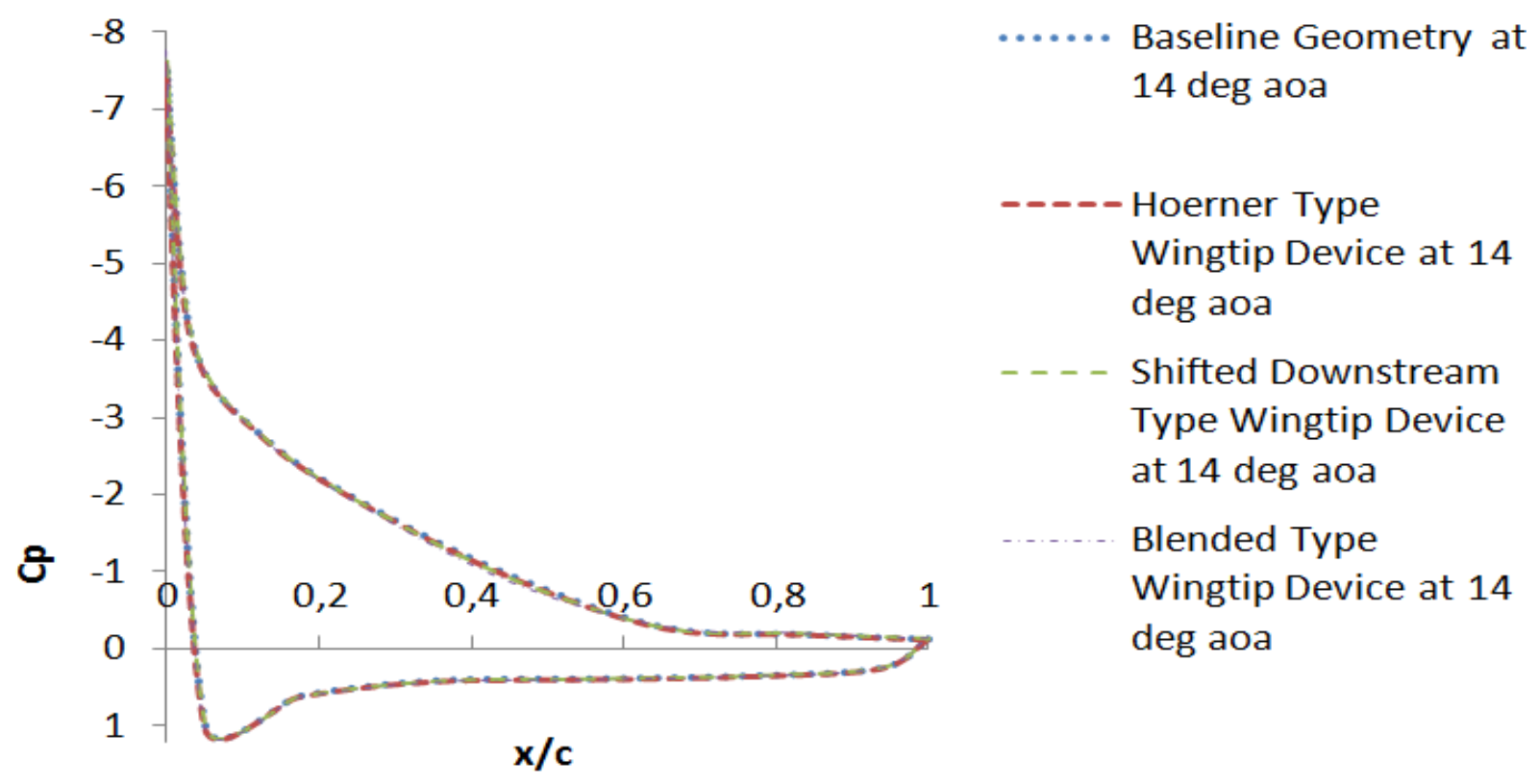

Figure 4.33 Wingtip Geometry Effect on Pressure Distribution at $14^{\circ}$ Incidence Angle 


\section{CHAPTER 6}

\section{CONCLUSIONS}

In the study, conventional design and aerodynamic improvement of a designed medium range TUAV has been performed. Main specifications are found and set as following; cruising altitute above $3500 \mathrm{~m}$, endurance of approximately 10-12 hours, range of $150 \mathrm{~km}$, payload of $60 \mathrm{~kg}$, wing span of $10 \mathrm{~m}$, aspect ratio of 12 and taper ratio of 0.45 . Simple takeoff gross weight estimation has also been performed during the initial steps of the design. In addition to found values by historical equations and experiences, various parameters are selected so as to obtain a maximum possible aerodynamic performance in UAV. For instance, wing position with respect to fuselage and fuselage shape. Several calculations about aerodynamic performance parameters and coefficients, selection of proper airfoil geometry and propeller size, better weight estimation, locating center of gravity and outer body sizing have been performed delicately. After that, aerodynamic improvement process based on proper wingtip geometry selection have been performed.

As depicted roughly, today's aircraft design must include a wide scope optimization processes in various aspects in order to compete with it's adversaries, even surpass them. The study includes an improvement process, althought it's performed only in aerodynamic topic. A standart aerodynamic optimization process includes following parameters: taper ratio, aspect ratio, airfoil type, span, area and sweep angle. However, such a study requires an employement of detailed gradient based genetic algorithm and teamwork study. Therefore, the aerodynamic improvement process employed in the thesis is based on a simpler and applicable approach for an angle of attack interval belonging to cruising stage. So, CFD for various wingtip devices have been performed.

Applied CFD methods are based on employement of both Navier Stokes and turbulence equations in order to obtain rather realistic results. Various turbulence models are compared with results gathered in previous studies and $k-E$ model fits best in computation time and accuracy consideration. Mesh independency test has guided the author to select an optimum mesh number and quality. In addition, effect of mesh number in convergence and stability has also been depicted. Meshing process is based on a compromise between computational time and accuracy. Converge criteria are also strictly followed in each calculation. 
Various wingtip geometries have been compared in various aspects. According to the results of the study, blended type wingtip device have proven its aerodynamic efficiency and performance for the given aircraft configuration. Manufacturer is also able to choose a simpler type wintip device to find an optimum point between ease of manufacturing and aerodynamic performance.

The study has revealed the employement of aerodynamic improvement ability without the need of governing an engineering team and detailed gradient based genetic algorithm. Employement of wingtip devices might be enough and adequate to reach desired performance in such a simple TUAV design.

In a future work, much more detailed analysis, including application of detailed genetic algorithm based on various improvement parameters can be applied. Besides, employment of commercial CFD codes for different geometrical configurations of blended winglet can also be performed. 


\section{REFERENCES}

[1] Abbas, A.,De Vicente, J., Valero, E., "Aircraft Technologies to Improve Aircraft Performance, Journal of Aerospace Science and Technology, Vol.28, 2013.

[2] Advisory Group for Aerospace Research and Development (1991), Special Course on Engineering Methods in Aerodynamic Analysis and Design of Aircraft, AGARD.

[3] Amerio, A., Boschetti, P.J, Cardenas, E.M. (2005), “Aerodynamic optimization of an UAV design", paper presented at AIAA $5^{\text {th }}$ Aviation, Technology, Integration and Operations Conference, Virginia, 25-28 September.

[4] Anderson, John D. (1999), Aircraft Performance and Design, Mc-GrawHill.

[5] Ansys Inc., “ANSYS CFX Solver Modeling Guide”, 2010.

[6] Beetle, J., Holloway, A.G.L., Venart, J.E.S. "A computational study of the aerodynamic forces acting on a tractor-trailer vehicle on a bridge in crosswind", Journal of Wind Engineering and Industrial Aerodynamics, Vol.91, 2003.

[7] Breuer, M., Durst, F., Khier, W. "Flow structure around trains under side wind conditions: a numerical study", Journal of Wind Engineering and Industrial Aerodynamics, Vol.91, 2002.

[8] Chen, Y, Li, P., Lin,Y., Yuan, C., Zhang,B. " Aerodynamic Design Methodology for Blended Body Wing Transport ", Chinese Journal of Aeronautics, Vol.40, 2004, pp

[9] Ekaterinaris, J.A., Kontogiannis, S.G., "Design, Performance Evaluation and Optimization of a UAV”, Journal of Aerospace Science and Technology, Vol.29, 2013.

[10] Giraldo, S., Garcia, J.M. (2008) “CFD Based Wing Shape Optimization Through Gradient Based Method", paper presented at International Conference on Engineering Optimization, Rio de Janerio, 1-5 June.

[11] HKS $720 \quad T$ engine data sheet. Retrieved from http://www.hksaviationuk.com/hks700t.html. [cited March 2014]

[12] Ikeda, T. (2006). Aerodynamic Analysis of a Blended Wing Body Aircraft Configuration. M.S Thesis, RMIT University.

[13] Karzc, J., Kacperski, L. (2012) "An Effect of Grid Quality on the Results of a Numerical Simulations of the Fluid Flow Field in an Agitated Vessel", 
paper presented at $14^{\text {th }}$ European Conference on mixing, Warszawa, 10-13 September.

[14] Lamber, D. (2008). Numerical Investigation of Blended Winglet Effects on Wing Performances. Project Report. Aalborg University.

[15] Lanzafame, R., Mauro, S., Messina, M., "Wind Turbine CFD modeling using a Correlation Based Translational model", Journal of Renewable Energy, Vol.52, 2013.

[16] Lee, J., Park,K., Sam Kim, B.,Won Han,J. "Optimal design of Airfoil with High Aspect Ratio in Unmanned Aerial Vehicles", Internation Journal of Aerospace and Mechanical Engineering, Vol.16, 2008.

[17] Liu, C., Tu, J., Yeoh, G.H. (2013), Computational Fluid Dynamics-A Practical Approach, Elseiver.

[18] Mesh Quality. Retrieved from http://www.arc.vt.edu/ansys_help /flu_ug/flu_ug_mesh_quality.html. [cited April 2014]

[19] Mojtaba Dehghan Manshadi (2011). The Importance of Turbulence Reduction in Assessment of Wind Tunnel Flow Quality, Wind Tunnels and Experimental Fluid Dynamics Research, Prof. Jorge Colman Lerner (Ed.), ISBN: 978-953-307-623-2, InTech. fromhttp://www.intechopen.com/books/wind-tunnels-andexperimental-fluiddynamics-research/the-importance-of-turbulence-reduction-in-assessmentof-wind-tunnelflow-quality. [cited April 2014]

[20] Obayashi, S. Multidisciplinary Design Optimization of Aircraft Wing Planform Base on Evolutionary Algorithms. Retrieved from http:// ieexplore.ieee.org/ stamp/stamp.jsp?arnumber=00726486. [cited March 2014]

[21] Pilot's Hanbook of Aeronautical Knowledge (2008). U.S Department of Transportation.

[22] Pope, S.P., Turbulent flows, Cambridge University Press.

[23] Raymer, D.P. (2005), Aircraft Design: A Conceptual Approach( $4^{\text {th }}$ ed.), Washington: American Institute of Aeronautics and Astronautics.

[24] Roskam, J., Methods for Estimating Stability and Control Derivatives of Conventional Subsonic Airplanes, 1971.

[25] Roskam, J., Tau Edward, L., Airplane Aerodynamics and Performance, DarCorporation, 1997.

[26] UAV Design $\quad$ Standarts. $\quad$ Retrieved $\quad$ from http://www.southampton.ac.uk/ jps7/D8\%20

website/UAV_certification\%20stds.pdf. [cited March 2014]

[27] Unmanned Aerial Vehicles (UAV's). Overwiev, History and Market. Retrieved from http://www.azom.com/article.aspx?ArticleID=10156. [cited January 2014]

[28] Vassberg, J.C., Jameson, A. (2006). Aerodynamic Shape Optimization Part II: Sample Applications. Retrieved from http://aerocomlab.stanford.edu/Papers/Vassberg-VKI-Lecture02.pdf. [cited March 2014]

[29] Wilcox, D.C. (1994), Turbulence Modeling for CFD ( $2^{\text {nd }}$ edition), DCW Industries. 
[30] Wingtip device. Retrieved http://en.wikipedia.org/wiki/Wingtip_device. [cited March 2014]

[31] Xuetao, Z. (2008). UAV Design and Manufacture. Project Report, National University of Singapore.

[32] Zakora, B., Molodchick, A. Classification of UAV (Unmanned Aerial Vehicle). Retrieved from http:// read.meil.pw.pl/abstracts/Student Abstract_Zakora_Molodchik.pdf. [ cited January 2014]

[33] Ziylan, A., 2005. Vizyon 2023 Teknoloji Öngörü Projesi. Savunma, Havacılık ve Uzay Paneli, TÜBITAK, ANKARA. 


\section{APPENDIX}

\section{INITIAL DESIGN CALCULATIONS}

\section{A1. WEIGHT ANALYSIS}

Initial weight analysis, weight improvement and calculations are demonstrated step by step. Formulas come from the chapter 2.

In order to find the total weight, one should use the following equation;

$$
\mathrm{W}_{0}=\mathrm{W}_{\text {payload }}+\mathrm{W}_{\text {fuel }}+\mathrm{W}_{\text {empty }}
$$

Takeoff phase weight ratio;

$$
\begin{gathered}
\frac{W_{1}}{W_{0}}=0.97 \\
\mathrm{~W}_{\text {fuel burned 0-1 }}=868-841.96=26.04 \mathrm{lbs}
\end{gathered}
$$

Climb phase weight ratio;

$$
\begin{gathered}
\frac{W_{2}}{W_{1}}=0.985 \\
\mathrm{~W}_{\text {fuel burned 1-2 }}=841.96-829.33=12.62 \mathrm{lbs}
\end{gathered}
$$

Cruise phase weight ratio;

$$
\frac{W_{3}}{W_{2}}=\exp \left[\frac{-R C_{b h p}}{550 \eta_{p}\left(\frac{L}{D}\right)_{\max }}\right]=\exp \left[\frac{-328083 \times 0.0001111}{550 \times 0.8 \times 22}\right]=0.996
$$




$$
\begin{gathered}
\mathrm{W}_{\text {fuel burned 2-3 }}=829.33-826.52=2.81 \mathrm{lbs} \\
\frac{W_{5}}{W_{4}}=\exp \left[\frac{-R C_{b h p}}{550 \eta_{p}\left(\frac{L}{D}\right)_{\max }}\right]=\exp \left[\frac{-328083 \times 0.0001111}{550 \times 0.8 \times 22}\right]=0.996 \\
\mathrm{~W}_{\text {fuel burned 4-5 }}=759.59-757.03=2.56 \mathrm{lbs}
\end{gathered}
$$

Loiter phase weight ratio;

$$
\begin{gathered}
C_{\text {bhp loiter }}=C_{\text {bhp cruise }} \times 1.25=0.000139 \mathrm{l} / \mathrm{sec} \\
(\mathrm{L} / \mathrm{D})=(\mathrm{L} / \mathrm{D})_{\max \cdot 0.866} \\
\frac{W_{4}}{W_{3}}=\exp \left[\frac{-E V C_{b h p}}{550 \eta_{p}\left(\frac{L}{D}\right)}\right]=\exp \left[\frac{-50400 \times 112.5 \times 0.000139}{550 \times 0.8 \times 19.052}\right]=0.910 \\
\mathrm{~W}_{\text {fuel burned 3-4 }}=826.52-759.59=66.93 \mathrm{lbs}
\end{gathered}
$$

Descent phase weight ratio;

$$
\begin{gathered}
\frac{W_{6}}{W_{5}}=0.995 \\
\mathrm{~W}_{\text {fuel burned 5-6 }}=749.53-745.79=3.747 \mathrm{lbs}
\end{gathered}
$$

Landing phase weight ratio;

$$
\begin{gathered}
\frac{W_{7}}{W_{6}}=0.997 \\
\mathrm{~W}_{\text {fuel burned 6-7 }}=757.03-753.24=3.79 \mathrm{lbs}
\end{gathered}
$$

In summary;

$$
\frac{\mathrm{W}_{7}}{\mathrm{~W}_{0}}=\frac{\mathrm{W}_{1}}{\mathrm{~W}_{0}} \times \frac{\mathrm{W}_{2}}{\mathrm{~W}_{1}} \times \frac{\mathrm{W}_{3}}{\mathrm{~W}_{2}} \times \frac{\mathrm{W}_{4}}{\mathrm{~W}_{3}} \times \frac{\mathrm{W}_{5}}{\mathrm{~W}_{4}} \times \frac{\mathrm{W}_{6}}{\mathrm{~W}_{5}} \times \frac{\mathrm{W}_{7}}{\mathrm{~W}_{6}}=0.856
$$




$$
\begin{gathered}
\frac{\mathrm{W}_{\mathrm{f}}}{\mathrm{W}_{0}}=1.06(1-0.856)=0.144 \\
\frac{W_{e}}{W_{0}}=0.91 W_{0}^{-0.05} \\
\mathrm{~W}_{\text {TOGW }}=715.15 \mathrm{lbs} \\
\mathrm{W}_{\text {fuel burned }}=\begin{array}{c}
\mathrm{W}_{\text {fuel burned 0-1 }}+\mathrm{W}_{\text {fuel burned 1-2 }}+\mathrm{W}_{\text {fuel burned 2-3 }}+\mathrm{W}_{\text {fuel burned 3-4 }} \\
+\mathrm{W}_{\text {fuel burned 4-5 }}+\mathrm{W}_{\text {fuel burned 5-6 }}+\mathrm{W}_{\text {fuel burned 6-7 }}=124.44 \text { lbs }
\end{array}
\end{gathered}
$$

In order to make a better weight estimation, followings should be performed;

Wing exposed area is found by;

$$
S_{\text {exp wing }}=S_{\text {wing }}-S_{\text {wing in the fuselage }}=38.427 f t^{2}-4.4 f t^{2}=34.027 f t^{2}
$$

Vertical tail exposed area is found by;

$$
S_{\exp V T}=S_{V T}-S_{V T \text { in the fuselage }}=7.34-(2.47)(0.09)=7.17 f t^{2}
$$

Since the aircraft has T-tail configuration, horizontal tail can be directy found by;

$$
S_{\exp H T}=S_{H T}=3.53 f t^{2}
$$

Fuselage area is foun by catia software as;

$$
S_{\text {fuselage wet }}=86.72 f t^{2}
$$

Using loading factors from table 3.6 and wetted areas, weights of the aircraft components are as following;

$$
\begin{gathered}
W_{\text {wing }}=2.5 \times 34.027=85.06 \\
W_{\text {fuselage }}=1.4 \times 86.72=121.4
\end{gathered}
$$




$$
\begin{gathered}
W_{V T}=2 \times 7.17=14.34 \\
W_{H T}=4 \times 3.53=14.34 \\
W_{\text {empty }}=W_{\text {wing }}+W_{\text {fuselage }}+W_{V T}+W_{H T}=320 \mathrm{lbs} \\
W_{0}=W_{\text {payload }}+W_{\text {fuel }}+W_{\text {empty }} \\
W_{0}=145.5+124.4+320=590 \mathrm{lbs} \\
\frac{\mathrm{W}_{\mathrm{e}}}{W_{0}}=0.54 \\
\frac{\mathrm{W}_{\mathrm{f}}}{\mathrm{W}_{0}}=0.144 \\
\mathrm{~W}_{0}=723 \mathrm{lbs}
\end{gathered}
$$

Cruise speed improvement can be seen in figure 2.2

\section{A2. AIRFOIL SELECTION}

$$
\begin{gathered}
\lambda=0.45 \\
\bar{c}=\frac{2}{3} c_{r} \frac{1+\lambda+\lambda^{2}}{1+\lambda}=\frac{2}{3} \times 0.457 \times \frac{1+0.45+0.45^{2}}{1+0.45}=0.347 \\
R e=\frac{U \times \bar{c}}{v}=995853.79 \\
M=\frac{v}{a}=\frac{46.29}{340}=0.013
\end{gathered}
$$




$$
C l_{\text {design }}=\frac{W}{S_{\text {ref }} q}=0.72
$$

According to found values, table 3.1 and figure 3.1, Eppler 562 airfoil has been selected

\section{A3. CALCULATION OF WING LOADING}

According to stall velocity constraint;

$$
\begin{gathered}
V_{\text {stall }}=\sqrt{\frac{2\left(\frac{W}{S}\right)}{\rho C_{L \max }}} \\
95.1=\sqrt{\frac{2\left(\frac{W}{S}\right)}{1.624 \times 10^{-3} \times 1.63}} \\
\frac{W}{S}=10.64 \mathrm{lbs} / \mathrm{ft}^{2}
\end{gathered}
$$

According to cruise speed constraint;

$$
\begin{gathered}
\frac{L}{D}=\left(\frac{\rho V^{2} C_{D 0}}{2\left(\frac{W}{S}\right)}+\frac{2 K}{\rho V^{2}} \times \frac{W}{S}\right)^{-1} \\
k=\frac{1}{\pi \mathrm{eAR}}=0.33 \\
22=\left(\frac{1.624 \times 10^{-3} \times 150^{2} \times 0.11}{2\left(\frac{W}{S}\right)}+\frac{2 \times 0.33}{1.624 \times 10^{-3} \times 150^{2}} \times \frac{W}{S}\right)^{-1} \\
\frac{W}{S}=120 \mathrm{lbs} / \mathrm{ft}^{2}
\end{gathered}
$$


According to landing run constraint;

$$
\begin{gathered}
S_{\text {landing }}=80\left(\frac{W}{S}\right)\left(\frac{1}{\sigma C l_{\text {max }}}\right)+S_{a} \\
S_{\text {landing }} \leq 800 \mathrm{~m}=2624 \mathrm{ft} \\
S_{a}=450 \\
2624=80\left(\frac{W}{S}\right)\left(\frac{1}{1 \times 1.63}\right)+450 \\
\frac{W}{S}=44.2 \mathrm{lbs} / f t^{2}
\end{gathered}
$$

Lowest value of wing loading has been chosen.

\section{A4. CALCULATION OF POWER TO WEIGHT RATIO}

According to takeoff distance constraint;

$$
\frac{W}{S}=T O P \sigma \frac{C_{l \max }}{1.21}\left(\frac{h p}{w}\right)
$$

Takeoff parameter (TOP) can be found by using Fig.3.5 as ;

$$
\begin{gathered}
\text { TOP }=350 \\
\frac{h p}{w}=0.0225
\end{gathered}
$$

According to cruise L/D constraint;

The parameter has been calculated as following [23];

$$
\left(\frac{P}{W}\right)_{\text {cruise }}=\frac{1}{(L / D)_{\text {cruise }}}
$$

According to airfoil data, $\mathrm{L} / \mathrm{D}$ value at $\alpha=1^{\circ}$ as 28.98 


$$
\left(\frac{P}{W}\right)_{\text {cruise }}=0.034
$$

According to maximum speed constraint;

The parameter has been calculated as following [4];

$$
\begin{gathered}
V_{\text {max }}=\left\{\frac{\left[\frac{T_{A \max }}{W}\right]\left(\frac{W}{S}\right)+\left(\frac{W}{S}\right) \sqrt{\left[T_{A \max } / W\right]^{2}-4 C_{D 0} K}}{\rho C_{D 0}}\right\} \\
T_{A \max }=\frac{\eta P_{A \max }}{V} \\
190=\left\{\frac{\left[\frac{T_{A \text { max }}}{W}\right](10.64)+(10.64) \sqrt{\left[T_{A \max } / 723\right]^{2}-4 \times 0.11 \times 0.33}}{1.624 \times 10^{-3} \times 0.11}\right\} \\
T=0.5 \times 1.624 \times 10^{-3} \times 150^{2} \times\left(0.11+0.33 \times 0.61^{2}\right) \times 34.027
\end{gathered}
$$

Then;

$$
P=59 k w=77 h p
$$

\section{A5. WING AND BODY DESIGN}

\section{A5.1 Fuel Space Calculation}

Fuel space is calculated as;

$$
V_{f}=\frac{W_{f}}{\rho_{f}}=\frac{126.63}{6}=21.98 \mathrm{gal}=0.083 \mathrm{~m}^{3}
$$




\section{A5.2 Locating and Sizing of Landing Gears}

Landing gear location and gear sizes are found as;

$$
\begin{gathered}
\bar{z}=\frac{b(1+2 \lambda)}{6(1+\lambda)}=5.51 \mathrm{ft} \\
x_{\text {cg wing }}=8.6 \mathrm{ft} \\
x_{\text {main landing gear }}=x_{\text {cg wing }}+0.1 \mathrm{c}=8.8 \mathrm{ft} \\
\alpha_{\text {stall }}=12^{\circ}
\end{gathered}
$$

So, the main landing gear is located $8.22 \mathrm{ft}$ away from the back side of the airplane

$$
\begin{gathered}
\tan \theta_{\text {static taildown }}=\frac{H_{2}}{x_{\text {main landing gear }}}=\frac{H_{2}}{8.22} \\
\tan 13^{0}=\frac{H_{2}}{8.22} \\
\tan \theta_{\text {tipback }}=\frac{x_{\text {cg aircraft }}-x_{\text {main landing gear }}}{H_{1}}=\frac{1.23}{H_{1}}
\end{gathered}
$$

So;

$$
H_{1}<4.59 f t
$$

Then;

$$
\begin{gathered}
x_{n}=x_{c g \text { wing }}-1.64=6.96 \\
x_{m}=0.2 \\
W_{0}=32.2(748)=24085.6
\end{gathered}
$$

By taking moments; 


$$
\begin{gathered}
2 F_{m}\left(x_{n}+x_{m}\right)=W_{0}\left(x_{\text {cg aircraft }}-1.64\right) \\
F_{m}=9973.9 \frac{f t s^{2}}{l b s} \\
w_{m}=9973.9 / 32.2=309.72
\end{gathered}
$$

For front landing gear;

$$
\begin{gathered}
F_{n}\left(x_{n}+x_{m}\right)=W_{0}\left(x_{c g \text { wing }}-x_{\text {cg aircraft }}-x_{m}\right) \\
F_{n}=4137.61 \frac{\mathrm{fts^{2 }}}{l b s} \\
w_{n}=4137.61 / 32.2=128.49
\end{gathered}
$$

Wheel diameters and widths can be found from the Table 11.1 of Raymer using information for general aviation aircraft in $A \cdot W^{B}$ equation as follows;

Wheel diameter and width of the nose landing gear:

$$
D_{\text {nose }}=1.51\left(W_{n}\right)^{0.349}=8.16 \text { in }_{\text {nose }}=0.715\left(W_{n}\right)^{0.312}=3.25 \mathrm{in}
$$

Wheel diameter and width of the main landing gear:

$$
D_{\text {main }}=1.51\left(W_{m}\right)^{0.349}=11.17 \text { in }_{\text {main }}=0.715\left(W_{m}\right)^{0.312}=4.28 \mathrm{in}
$$

Hence, the followings were selected from Ref.[23] table 11.2. 
Table A5.1 Specifications of Selected Tires

\begin{tabular}{|l|l|l|l|l|l|l|}
\hline Tires & Type & Size & $\begin{array}{l}\text { Speed } \\
\text { mph }\end{array}$ & $\begin{array}{l}\text { Max load } \\
\text { lb }\end{array}$ & $\begin{array}{l}\text { Max. } \\
\text { width in. }\end{array}$ & $\begin{array}{l}\text { Max. } \\
\text { diameter } \\
\text { in. }\end{array}$ \\
\hline Front & Type 3 & $8.50-10$ & 120 & 1200 & 5.05 & 13.25 \\
\hline Rear & Type 3 & $8.50-10$ & 210 & 1200 & 5.05 & 13.25 \\
\hline
\end{tabular}

\section{A6.AERODYNAMIC ANALYSIS}

\section{A6.1.Outer Geometry Dimensions}

As for horizontal tail;

$$
\begin{gathered}
S_{H T}=\frac{C_{H T} \bar{c} S_{W}}{L_{H T}}=\frac{0.7 \times 0.695 \times 77.98}{10.72}=3.53 f t^{2} \\
L_{H T}=0.65\left(l_{\text {fuselage }}\right)=10.72 f t, \text { where } 0.65 \text { comes from sailplane assumption [23]; } \\
A R_{H T}=\frac{b_{H T}^{2}}{S_{H T}}=6 \\
b_{H T}=5.94 f t \\
\lambda_{H T}=\frac{\mathrm{c}_{\mathrm{T}, \mathrm{HT}}}{\mathrm{c}_{\mathrm{R}, \mathrm{HT}}}=0.5 \\
\mathrm{c}_{\mathrm{T}, \mathrm{HT}}=0.56 \mathrm{ft} \\
\mathrm{c}_{\mathrm{R}, \mathrm{HT}}=1.12 \mathrm{ft}
\end{gathered}
$$

As for vertical tail; 


$$
\begin{gathered}
S_{V T}=\frac{C_{V T} b S_{W}}{L_{V T}}=\frac{0.04 \times 25.26 \times 77.98}{10.72}=7.34 \mathrm{ft}^{2} \\
A R_{V T}=\frac{b_{v t}{ }^{2}}{S_{V T}}=1.2 \\
b_{v t}=2.96 \mathrm{ft} \\
\lambda_{V T}=\frac{\mathrm{c}_{\mathrm{T}, \mathrm{VT}}}{\mathrm{c}_{\mathrm{R}, \mathrm{VT}}}=0.8 \\
\mathrm{c}_{\mathrm{R}, \mathrm{VT}}=2.45 \mathrm{ft} \\
\mathrm{c}_{\mathrm{T}, \mathrm{VT}}=1.95 \mathrm{ft}
\end{gathered}
$$

\begin{tabular}{|c|c|c|c|c|c|}
\hline$C_{L \alpha \text { wing }}\left(\operatorname{deg}^{-1}\right)$ & 0.11 & $\mathrm{C}_{\mathrm{lmaxplain}}$ & 1.552 & $C_{\text {D 0 miscellaneous }}$ & 0.091 \\
\hline$C_{L \alpha H . T}\left(\operatorname{deg}^{-1}\right)$ & 0.38 & $C_{1 \max 10^{0} \text { flap }}$ & 1.63 & $\mathrm{C}_{\mathrm{DO}}$ & 0.104 \\
\hline Downwash $\left(\frac{\partial \varepsilon}{\partial \alpha}\right)$ & 0.175 & $\mathrm{C}_{\text {D0 L.G }}$ & 0.042 & $\mathrm{C}_{\mathrm{D} \text { cruise }}$ & 0.0254 \\
\hline $\mathbf{M}_{\text {cruise }}$ & 0.1323 & $C_{D 0 \text { flap }}$ & 0.043 & $\mathrm{C}_{\mathrm{L} \text { cruise }}$ & 0.62 \\
\hline$C_{1 \text { design }}$ & 0.72 & $C_{\text {D0 } c}$ & 0.0128 & $\mathbf{V}_{\text {Stall }}(\mathrm{m} / \mathrm{s})$ & 28.1 \\
\hline $\mathrm{V}_{\max }(\mathrm{m} / \mathrm{s})$ & 79.24 & $\mathrm{~V}_{\text {cruise }}(\mathrm{m} / \mathrm{s})$ & 79.24 & $\left(\mathrm{C}_{\mathrm{L}} / \mathrm{C}_{\mathrm{D})_{\text {max }}}\right.$ & 24.4 \\
\hline$\left(C_{L} / C_{D}\right)_{\text {cruise }}$ & 22 & $C_{m}$ & -0.155 & & \\
\hline
\end{tabular}

Other parameters are selected according to ref.[23]

\section{A6.2 Lift Curve Slope and Aerodynamic Coefficients \& Parameters}

Table A6.1 Parameters Related with Aerodynamic Performance

Wing lift curve slope is;

$$
C_{L_{\alpha \text { wing }}}=\frac{2 \cdot \pi \cdot A R_{\text {wing }}}{2+\sqrt{4+\frac{A R_{\text {wing }}^{2} \beta^{2}}{\eta^{2}}\left(1+\frac{\tan ^{2} \Lambda_{c / 2}}{\beta^{2}}\right)}} \cdot \frac{S_{\text {exposed }}}{S_{\text {ref }}}
$$




$$
\begin{gathered}
\eta=\frac{C_{l \alpha}}{2 \pi / \beta}=\frac{2 \pi / \mathrm{rad}}{2 \pi / 0.987}=\frac{6.87}{6.36}=1.07 \\
\beta^{2}=1-M^{2}=1-\left(\frac{45.72}{295}\right)^{2}=0.987 \\
F=1.07\left(1+\frac{d}{b}\right)^{2}=1.258 \\
C_{L_{\alpha \text { wing }}}=\frac{2 \times \pi \times 12}{2+\sqrt{4+\frac{12^{2} \times 0.987^{2}}{1.07^{2}}\left(1+\frac{0}{\beta^{2}}\right)}} \cdot \frac{34.027}{38.427}=0.11 \mathrm{deg}^{-1}
\end{gathered}
$$

Horizontal tail lift curve slope is;

$$
\begin{gathered}
C_{L_{\alpha H . T}}=\frac{2 . \pi \cdot A R_{H . T}}{2+\sqrt{4+\frac{A R_{\text {wing }}^{2} \beta^{2}}{\eta^{2}}\left(1+\frac{\tan ^{2} \Lambda_{c / 2}}{\beta^{2}}\right)}} \cdot \frac{S_{\text {exposed }}}{S_{\text {ref }}} . F \\
C_{L_{\alpha H . T}}=\frac{2 \times \pi \times 6}{2+\sqrt{4+\frac{6^{2} 0.987^{2}}{1.07^{2}}\left(1+\frac{0}{0.987^{2}}\right)}} \times \frac{7.29}{3.53} \times 3.08=0.38 \mathrm{deg}^{-1}
\end{gathered}
$$

Downwash factor is found by;

$$
\begin{gathered}
\left(\left.\frac{d \varepsilon}{d \alpha}\right|_{M}\right)_{\text {downwash }}=\left.\frac{d \varepsilon}{d \alpha}\right|_{M=0} \cdot \frac{\left.C_{L_{\alpha \text { wing }}}\right|_{M}}{\left.C_{L_{\alpha \text { wing }}}\right|_{M=0}} \\
\left.\frac{d \varepsilon}{d \alpha}\right|_{M=0}=4.44\left[K_{A} K_{\lambda} K_{H} \sqrt{\cos \Lambda_{\frac{c}{4}}}\right]^{1.19} \\
K_{A}=\frac{1}{A R_{\text {wing }}}-\frac{1}{1+\left(A R_{\text {wing }}\right)^{1.7}}=\frac{1}{12}-\frac{1}{1+(12)^{1.7}}=0.097 \\
K_{\lambda}=\frac{10-3 \lambda}{7}=1.235 \\
K_{H}=\frac{1-\frac{h_{\text {tail }}}{b}}{\left(\frac{2 l_{\text {tail }}}{b}\right)^{1 / 3}}=1.6
\end{gathered}
$$




$$
\left(\frac{\partial \varepsilon}{\partial \alpha}\right)=0.175
$$

Aerodynamic coefficients are found as;

$$
C_{L \max \text { for plain flap }}=(0.9) C_{l \max }\left(\cos \Lambda_{\frac{c}{4}}\right)=0.9 \times 1.552=1.396
$$

\begin{tabular}{|c|c|c|c|c|c|c|c|c|c|c|}
\hline$\alpha$ & CI & Cd & $\mathrm{Cm} 0.25$ & $u$. & .L. & s.u. & L. & LID & A.c. & C.P. \\
\hline$[9]$ & I-] & I-] & I-] & I-] & I-] & [-] & [-] & [-] & I-] & [-] \\
\hline 0,0 & 1,227 & 06057 & $-0,256$ & 0,136 & 0,228 & 0,971 & 0,989 & 20,253 & 0,265 & 0,459 \\
\hline 1.0 & 1,320 & 0,06841 & $-0,258$ & 0,109 & 0,254 & 0,969 & 0,989 & 19,297 & 0,264 & 0,445 \\
\hline 2,0 & 417 & 07732 & $-0,259$ & .082 & 269 & 967 &, 989 & 8,321 & .263 & .433 \\
\hline 3,0 & 1,510 &, 08660 & $-0,260$ & 0,056 & 293 & 965 &, 989 & 7,438 & 0,262 & .422 \\
\hline 4,0 & 1,596 & .09594 & $-0,261$ & .03 & 11 & 961 &, 989 & 6,634 & 1.262 & 0,414 \\
\hline 5,0 & 670 & 0,10515 & $-0,262$ & 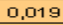 & 31 & 957 & 990 & 381 & 262 & 407 \\
\hline 6,0 & .733 & 11400 & $-0,263$ & 0,007 & 354 & 951 & 1,990 & 5,205 & 0.260 & 1,402 \\
\hline 7,0 & 1,783 & 0,12168 & $-0,263$ & 0,005 & 70 & 940 & 890 & 653 & .256 & .398 \\
\hline 8,0 & 1,818 & 12763 & $-0,263$ & 0,004 & 400 & 927 & .989 & 4,248 & 1.243 & .395 \\
\hline 9,0 & 1,819 & 0,13136 & $-0,263$ & 0,003 & 415 & 906 & .989 & 847 & .292 & 394 \\
\hline 10,0 & 1,796 & 0,13320 & $-0,262$ & 0,0 & 39 & 885 & .989 & 486 & .269 & 396 \\
\hline 11,0 & 1,752 & 0,13367 & $-0,262$ & 0,002 & 468 & 862 & .989 & 106 & 266 & 399 \\
\hline 12 & 688 & 13394 & $-0,261$ & 0.0 & 509 & 836 & 989 & 600 & 263 & 404 \\
\hline 13, & 1,610 & 0,13354 & $-0,260$ & 0,001 & 540 & 816 & .989 & 054 & .262 & .411 \\
\hline 14. & & & & & & & & & 308 & \\
\hline 15. & 376 & 0,13883 & $-0,246$ & 0,001 & 596 & 616 & .989 & 910 & 1,335 & .429 \\
\hline 16. & & & & & & & & & 322 & \\
\hline 17 & 143 & 0,16117 & $-0,229$ & 0,001 & 0,636 & 429 & 0,989 & 094 & 0,333 & .450 \\
\hline 18 & 20 & & & 0,001 & & & & & 0,35 & \\
\hline
\end{tabular}

For fully extended flap;

Figure A.1 Wing Lift and Drag Coefficients for Fully Extended Flaps Case

$$
C_{L \max \text { for } 10^{\circ} \text { flap }}=1.63
$$

Parasitic drag coefficient is found as following;

$$
\begin{gathered}
C_{D 0}=\frac{\sum\left(C_{f c} F F_{c} Q_{c} S_{w e t c}\right)}{S_{r e f}}+C_{D \text { misc }}+C_{L \& P} \\
\left(C_{D 0}\right)_{c}=\frac{\sum\left(C_{f c} F F_{c} Q_{c} S_{\text {wet } ~}\right)}{S_{\text {ref }}} \\
C_{D \text { misc }}=C_{D 0 \text { flap }}+C_{D 0 L G} \\
\left(\frac{D}{q_{\infty}}\right)=(3 \times 0.3+3 \times 0.25)=1.65 \\
C_{D 0 L G}=\frac{\left(\frac{D}{q_{\infty}}\right)}{S_{\text {wing }}}=0.042
\end{gathered}
$$




$$
\Delta C_{D 0 \text { flap }}=F_{\text {flap }} \frac{C_{f}}{c} \frac{S_{\text {flapped }}}{S_{\text {ref }}}\left(\delta_{\text {flap }}-10^{0}\right)=0.01 \times 0.2 \times 0.12 \times 20=0.049
$$

Wing form factor is;

$$
\begin{gathered}
F F=\left[1+\frac{0.6}{\left(\frac{x}{c}\right)_{m}}\left(\frac{t}{c}\right)+100\left(\frac{t}{c}\right)^{4}\right]\left[1.34 M^{0.18}\left(\cos \Lambda_{m}\right)^{0.28}\right] \\
F F=\left[1+\frac{0.6}{0.4} \times 0.15+100(0.15)^{4}\right]\left[1.34(0.013)^{0.18}(1)^{0.28}\right]=1.185
\end{gathered}
$$

Fuselage form factor is;

$$
\begin{gathered}
f=1.07\left(1+\frac{d}{b}\right)^{2}=7.86 \\
F F=\left(1+\frac{60}{f^{3}}+\frac{f}{400}\right)=1.129
\end{gathered}
$$

Form factor for horizontal and vertical tails;

$$
\begin{aligned}
& F F_{H T}=\left[1+\frac{0.6}{0.4}(0.17)+100(0.17)^{4}\right]\left[1.34(0.013)^{0.18}(1)^{0.28}\right]=1.24 \\
& F F_{V T}=\left[1+\frac{0.6}{0.4}(0.17)+100(0.17)^{4}\right]\left[1.34(0.013)^{0.18}(1)^{0.28}\right]=1.24
\end{aligned}
$$

Wetted area calculations are as;

$$
S_{\text {wet }}=S_{\text {exposed }}\left[1.977+0.52\left(\frac{t}{c}\right)\right]
$$


Table A6.2 Wetted and Reference Areas for Different Surfaces

\begin{tabular}{|c|c|c|}
\hline Components & $\mathbf{S}_{\text {ref }}\left(\mathbf{f t}^{2}\right)$ & $\mathbf{S}_{\text {wet }}\left(\mathbf{f t}^{2}\right)$ \\
\hline Wing & 38.126 & 78.34 \\
\hline Fuselage & - & 86.72 \\
\hline H.Tail & 3.53 & 7.29 \\
\hline V.Tail & 7.34 & 15.16 \\
\hline
\end{tabular}

Table A6.3 Resulting Friction Coefficients for Different Surfaces

\begin{tabular}{|c|c|c|c|c|c|c|}
\hline Components & Length(ft) & $\mathbf{R e}$ & $\mathbf{C}_{\mathbf{f}}\left(\mathbf{1 0}^{-\mathbf{3}}\right)$ & $\mathbf{F F}$ & $\mathbf{Q}$ & $\mathbf{S}_{\text {wet }}\left(\mathbf{f t}^{\mathbf{2}}\right)$ \\
\hline Wing & 25.26 & 97503152 & 2.13 & 1.185 & 1 & 78.34 \\
\hline Fuselage & 17.1 & 64654871 & 2.25 & 1.129 & 1 & 86.72 \\
\hline H.Tail & 5.94 & 21235059 & 2.665 & 1.24 & 1 & 7.29 \\
\hline V.Tail & 2.96 & 10198270 & 2.94 & 1.239 & 1 & 15.16 \\
\hline
\end{tabular}

$$
\begin{gathered}
\left(\mathrm{C}_{\mathrm{D} 0}\right)_{\mathrm{c}}=\frac{\sum\left(\mathrm{C}_{\mathrm{fc}} F F_{c} Q_{c} S_{\text {wetc }}\right)}{S_{\text {ref wing }}}=0.0128 \\
\mathrm{C}_{\text {D0 total }}=\left(\mathrm{C}_{\mathrm{D} 0}\right)_{\mathrm{c}}+\mathrm{C}_{\text {D0 miscellaneous }}=0.104
\end{gathered}
$$

\section{A7. MANEUVRABILITY AND LOAD FACTOR PARAMETERS}

Parameters for minimum turn radius condition are as;

Table A7.1 Different Parameters for Minimum Turning Radius Condition

\begin{tabular}{|l|l|l|l|l|}
\hline \multicolumn{1}{|c|}{ Altitude(ft) } & \multicolumn{1}{|c|}{$\boldsymbol{\rho}\left(\mathbf{s l u g} / \mathbf{f t}^{\mathbf{3}}\right)$} & $\mathbf{V}$ at $\mathbf{R}_{\min }(\mathbf{f t} / \mathbf{s})$ & \multicolumn{1}{|c|}{$\mathbf{n}$ at $\mathbf{R}_{\min }$} & \multicolumn{1}{|c|}{$\mathbf{R}_{\min }(\mathbf{f t})$} \\
\hline 0 & 0,0023769 & 190,24 & 0,3562 & 1120 \\
\hline 10000 & 0,0017553 & 228,1009 & 0,3523 & 1611 \\
\hline
\end{tabular}

Parameters for maximum turn rate condition are as; 
Table A7.2 Different Parameters for Maximum Turn Rate Condition

\begin{tabular}{|l|l|l|l|l|}
\hline \multicolumn{1}{|c|}{ Altitude(ft) } & \multicolumn{1}{|c|}{$\boldsymbol{\rho}\left(\mathbf{s l u g} / \mathbf{f t}^{\mathbf{3}}\right)$} & $\mathbf{V}$ at $\boldsymbol{\omega}_{\max }(\mathbf{f t} / \mathbf{s})$ & $\mathbf{n}$ at $\boldsymbol{\omega}_{\max }$ & $\boldsymbol{\omega}_{\max }(\mathbf{r a d} / \mathbf{s})$ \\
\hline 0 & 0,0023769 & 148,84 & 0,25 & 0,15 \\
\hline 10000 & 0,0017553 & 178,454 & 0,236 & 0,088 \\
\hline
\end{tabular}

A8. CENTER OF GRAVITY AND STATIC MARGIN CALCULATIONS

Table A8.1 $x_{c g}$ Location for Different Components of the Aircraft

\begin{tabular}{|c|c|c|c|}
\hline Components & Weight (lbs) & CG of Component & Location of $\mathbf{x}_{\mathbf{C G}} \mathbf{( f t )}$ \\
\hline Wings & 85.06 & $\begin{array}{c}0.40 \text { of its Mean } \\
\text { Chord }\end{array}$ & 8.60 \\
\hline Fuselage & 121.408 & 0.5 of its Length & 8.505 \\
\hline Engine & 80.78 & 0.5 of its Length & 1.236 \\
\hline Payload & 145.5 & 0.5 of its Length & $7.97 \mathrm{ft}$ from nose \\
\hline Fuel & 163 & CG of Aircraft & 6.5 \\
\hline Horizontal tail & 14.12 & $\begin{array}{c}0.40 \text { of its Mean } \\
\text { Chord }\end{array}$ & 16.62 \\
\hline Vertical tail & 14.34 & $\begin{array}{c}0.40 \text { of its Mean } \\
\text { Chord }\end{array}$ & 15.23 \\
\hline Total $\boldsymbol{x}_{\boldsymbol{c g}}$ & \multicolumn{3}{|c}{} \\
\hline
\end{tabular}


Table A8.2 $y_{c g}$ Location for Different Components of the Aircraft

\begin{tabular}{|c|c|c|c|c|}
\hline Components & Weight (lbs) & $\begin{array}{c}\text { CG of } \\
\text { Component }\end{array}$ & $\begin{array}{c}\text { Location of } \\
\mathbf{y}_{\mathbf{C G}}(\boldsymbol{f t})\end{array}$ & $\begin{array}{c}\mathbf{0 . 5} \boldsymbol{y}_{\boldsymbol{c g} \text { fus }} \\
-\boldsymbol{y}_{\boldsymbol{c g}}\end{array}$ \\
\hline Wings & 85.06 & $\begin{array}{c}\text { Mean chord } \\
\text { height }\end{array}$ & 0.31 & $1.06-0.31=0.75$ \\
\hline Fuselage & 121.408 & 0.5 of its diameter & 1.066 & $1.06-1.06=0$ \\
\hline Engine & 80.78 & 0.5 of its height & 1.066 & $1.06-1.06=0$ \\
\hline Payload & 145.5 & 0.5 of its height & 1.066 & $1.06-1.06=0$ \\
\hline Fuel & 126.63 & 0.5 of its height & 1.066 & $1.06-1.06=0$ \\
\hline Horizontal tail & 14.12 & $\begin{array}{c}\text { Mean chord } \\
\text { height }\end{array}$ & 1.32 & $\begin{array}{c}\mathbf{0 . 5} \text {. } \mathbf{y}_{\text {cg fus }}+ \\
\mathbf{y}_{\text {cg }}=\mathbf{2 . 3 8}\end{array}$ \\
\hline Vertical tail & 14.34 & $\begin{array}{c}\text { Mean chord } \\
\text { height }\end{array}$ & 2.68 & $\begin{array}{c}\mathbf{0 . 5} \mathbf{5} \mathbf{y}_{\text {cg fus }}+ \\
\mathbf{y}_{\text {cg }}=\mathbf{3 . 7 4}\end{array}$ \\
\hline Total $\boldsymbol{y}_{\boldsymbol{c g}}$ & & & & $\begin{array}{c}\mathbf{0 . 2 3} \mathbf{f t} \text { above } \\
\text { fuselage }\end{array}$ \\
\hline
\end{tabular}

Early value was $x_{c g}=7.57$

Static margin $=\frac{x_{n}-x_{c g}}{\bar{c}}=\frac{8.28-7.57}{2.099}=\% 33$ 
A9. TECHNICAL DRAWINGS
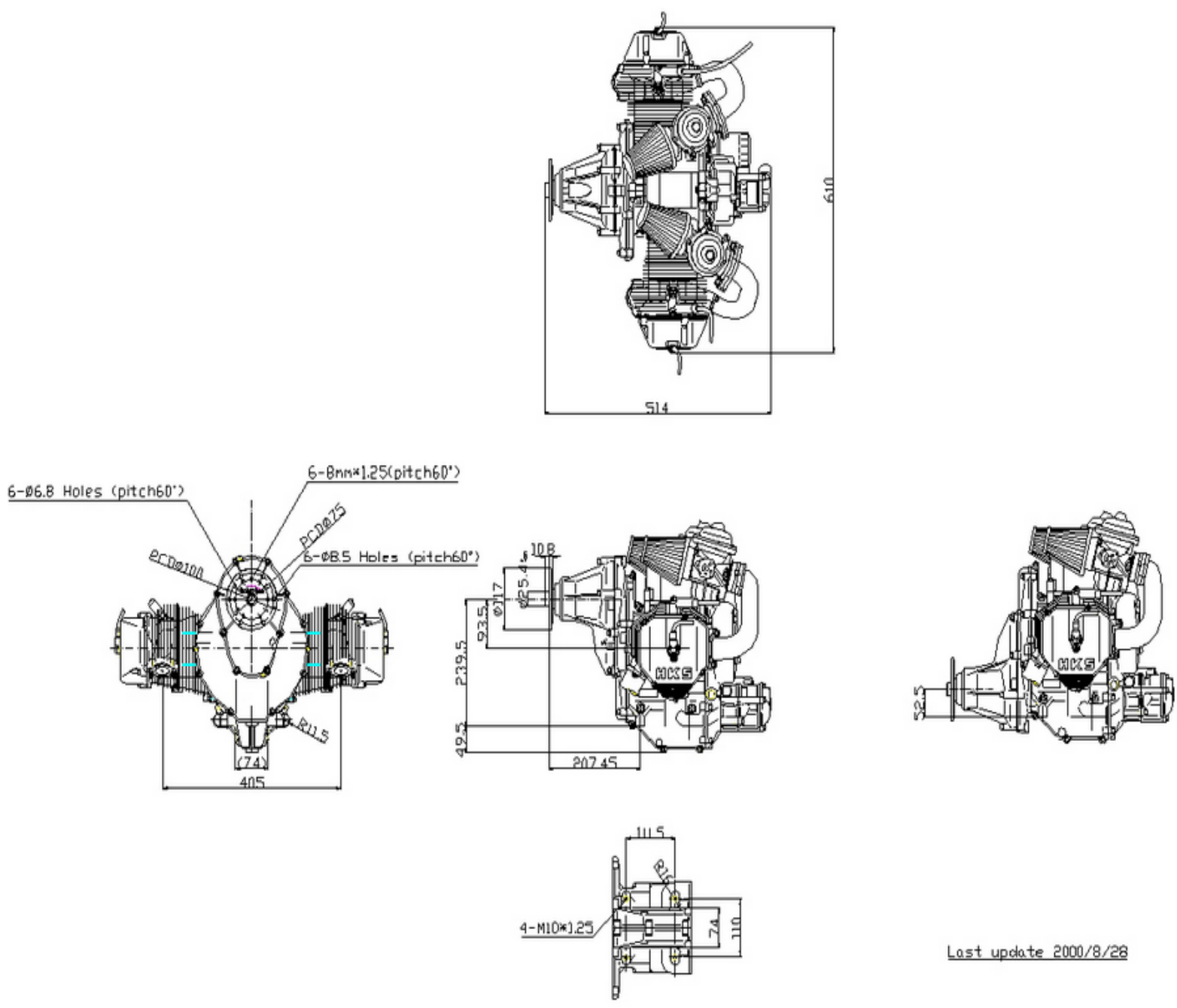

Last update 2000/8/28

Dimension of mount boss

Figure A.2 Technical Drawing of the Aircraft Engine 


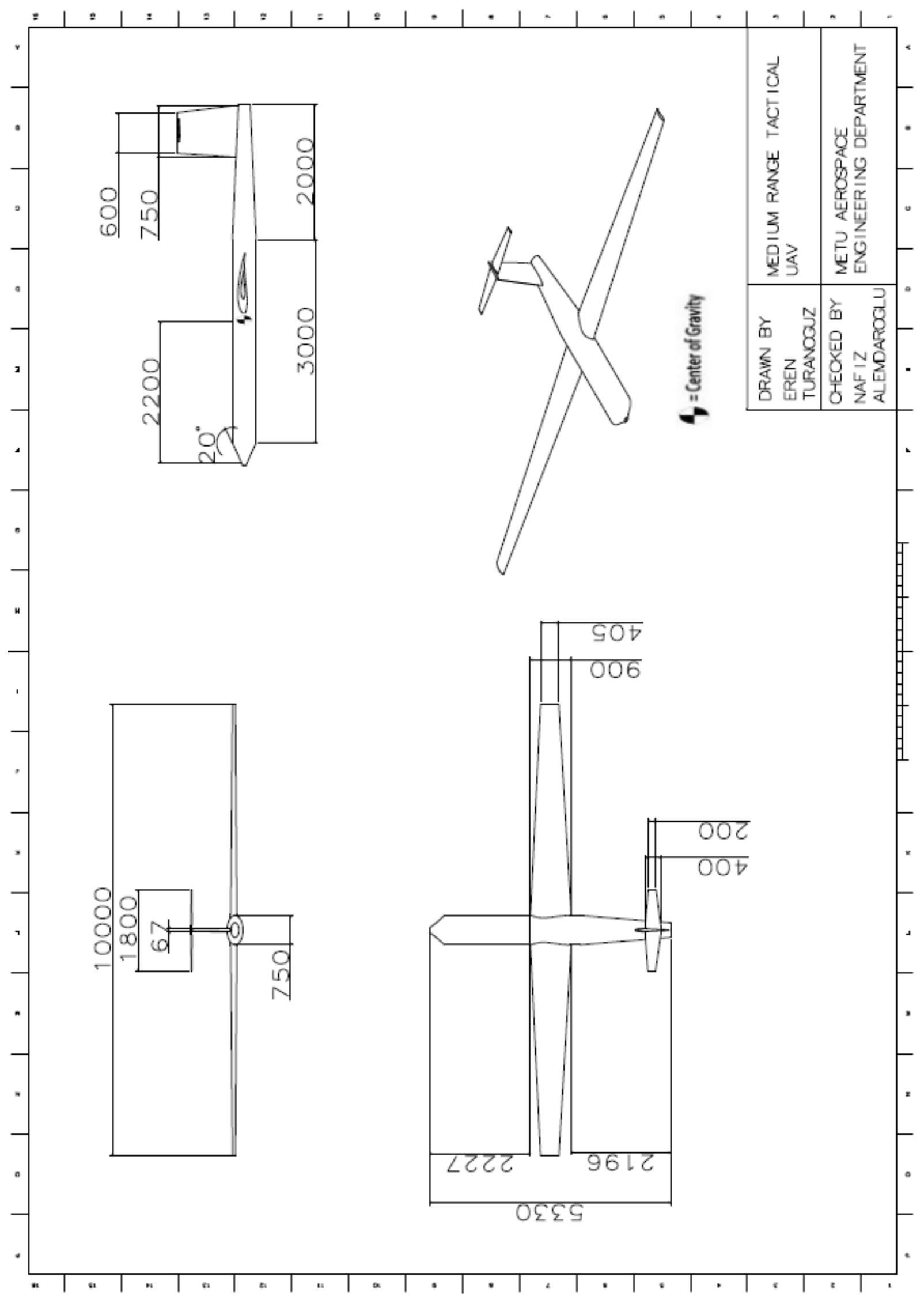

Figure A.3 Aircraft Baseline Geometry Technical Drawing 


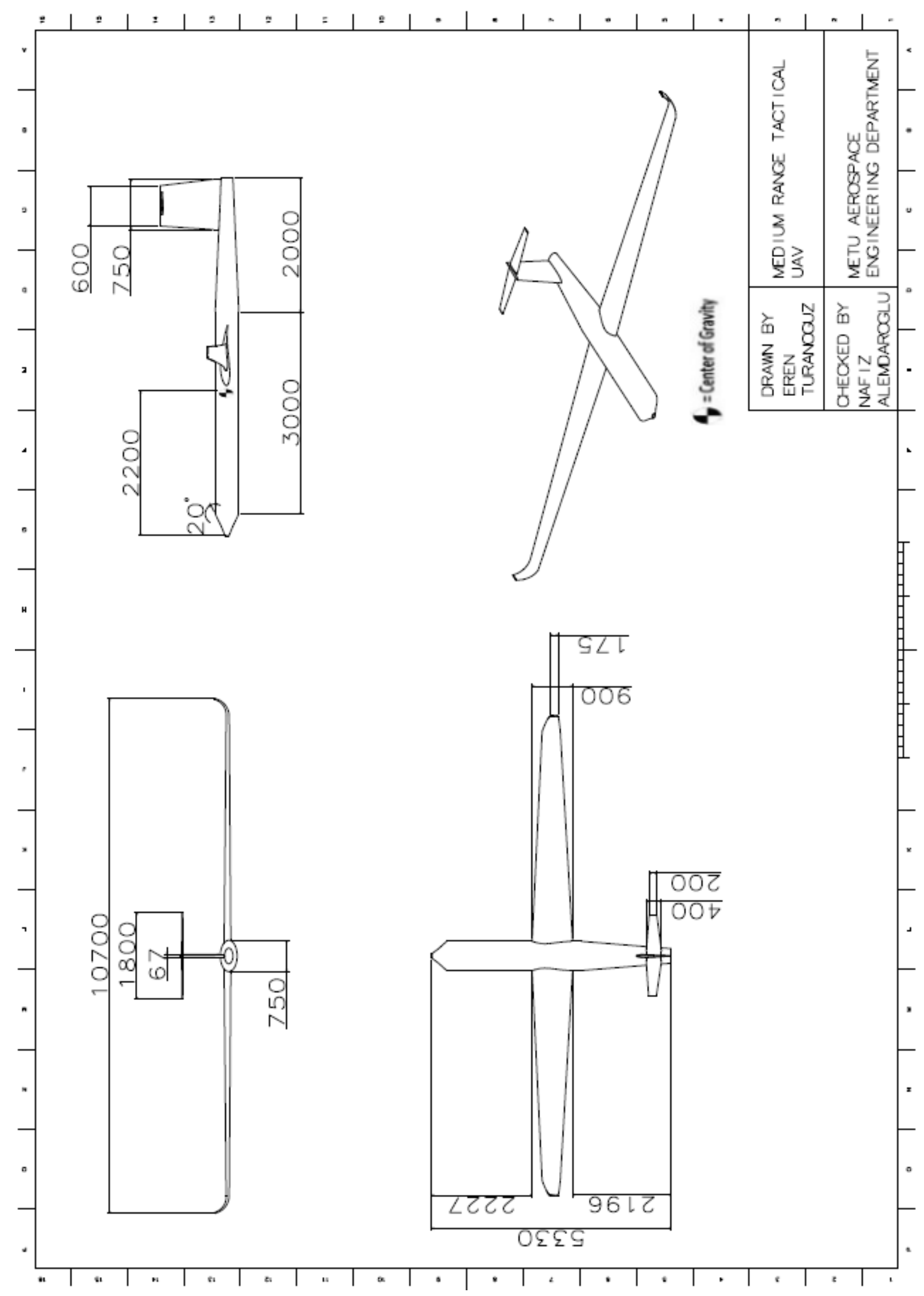

Figure A.4 Aircraft Final Geometry Technical Drawing 